




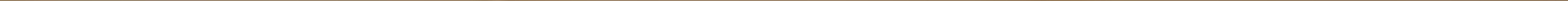





\title{
RAW SILK
}

\section{A Practical Hand-Book for the Buyer}

\author{
by
}

\section{LEO DURAN}

\footnotetext{
A STUDY OF RAW SILK PRODUCTION AND FILATURES IN EUROPEAN AND ASIATIC COUNTRIES; THE CONDITIONS OF BUSINESS ON ALL THE GREAT

MARKETS OF THE WORLD; A COMPLETE DESCRIPTION OF THE

MANAGEMENT OF AN ITALIAN FILATURE; HOW TO ESTAB-

LISH AGENCIES AND INSPECT RAW SILK IN CHINA AND

JAPAN ; CLASSIFICATION OF EUROPEAN AND

ASIATIC SILKS, AND COMPARATIVE PRICES;

LIST OF LEADING HOUSES IN THE

WORLD DEALING IN RAW SILK,

AND OTHER FFATURES.
}

With many illustrations

2nd Revised Edition

\section{SILK PUBLISHING COMPANY}

\section{Broadway NEW YORK}




\section{To the Silk Students of America}

This book is respectfully dedicated in the hope that it will give them a more intelligent perception regarding the whole subject of raw silk, both as regards countries of production and of manufacture.

Leo DURAN. 



\section{FOREWORD}

SO much has been written on the general subject of S the production and manufacture of silk that it would be superfluous to add anything along these lines. The works of Pariset, Vignon, Silbermann, Hedde and Rayner contain a general survey of the production and handling of raw, thrown, dyed and manufactured silks, including silk history from the most ancient times.

There is, however, no book in any language devoted solely to raw silk, written by a specialist who has studied the subject thoroughly in the different countries of production. Furthermore, business conditions since the latest standard works were published have changed to such an extent that a revision of this part of the subject is timely.

This study will prove valuable to those people engaged in the silk trade everywhere, for they will have a chance to learn how silk is handled in all countries of the world, thus obviating the necessity of going abroad to acquire this information.

The Author. 
THE success of the first edition of RAW SILK, which is 1 still the only book of its kind in the English language, has prompted us to issue a second edition.

We have asked the author to complete his study of the world's silk production, and owing to many changes in business conditions, it has been found necessary to revise some parts of the book and add further information. We believe that our readers, past, present and future, will find the work even more valuable than the previous volume. The wide interest shown in the first edition has made possible the publication of this, the second.

THe Editors. 


\section{CONTENTS}

\section{PART I. THE STORY OF RAW SILK}

PAGE.

I. The Mulberry and the Butterfly........... 13

II. Scientific Life of the Silkworm............... 20

III. Domestic and Wild Cocoons.................. 28

IV. Growth and Development of the Modern Filature... 35

V. Conditioning, Testing and Boiling Off.......... 44

VI. Percentage System of Inspection............. 51

PART II. RAW SILK IN EUROPE

I. The Raw Silk Industry of Italy............ 57

II. Sericulture and Filatures of France.......... 78

III. Lyons, the City of Silks $\ldots \ldots \ldots \ldots \ldots \ldots \ldots$. . . 80

IV. The Levant $\ldots \ldots \ldots \ldots \ldots \ldots \ldots \ldots \ldots \ldots \ldots \ldots \ldots \ldots \ldots \ldots$

PART III. RAW SILK IN THE FAR EAST

I. Raw Silk Inspection in the Far East........... 95

II. Japan :

I. Japanese Filatures $\ldots \ldots \ldots \ldots \ldots \ldots \ldots \ldots$. 10 ?

II. The Silk Exchange $\ldots \ldots \ldots \ldots \ldots \ldots \ldots, 108$

III. Silk Waste $\ldots \ldots \ldots \ldots \ldots \ldots \ldots \ldots \ldots \ldots \ldots$

IV. Re-reels . ........................ 112

V. The Crop and How it is Manipulated...... 115

VI. Inspection $\ldots \ldots \ldots \ldots \ldots \ldots \ldots \ldots \ldots \ldots . \ldots \ldots$

VII. Private Chops ....................... 12?

VIII. Is the Standardization of Japan Kaw Silk Possible? ......................... $12: 3$

IX. How to Improve Japanese Raw Silks...... 195 
III. China :

PAGE

I. The Shanghai Market $\ldots \ldots \ldots \ldots \ldots \ldots, 137$

II. Raw Silk in the Canton Province......... 141

III. Sericulture in Indo-China .............. 148

PAR'T IV. THE NEW YORK MARKET

I. Improving the Raw Silk Business in New York.... 153

II. Quilling and Coning. Establishing a Raw Silk Buying Agency in the Far East............... 15

III. The Making of a Raw Silk Salesman............ 162

IV. Raw Silks Used in New York............... 167

\section{CLASSIFICATIONS}

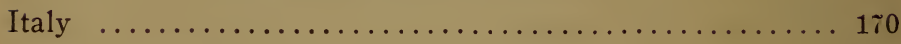

Japan Filatures ............................ 170

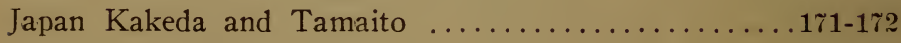

China Steam Filatures ...................... 1 1 $2_{2}$

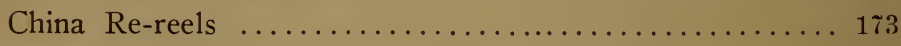

China Tsatlee Crossreels ....................... 176

China Tussah Filatures $\ldots \ldots \ldots \ldots \ldots \ldots \ldots \ldots \ldots . \ldots 178$

Canton Filatures ........................... 178

RAW SILK FIRMS OF THE WORLD

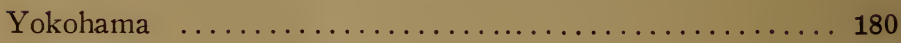

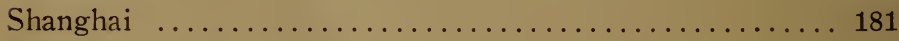

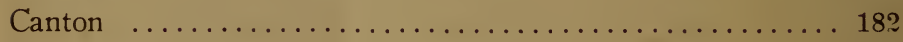

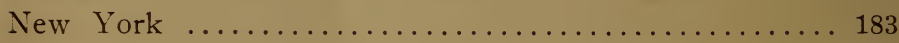

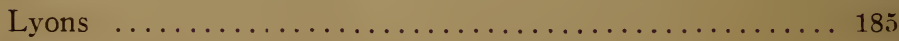

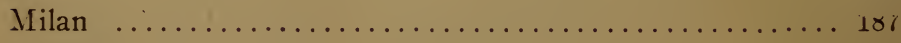

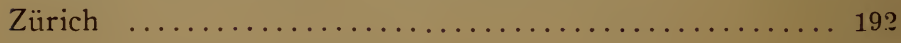




\section{List of Illustrations}

PAGE.

Folding Map of Raw Silk Production of the World.... Insert Feeding Silkworms in Asia.................... 15

Adult Males and Females of Bombyx Mori......... 18

Silkworms at Different Ages.................. 22

A Full Grown Silkworm...................... 23

Examination to Prevent Diseasss of Silkworms......... 25

Different Shapes of Cocoons ................... 30

Tussah Cocoon and Butterflies.................... 32

Old Reeling Process in Japan $\ldots \ldots \ldots \ldots \ldots \ldots \ldots \ldots \ldots \ldots \ldots \ldots$

Reeling "Chambon System" .................... 38

Reeling "Tavelette System"...................... 39

Raw Silk Imperfections $\ldots \ldots \ldots \ldots \ldots \ldots \ldots \ldots \ldots \ldots+46$

Percentage Test (Table)..................... 52

The Inspector's Sizing Scales and Reeler............ 53

Automatic Cocoon Beater and Catching Whee's........ 65

Italian Basins and Travelers in Cases............. 66

A Jacquard Hand Loom in Lyons, France............. 8 ?

Outside View of a Japanese Filature.............. 107

Silk Waste Drying in a Filature Yard.............. 112

American Standard Re-Reeled Skeins............... 114

Selecting Cocoons in Japanese Filature Warehouse...... 117

Japanese Country Reeling..................... 120

Model Filature of Maruyama, Japan..............126-127

A China Steam Filature..................... 136 

PART I

THE STORY OF RAW SILK 



\section{CHAPTER I.}

\section{The Mulberry and the Butterfly}

$\mathrm{N}$ order to be clear it is better to begin with the principle 1 of life of the domestic silkworm, viz.: his only food, the mulberry. All attempts to feed the worm on the leaves of other trees have proved failures.

The four mulberry families are: The white, the black, the red, and the multicolor.

In the wild state, the tree bears a delicious little black fruit of a rather acidulated flavor. If grafted, the doubled quantity of leaves absorbs the life of the tree and its fruit never ripens.

The black mulberry was known in China and Italy in the oldest times. It was frequently used as an ornament in gardens. The leaves are in the form of a heart-short, thick, rough surfaced. As it grows very slowly and does not improve much yearly, the white mulberry has been generally substituted all over Europe. The Japanese "kuwano-ki" is cultivated on mountains preferably to plains, and also on the shores of rivers. The species Yozume, Nezumi, Kikonha, etc, are smaller than the Chinese mulberry and never grow higher than four feet. Some along the rivers are only one foot high.

The leaves are very tender. When the trees are forty years old they are destroyed and replaced by new ones.

The white mulberry comes from China, and was introduced in southern Italy in the eleventh century. It has the advantage of growing rapidly in any climate and on almost any piece of ground. Not only is it quicker of growth, but the nutritious substances found in the leaves are such that the silkworms feed better and grow stronger 
than on any other. The multicolor mulberry has some similarity to the white, but the leaves are not so tender.

In the orchards, the young mulberries are grafted at six months and transplanted in rich, damp ground. After five years a tree ought to give forty pounds of leaves, at ten years one hundred and twenty pounds, at twenty years two hundred and ten pounds.

A tree can live seventy years if properly cared for, which means that the leaves must be spared at least one season out of three. In that case the leaves have a better shape and color.

The climate is of little or no consequence, as the mulberry grows in Russia and Sweden, as well as in Asia, provided the changes of weather are not too marked. In Japan the shortage of crop is often caused by the sudden frosts of May. It may safely be said that wherever vineyards are successful the same grounds are good for mulberry growing.

When the time is ripe for picking the leaves it is necessary to choose a dry day, inasmuch as the leaves ought to be fresh, but not humid. The picking is done from the base to the top of the trees and the leaves are packed in sacks. Before feeding the worms the leaves are spread on an open aerated place until no trace of humidity is left.

It is a good idea to feed the worms from wild leaves during the three first stages, and from domestic leaves during the balance. The quality of the fibre seems to be benefited in this way.

The difference in the nutritive qualities is quite marked between trees of the same family growing in totally different soils, but scientific demonstration tends to show that particularities of the worm life are always the same, although the quality of the fibre is different. Questions regarding the best conditions of soil and climate have been fully solved, and it would be possible to obtain one quality always quite similar in results by nourishing the worms from extensive and well-kept mulberry orchards. Unfortunately, modern filatures are always in the habit of mixing cocoons according to their appearance and reeling percentage, not according to their rearing. I have noticed often 


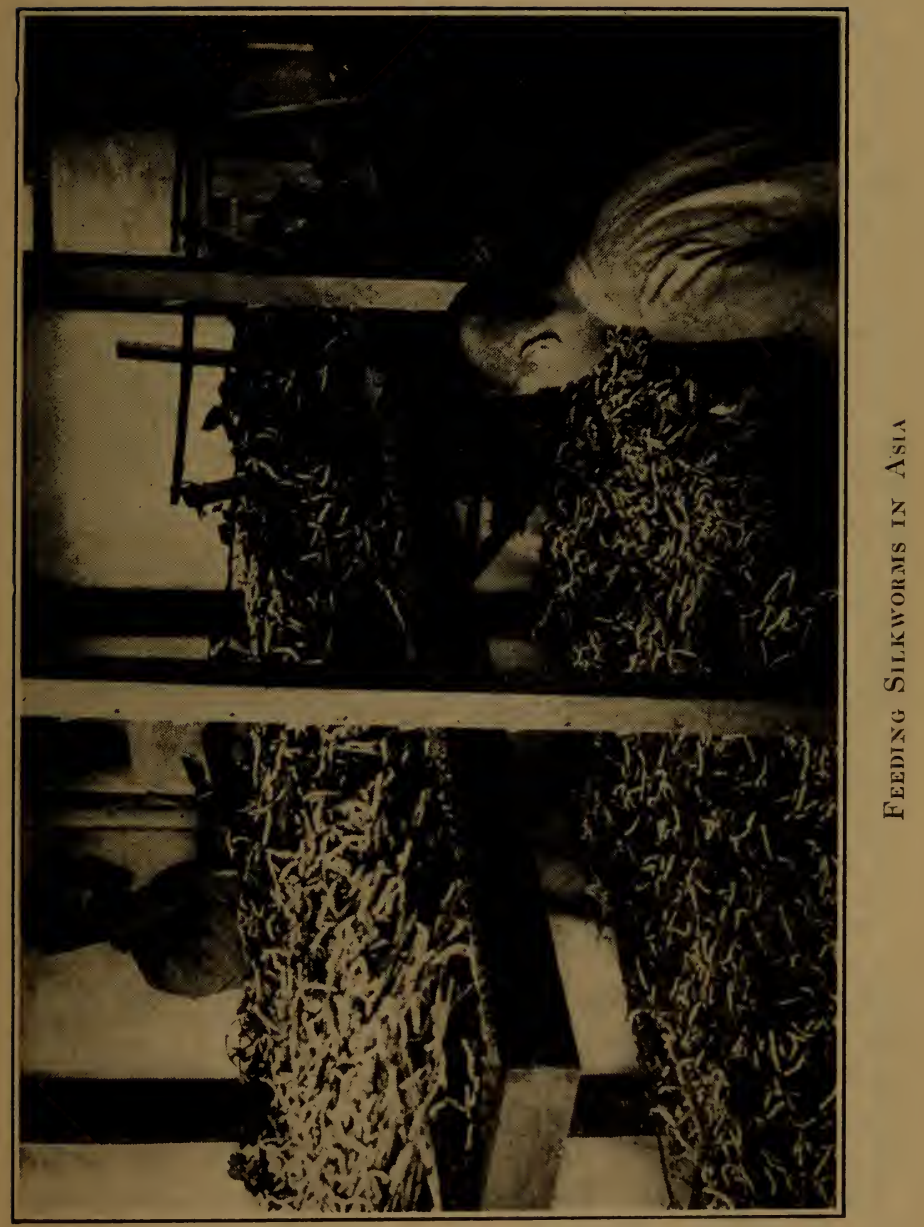


that in almost every country, filatures under pressure from unavoidable causes, import cocoons of other countries or provinces to be reeled alone or mixed with local cocoons.

When the crop of Cevennes cocoons is short, good Italians or Syrians make up the shortage. The silks are sold as second choices only, and cannot compare with the silks spun from real Cevennes, although reeled by the same experienced hands. In Japan it is common for cocoons from Bushu to be reeled in Sinshiu, and vice versa.

I may note in passing a curious occurrence which happened in Japan during the latter part of the season 1907. The crop was too small for the large American demand and prices were pushed up to yen 1,400 for No. 11/2 Kansai. A number of clever silk men imported Chinese cocoons and reeled and exported them as genuine Japanese raw silks under the usual chops, so that probably 1,000 bales of the same were accepted by American manufacturers who make it a rule not to buy Chinese silks!

A Fukaya reeler achieved quite a reputation for his chop the day he had a chance to reel Chinese cocoons. There are many Japanese filatures reeling Chinese cocoons. The cultivation of yellow cocoons from imported Italian eggs has been developed during the last five years, and proves very successful.

All of which goes to show that the vogue of Japan filatures is due to their wide range of qualities and to their accommodating our mills better than China steam filatures.

The above examples show that an equal quality of cocoons of different breedings do not sensibly alter a quality already established, as long as the workmanship remains the same; but to obtain the perfect regularity of a first-class production it is undoubtedly necessary that silkworms be fed from the same class of mulberries, under the same atmospheric conditions.

One fact has not escaped the observer's eye: The value of a certain class of raw spun from one yearly crop of cocoons is always greater at the beginning of the season than later on. It is easy enough to understand that the cocoons have not yet been adulterated, mixed or substituted by others as may happen later in the season. 


\section{Feeding the Worms}

The statistics show that the worms eat twenty-five pounds of mulberry leaves for one pound of cocoons. There are twelve pounds of cocoons to one pound of raw silk.

One ounce of eggs should give not less than one hundred and thirty pounds of cocoons, if the hatching is done under favorable condition. To feed such enormous quantities in larger proportions the farmers must provide the proper number of mulberry trees. . One..ounce of eggs requires one thousand five hundred pounds of leaves, or about twelve trees, averaging ten years of existence. That quantity of leaves cost in Europe about $\$ 10$.

In practice the farmers ought to get an average of ninety pounds of cocoons per ounce. Supposing he sells them at $\$ 0.75$ per pound, he makes a profit of $\$ 67.50$ against $\$ 20$ expenses, or a net profit of $\$ 47.50$ per ounce of eggs. Of course, risks of frosts, illnesses, business depressions, etc., a-c to be accounted for, but, as a rule, the small farmers in the country owning a few mulberries and time to spare make good profits hatching silkworms.

In China and Japan silkworms may be seen on one farm out of two, because mulberry trees are plentiful. Europeans, living in a warm climate, ought to follow their example.

\section{The Butterfly}

The mulberry butterfly comes out of the cocoon abour ten to twelve days after the silkworm has started spinning it. During this period several transformations take place inside the cocoon. Three days after the cocoon is built, the worm becomes lifeless and dry, and is slowly transformed by nature into a chrysalis, an almond-shaped brown object having nothing of the worm or the butterfly.

The hard coating of the chrysalis becomes thinner as the butterfly forms itself inside, and some morning, between five and seven o'clock, the coating is cracked and the butterfly frees itself. The head of the butterfly touches the upper-inside of the cocoon. 
A few drops of alkaline acid from its mouth are sufficient to soften the gummy threads and they are easily pushed aside as the butterfly emerges to light-an ugly, fat and wet insect. Its color is of a whitish or brownish hue; the body is yet soft, but after fifteen minutes the wings are rigid. The female is larger than the male, and both are unable to fly.

During their short life the bombyces, it is often remarked, live on love and fresh water, because until death they eat

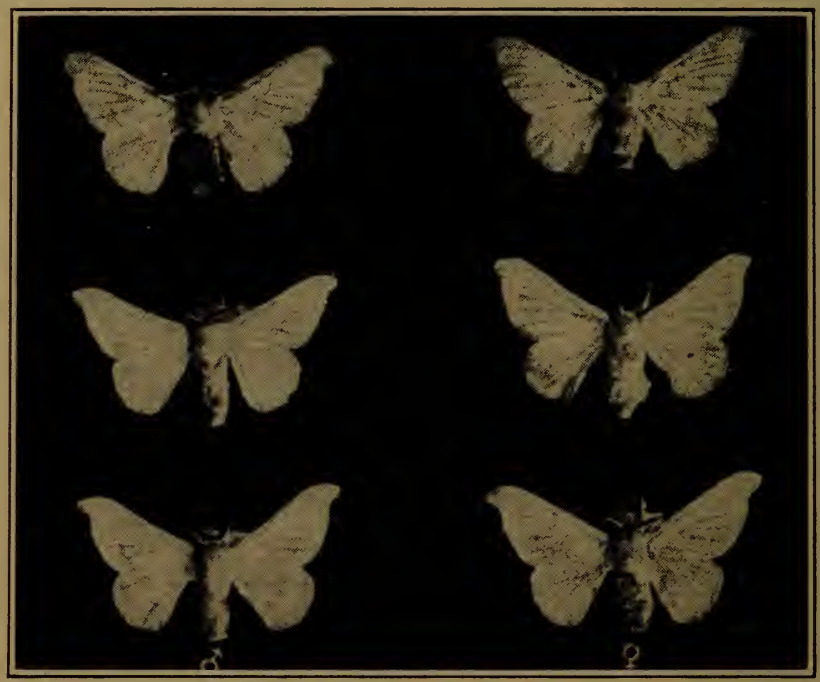

Adult Males and Females of the Bombyx Mori

nothing; and no sooner has the male got out of the pierced cocoon than he looks for a female and when he finds one the fecundation may last twenty-four hours. But, lo! the watchful hatcher is there to bring that long courting to a stop, for the fecundation is regulated scientifically, and according to season, to a reduced time of five to six hours. Of course, the butterflies are skilfully selected beforehand, all sick or weak ones being eliminated.

The female bombyx lays down some seven hundred eggs, 
and during the first thirty-six hours an average of four hundred.

The hatchers place the fenlales on pieces of linen or cotton about half a foot square. The eggs, once laid, are washed in pure water, but are left on the linen until wanted, when they can be detached with a dull knife.

As soon as the bombyces are dead they are submitted to the microscope, and if some are found to be infected by any disease they are destroyed, else they would communicate the germs to others.

If we take it that a female lays four hundred to five hundred eggs, seventy to eighty females will be necessary to make an ounce, or about 35,000 eggs. These eggs, brought to hatching and the worms fed on mulberry leaves will accomplish once more one of the most wonderful evolutions of Nature: the endless transformation of a worm into an insect, of an insect into a worm, with the mysterious incidental result: The silk thread. 


\section{CHAPTER II.}

\section{Scientific Life of the Silkworm}

$T^{H E}$ silkworm from which the silk thread issues is I called bombyx. The bombyx mori (mulberry silkworm) is the largest species and produces the original silk thread. A number of silkworms,--the bombyx pernyi (oak's silkworm and yamamai of Japan), the mylitta (jujube), cynthia (ailanthus), cecroprie (plum), etc.,-produce different kinds of silk of more or less use, although the yamamai of Japan and the tussah of Asia, are hatched in large quantities and the silk spun to make goods of rough appearance.

The bombyx mori species are of two kinds; one of them reproduces several times every year, the other reproduces only annually. The latter are by far the best and cast their skins four times before building their cocoons.

The egg laid by the butterfly is slightly flat and only about one mm. long. Its specific gravity as compared with water is 1.08. Its color is yellow during the first day and then gray or brown the six following days.

There is a lapse of ten months between the laying time and the hatching. During that time the egg, of which composition was:

Phosphoric acid, $53.8 \%$.

Potassium, $29.5 \%$.

Magnesium, $10.3 \%$.

Calcium, $6.4 \%$.

absorbs oxygen constantly, and loses in exchange carbonic acid and water, so that at hatching time the weight has been reduced by thirteen per cent, and the color has varied from gray to blue, purple, yellow and white. This is proof of the vitality of the egg, which is hardly noticeable during the winter, but very perceptible in summer.

The eggs are hatched artificially, or the results would never be simultaneous, and by doing this the season is more 
easily selected according to vegetation. The eggs are taken to heated rooms and kept in incubation for twenty-five to thirty days. After that lapse of time the hatching begins and ends three or four days later.

There are several conditions which are regarded as necessary for the successful hatching of silkworm eggs.

It is a fact that they must be submitted to cold weather, for the action of warm weather only has not been able to give satisfactory hatchings. The egg's life is then divided in three periods: the time elapsing between the laying and the cold season, during the cold season, and after the cold season, when the warm weather renews the life of the egg for hatching. However, if during the third period cold prevails, the egg is liable to die. The conclusion is that the egg must be cared for methodically. Some Italian establishments have extensive cold storage rooms to keep the eggs. It is best to place the eggs before winter in well ventilated dry places where weather variations are unknown. It is also easier to maintain in such hatching houses a cold temperature (as long as a year if wanted), to keep the eggs from hatching, but as soon as the third period has begun the warm temperature must be maintained.

The necessity of a cold period applies only to the eggs of the annual hatching kind, as we see the Bengals and South Chinas, which are of the multi-crop kind, living through steady warm weather.

It is very important that the eggs should be given plenty of room because the worms once alive must breathe freely, and it further prevents an excess of double or treble cocoons.

As soon as the hatching has begun, the mulberry leaves are brought for the little worms to feed on.

One gram of eggs ought to give one thousand two hundred to one thousand five hundred worms. There is always a small amount of eggs prematurely hatched on account of their having been laid in warm and dry weather.

The worm is but three $\mathrm{mm}$. long when brought to life and weighs about one-half milligram. During the feeding, which lasts from thirty-three to thirty-eight days, it grows 

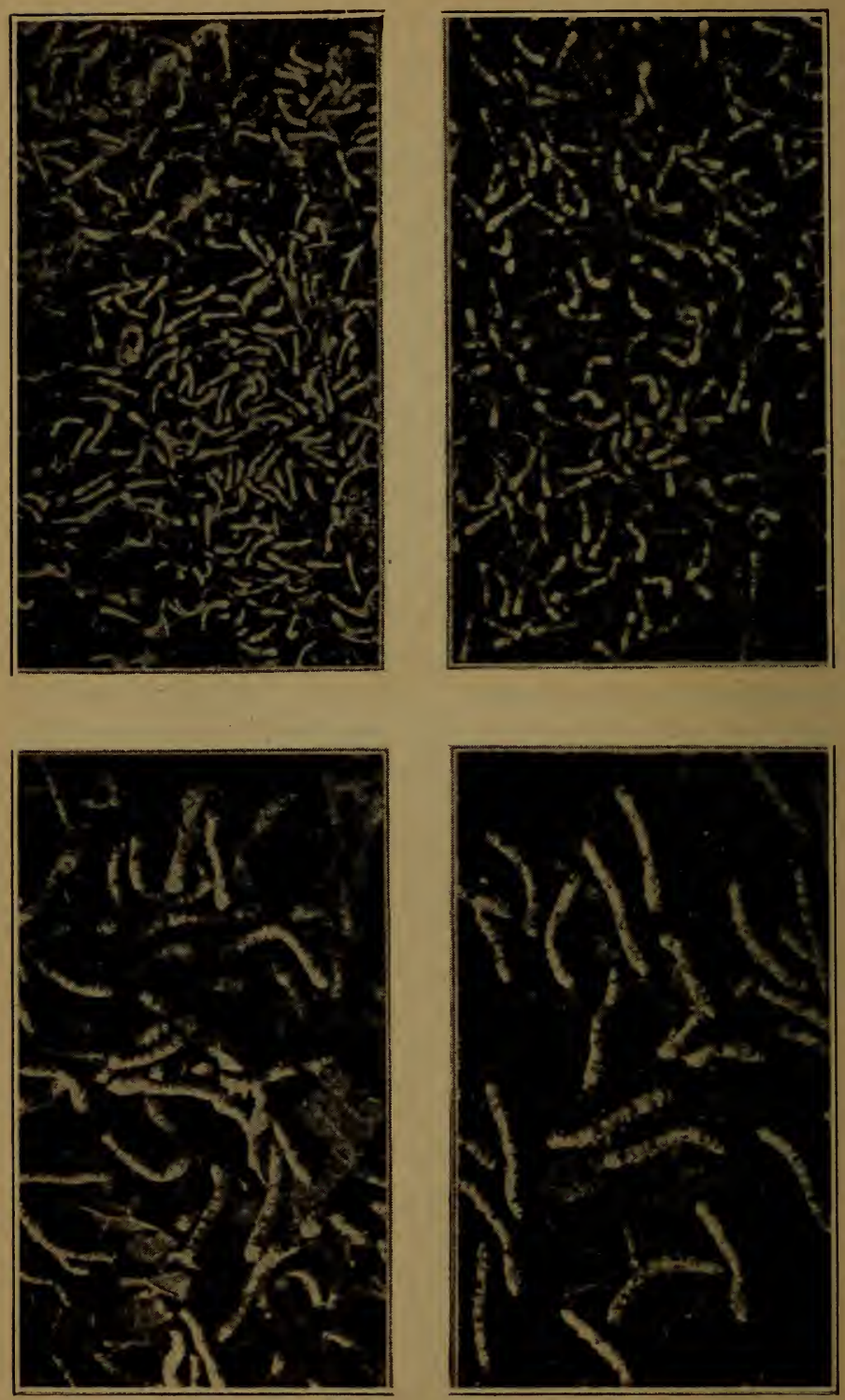

Silkwonis at Differext Ages 
with an extraordinary rapidity, moulting four times, until its length is nine $\mathrm{cm}$. and its weight five grams. During that time the worm feeds continually from mulberry leaves. It has a voracious appetite except when losing its skin, then it stops eating altogether, but as soon as it has gotten rid of the old skin the appetite is even stronger than before. The worm grows in the proportion of one to ten thousand.

When the worm reaches its maximum weight, that is about a week after the last change of skin, the glands containing the liquid that will be the future silk become inflated and the worm is unable to eat any more. It digests the last leaves left in its stomach and finally rids itself of a drop of pure potassium. The worm has now lost about one

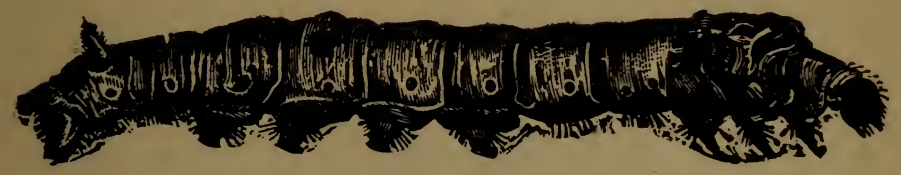

A Full Grown SiI.Kwory

gram in weight, and is ready to make its cocoon. It waves its head to and fro until it finds an obstacle, which it will climb at once, spitting out at the same time its first thread. The silk glands are now very large and represent as much as one-fifth the weight of the worm. The silk thread emitted by the worm is composed of fibroin overcoated with sericin, or silk gum, and some coloring matter producing yellow, green or brown cocoons. The coloring matter is kept in a gland near the mouth of the worm and is deposited on the thread when it comes out. The white fibres are less elastic, but thicker and stronger than the yellow ones.

When the worms are ready to make their cocoons the hatchers place dry twigs and branches on wooden frames. where the worms choose the place to build their cocoons. With a few exceptions the worms start their work at once. and within five or six hours the outside of the cocoon is spun. Hastily the worm completes the inside, so that the cocoon is finished in twenty-four hours. 
If we open the cocoon we see the worm in a lethargic state. Its skin is milky white and it is slightly shorter. If we open the cocoon only three days after the cocoon is made, a great change has taken place. The worm has become a chrysalis. The chrysalis is now an ovoid mass, elongated, without appearance of life, although the insect is actually breathing and is very sensitive to bad ventilation. The insect coat is harder after a few days, and the color brown to yellow. The wings are still hard and fast against the body, and the lower part only is flexible.

The weather has much to do with the new life of the chrysalis. With a high temperature and wet weather the chrysalis may become a butterfly and pierce the cocoon within six days. On the contrary, at a low temperature the cocoons may be kept as long as one year in the house for rearing silkworms, but in practice some are treated in a different way. The cocoons are collected from the twigs and are cleaned of their first coating of loose silk wound irregularly around the cocoon. A choice is made of the double and flat cocoons; also a few cocoons are kept apart to allow the moth to come out to lay a new crop of eggs. The pierced cocoons cannot be sent to the filature and are sold to the waste silk industry.

All good cocoons are suffocated in hot, dry air at eighty degrees Réaumur, and are weighed ready to be brought to the filature.

The cocoon does not come to maturity without troubles, because the silkworm is subject to several diseases, which reduce a part of the crop every season and sometimes prove ruinous to the hatchers.

Four diseases have already done much damage in the crops the world over. They are: Bassianite (muscardine), Pepperite (pebrine), Indigestion (flacherie), Laziness (grasserie).

Bassianite (after the name of De Bassi, an Italian, who discovered the cause of the disease) is extremely contagious, and appears usually between the third and fourth moultings. The initial cause is an excess of warm, humid weather. Microscopic mushrooms spread themselves on the silkworm and also on the mulberry leaves in white stains. 
When the parasite is sufficiently developed, the blood circulation of the silkworm is gradually stopped, so that the worm dies before spinning its cocoon; even when it succeeds in spinning it, it never becomes a chrysalis; its body becomes very hard and, being white coated, it resembles a sugar plum as much as anything. Precautions against this disease can easily be taken by using sulphuric fumigations.

The pepperite (because the color of the worm, of white

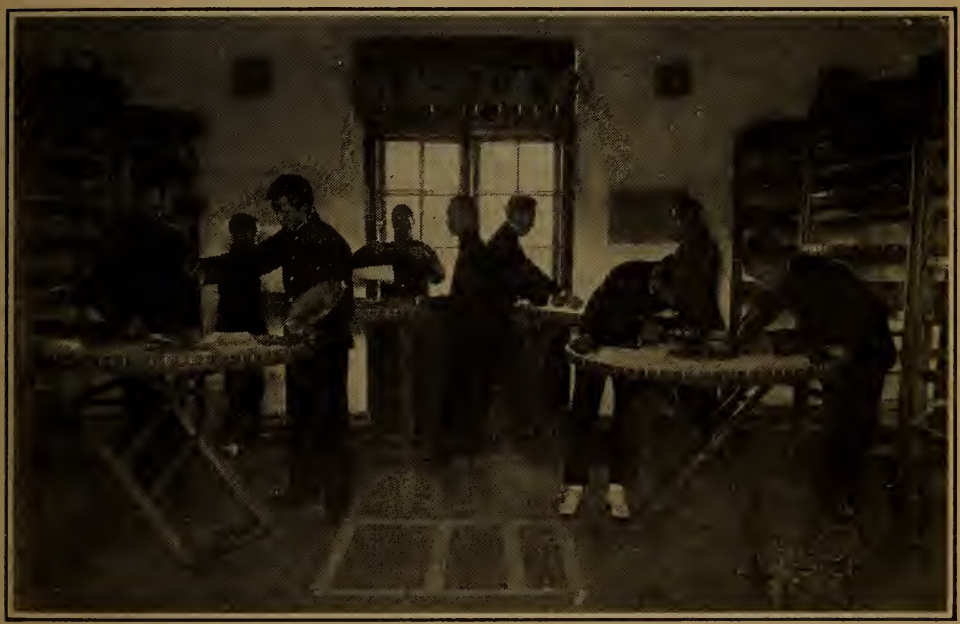

Examination to Prevent Diseases of Silkworis

to rose, becomes pepper-spot colored) is caused by small microbes that develop in the body of the worm. The origin of this is not known; it is hereditary, and a few leaves spoiled with the excretions of sick worms are sufficient to poison a whole roomful of healthy worms. To Louis Pasteur must be given the credit of discovering the location of this ruinous disease, especially in Europe, when between 1852 and 1857 , the Italian and French crops were reduced enormously so that it was necessary to import millions of eggs from China and Japan to make up for the loss. At 
present the silkworm houses, where a few worms are dying of pepperite, are whitewashed clean and given a chloride fumigation. It has been thus possible to check the disease.

At the fifth period a number of worms suffer from indigestion which is caused by vibriones eating the intestinal tubes. It is hereditary and contagious. It causes little damage if the worms are given fresh air and healthy mulberry leaves.

Laziness (grasserie) is always caused by carelessness on the hatcher's part, because it originates with such circumstances as poor ventilation, cold and humid air, which can be easily prevented. In such cases the worms, when the time for spinning their cocoons has come, move very slowly, losing as they move along a thick glue that stains everything. But although many worms may die of this sickness in the same room it is by far the least dangerous of all their ailments, because it does comparatively little damage. Of course, scientific silkworm raising ought to be rid of every disease. Good ventilation, uniform temperature, well selected dry food, can certainly give as much as one hundred and fifty pounds of cocoons to the ounce of eggs. There are about seven hundred Italian, eight hundred and fifty Japanese and nine hundred Cantonese cocoons to the pound.

The selection of eggs is the most important duty of the hatcher. The moths are subject to the same sickness as the worms inasmuch as some of them actually do not suffer from the diseases described above until transformed into butterflies. The first thing is the choice of healthy butterflies. Within two seasons the hatchers are able to eliminate nearly all defective eggs and to make a selection of the perfect ones, among which the element of reproduction will be given the preference. Once out of the cocoons, one butterfly out of a hundred is examined with the microscope (crushed in a little water, the microbes can be seen at once), and the others are then paired to lay the eggs. The butterflies crushed one by one afterwards may be examined once more with the microscope to make sure that no disease will infect the eggs. This is rather complicated, but the results are so gratifying that it is worth the trouble 
when it is known that one bad egg may spoil ten thousand good ones.

Good care in the hatching industry is the only source of profit. The Chinese lose a large amount of worms every year because they do not allow them enough room to grow and no care is taken either of the size of the worm, two facts which are recognized scientifically as indispensable for the welfare of the crop. Worms of the same size when kept together give much better results. Their food ought to be given sparingly and on time.

Mulberry leaves are the exclusive food for the worms. The white mulberry tree, by far the best, comes from China; the black and red mulberry trees are found everywhere in Europe. The leaves when picked must be given fresh to the worms, but never damp, because the tree, growing best in humid soil, the leaves contain a sufficient degree of moisture. During its short life the worm eats fifty times its weight.

The interesting insect that produces King Cocoon and Queen Silk is reared in almost every climate and by every nationality. The world's production of cocoons from the bombyx at the present time is more than one billion pounds. 


\section{CHAPTER III.}

\section{Domestic and Wild Cocoons}

$\mathrm{T}^{\mathrm{T}}$ is interesting to know what particular cocoons are to 1 be found in the producing centers of the world; whether from the mulberry Bombyx or any ather Bombyx.

We shall make a distinction between cocoons from worms of annual reproduction, cocoons from worms reproducing twice a year (bivoltins), from worms reproducing thrice a year (trivoltins) and from three to eight times a year (polyvoltins).

\section{Domestic Cocoons}

ITALY AND FRANCE.-The cocoon of the Bombyx Mori hatched annually is the only one that has given satisfaction.

It is said that some trivoltin kinds are found in Tuscany and Milan, but these are the exception. The cocoons from Cevennes, France, are supposed to be the best in the world, although silks from that district are sometimes dusty. Piedmonts and Friouls from Italy give the best results.

CHINA.-So large is the variety of cocoons found in China that it is almost impossible to describe them all. There are at least five polyvoltin kinds, yellow, green or white. The Canton cocoons are all polyvoltins. In the northern provinces there are several annual kinds.

The Chinese yellow cocoons, in general, are of poorer nature than Europeans, many of them are very bad, excepting those of the Tsie-Kiang Province.

Filature experts have said in several instances that with better material and work the Chinese would be able to produce out of the Tsie-Kiang or Woo-Sie cocoons a thread that would beat any Piedmont Extra. Mr. Warde, in the Lyons laboratory, made an official test a few years ago, showing that the fibre of a good Woo-Sie cocoon has 
twenty per cent more tenacity than any good cocoon from Italy or France. On the other hand, European cocoons weigh about three deniers with a good average quality, while Chinese cocoons weigh only one denier, with great irregularity in the quality (four-fifths interior to one-fifth best). In the north, silks are usually clean, comparing very favorably with European silks when well reeled. In the south, owing to the hot and damp climate, cocoons are poorer, and the silk comes out hairy, gummy, with little tenacity and medium elasticity.

The best selection of white cocoons spun in the steam filatures under European supervision produce a beautiful silk, the rival of the best Japans.

JAPAN.-About ten kinds of cocoons are hatched in Japan from April to November. The greatest part are annuals and white.

Since Italian and Chinese eggs have been introduced, there are many selections, but in. the native product there is no such diversity of cocoons as in China, but the Japanese take much more care in the selection and hatching of eggs, so that they practically control the crop during two-thirds of the season. The raw silks shipped to America are selected from among, the nervy and hard natured silks. The color is somewhat poor and they are reeled rather irregularly. Europeans prefer the soft natured silks on account of their beautiful white color, but the quality is not as good.

INDIA.-The Bombyx Fortunatus is about the only domestic cocoon. Bengal cocoons are polyvoltins of yellow color. Out of six crops, the first is by far the best. These raw silks are always dusty, a little superior in quality to the best Cantons.

THE LEVANT.-Under that name are understood cocoons hatched in Turkey, Greece, Bulgaria, Syria and Persia, where the French and Italian filatures supply themselves largely when there is a shortage in their own crop. At any time Levantine cocoons are found in stock at Marseilles and Milan to provide the filatures of those countries, and are often sold as white Italians. They give fairly good results in the coarser sizes. 
The worms are mostly bivoltins and cocoons white to greenish in all districts except the Salonika light yellow and the Syrian yellow.

RUSSIA.-The production of Caucasian white or yellow cocoons has been stationary for the last thirty years (about $3,000,000$ pounds); they are all polyvoltins of good nature but badly reeled by natives.

INDO-CHINA.-The cocoons compare very favorably with those of the Kwang-Tung Province. Two-thirds are yellow and one-third white polyvoltins.

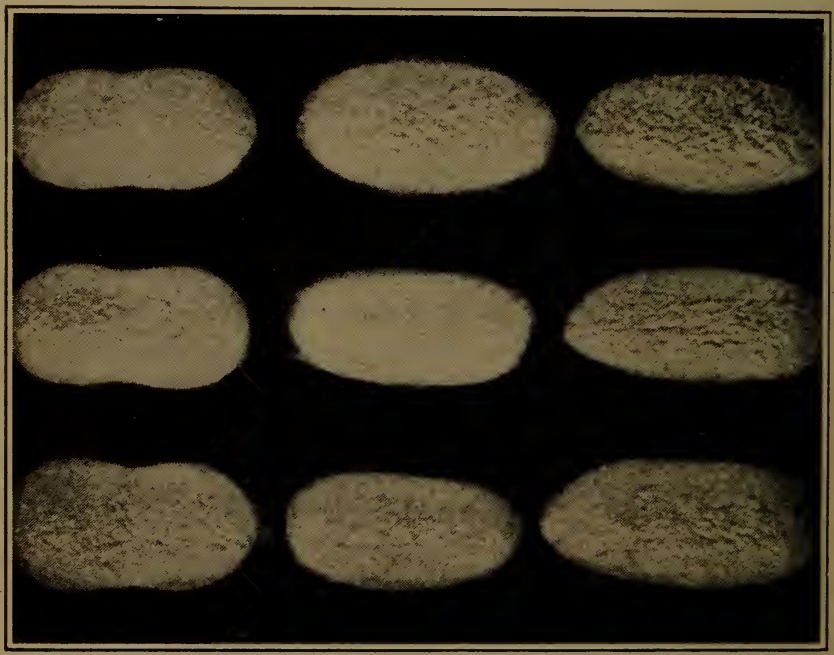

Different Shapes of Cocoons

The climate of Tong-King is really good for raising the worms, but the natives are lazy and their reeling process primitive. The French Government has established a numher of filatures with excellent results.

Other countries like Spain, Hungary, and Switzerland, each contribute a small crop of cocoons which are all annuals of the Bombyx Mori family. 


\section{Wild Cocoons}

Wild silks are the product of silkworms which cannot be domesticated and live freely on the mulberry and other trees.

The silkworms make two kinds of cocoons: partly opened or closed. Those that are entirely opened can only be used in connection with the waste silk business. All wild silkworms must be closely watched on the tree where they choose to spin their cocoons and picked before the butterfly has time to get out of his prison.

The Antherea Pernyi and Mylitta, found in Asia, are most commonly known in the silk business as Tussahs (from the Indian Tussor). Their cocoons, which are larger than the Bombyx Mori's, seem to be closed, but are really made up of several tubular coatings closed at each end by the gums so that the reeling is done differently than with the ordinary cocoon.

The basins -used in the filatures must be flat because if cocoons ar'e completely immersed in water the gums at each end dissolve and this allows water to get inside, which should be prevented for proper reeling. The cocoons once wet are deposited on wooden tablets and unwound from them. It is called dry reeling. In the wet reeling (waterreels) cocoons are unwound in hot water and soda. It is to be noted that the latter system shows a much larger percentage of waste.

There is less mineral substance in the fibre of the Antherea than in the Bombyx Mori and it has been found necessary in practice to mix a gummy preparation with the water in the basins in order to obtain the raw. The Chinese add some dark greasy matter to the soda, which gives such a brownish color to tussahs. This is removed easily in a hot-water bath.

Before 1875, tussahs were not used much in the silk industry, owing to the color of the raw being uneven. Since then it has been bleached white through a chemical composition of oxygen, water and bioxyd of barium. The natives in India and China reel tussahs showing irregularities anywhere from fifty to one hundred and fifty deniers 


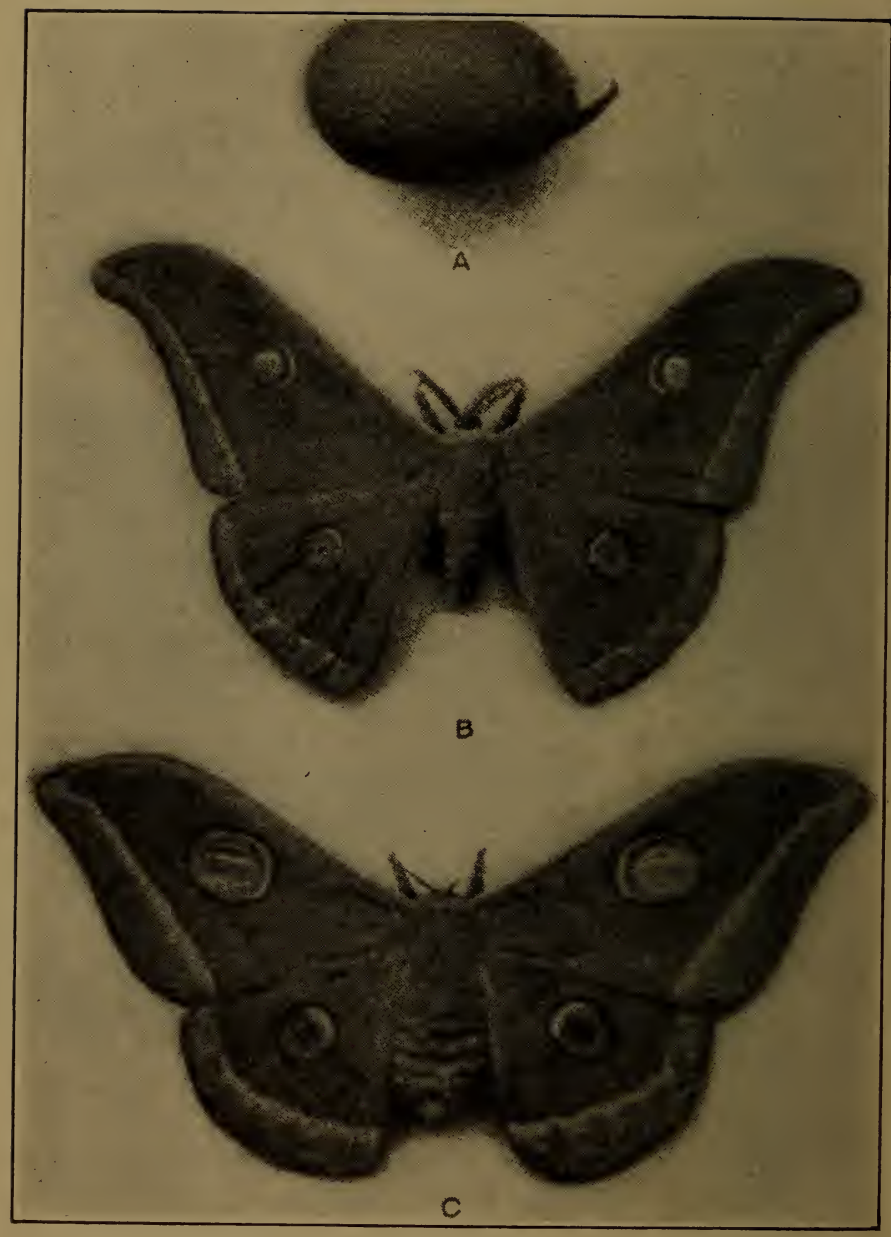

Tussah Cocoon and Butterfles 
variation. Filatures, however, especially in Chee-foo, reel off silks quite perfect, both in uniformity and cleanliness, and tussahs are now well represented in the fashions of the day, mixed with other silks, douppions, schappe, cottons, etc. Other wild cocoons, as the Theophila and the Rondotia, must not be regarded as tussahs. They are entirely closed, contain a proportion of gum equal to that of the Bombyx Mori, but are smaller, white, gray and dark gray. They are found on the mulberry tree in the center of dried leaves, which are bound entirely around them with the first threads emitted by the worm. It is strange that wild worms, living on mulberry trees, cannot be in any way domesticated, while those living on trees, like the jujube, the oak, the ailanthus, the Palma-Christi, etc., have all been domesticated after a time.

The Yamamai, the Assama, the Milytta and the Pernyi are the most interesting.

The Japanese Antherea, or Yamamai, is found mostly in the districts of Sinshiu, Mino, Goshiu and Tamba. The worm is green, eating exclusively oak leaves, and builds a large, light green cocoon. The nature of the fibre is about equal to the domestic, but the excess of mineral substance makes it difficult to dye. It is exclusively used by natives to mix with ordinary silk, and weave heavy. expensive goods.

The Assama, or Mounga, is found in Assam and parts of Turkestan. The cocoon is dark gray, weighing fully five deniers. It is subject to deadly parasites deposited by flies and piercing the cocoon ahead of time. Thus the cocoon must be unwound quite fresh. The Pernyi, hatched in Manchuria, Shang-Tung, Honan, Kiang-Sou, Ze-Tchun, and Tchi-li, is now being more and more domesticated. Like the Yamamai, it feeds on oak leaves. The crop is four million pounds yearly. Part of the silk is reeled in filatures, the other part is reeled by natives on spindles. The Milytta. or Tussor (that last name is applied wrongly to wild silk filatures all over the world), is found in India living on several kinds of trees. The cocoon is very big, light yellow to dark brown, weighing usually $8 / 10$ deniers. The raw is reeled out of two, three, four, and eight cocoons. Most 
of the tussahs coming on the New York market are Chinese eight cocoons.

Several kinds of wild cocoons are found in other parts of Asia and Africa, but are practically unknown to the silk industry. 


\section{CHAPTER IV.}

\section{Growth and Development of the Modern Filature}

MPRESS Si-Ling-Chi, wife of Hoang Tee, inventor of E the calendar, is said to have been the first to introduce a method of gathering threads from cocoons and of reeling them into a continuous fibre that could be twisted, dyed and woven.

In that case the existence of the filature goes as far back as $2700 \mathrm{~B}$. C., but it is nat impossible, progress being very slow in China, that even before the time of Si-Ling-Chi, some five or ten thousand years ago, the Chinese had already found out how to use the silkworms. Empress SiLing-Chi is known today in China as "Te ching tsun kou niang," Goddess of the silkworms. Strange to say, the oldest Chinese prints, dating three thousand years back, and illustrating silk reeling, show that the reeling machine used then did not differ very much from the ones still in existence today, in the provinces, where the steam machine is unknown.

The first hand filatures were introduced in Japan during the year $310 \mathrm{~A}$. D.

Under Justinian, 555 A. D., Nestorian monks brought to Constantinople the formulae of an industry long kept secret in China.

Gradually silk culture spread to Italy, Spain, France, Arabia and Egypt, and from there extended over the countries where the soil and climate were favorable to sericulture. The first reeling machines were very simple, and the goods made out of such irregular raws as we see by samples kept in museums, were exceedingly coarse. The reeling was done by hand exclusively. The cocoons being unwound either around a cylinder or a spindle-like piece of wood, 
the thread had to be cleaned and given some kind of twist by hand.

During the fourteenth and fifteenth centuries some improvement came out of re-reeling, but the first filature, that is, the first assembling of several basins under one roof

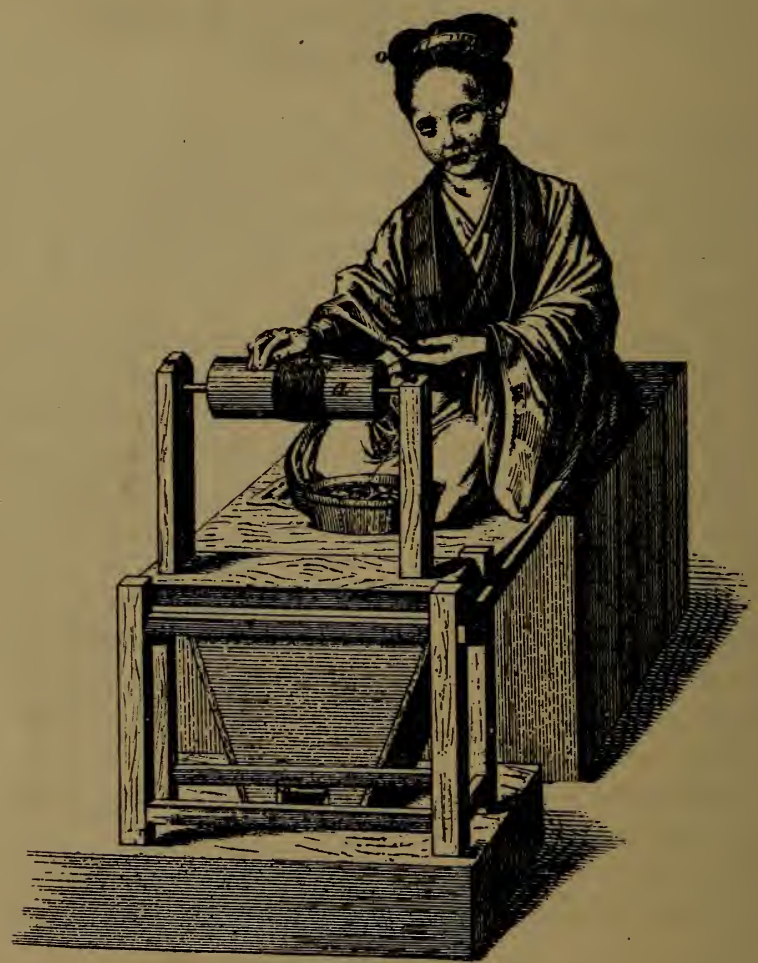

Old Reeling Process in Japax

with the aim of improving the quality, was started by $V$ aucanson, the great French mechanician, during the year 1750. It was built at Pont d'Aubenas in Ardèche. There, for the first time, the question of speed was resolved, several travelers being regulated by one man and the threads being passed through hooks moving horizontally. The cross reels were thus obtained. The several fibres coming 
Growth and Developaient of the Modern Filature $3 i$

Irom the cocoons were united in a little hole perforated through a piece of glass instead of being brought together by hand. The next improvement was to dry the silk by allowing sufficient length between the basin and the traveler which made further re-reeling easier.

Until the nineteenth century the filature was entirely under the influence of the Orient; not only on account of the cocoons being largely imported from the Far East, but also because the reeling machines showed little improvement on the Chinese system of centuries ago.

During the nineteenth century, Europeans began to study the silkworms closely: A new science spread over Europe: the hatching of cocoons, and an analytical study of all reeling processes, until a perfectly logical and mathematical system of reeling was obtained. European filatures were born. The Chinese and Japanese themselves took advantage of this advance and at the present time the two systems of reeling, French two, four, six ends coupled, and Italian one to eight ends, are used the world over.

In the French filature the reeling girl, having first beaten the cocoons with a small brush broom in hot water draws out the first coarse thread (thirty per cent), which will become frisons (waste silk). As soon as the following fibres come out clean she collects them from the broom, and, holding them in her left hand, she gathers as many ends as necessary to make the raw; say six cocoons (six cocoons at two deniers $=$ twelve deniers). These six ends are passed through a little hole, where they are united into a single thread.

The hole is pierced in the center of a glass ring above the basin and prevents cocoons jumping after the thread.

A very important point is the twisting. In the French filature or "Chambon," the glass rings are always coupled so that the two fibres are twisted on each other (about two hundred times). By this operation the fibres are made regular, well aggregated, perfectly cylindrical, and cleaned of gross irregularities. When dirt or pieces of cocoons are taken up, they break the threads in the twisting, so that the reeling girl has to clean and retie them. After the twisting, the threads are passed through hooks and twisted 
once more, but only one time on each other. This is only to prevent both threads getting on the same traveler in case of a break.

The above system of reeling gives greater regularity and perfection of finish to the silks, but on the other hand, it is not possible to work properly more than four ends per basin or about three hundred grams of silk a day.

The Italian filature has the advantage of reeling, according to the cleverness of the reeling girl, any number of ends, which increases largely the production.

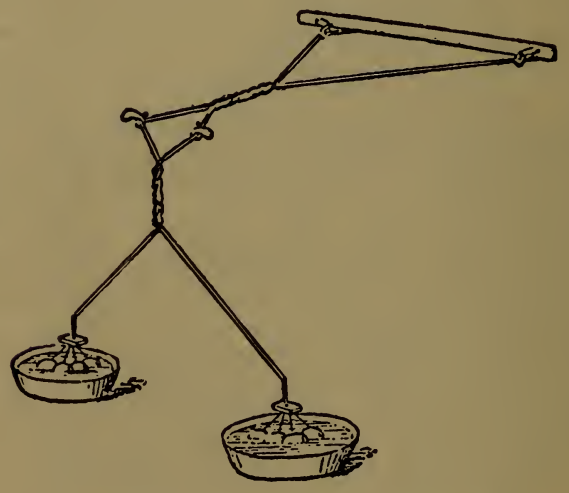

Reeling, Chambon System

The apparatus is the same as the French, except that the twisting is done over on the fibre itself; that is, it goes directly from the ring, $A$, to a small wheel, $B$, and runs back to another wheel below, $C$, to go up again, twisting itself between $B$ and $C$, and running up to a third wheel, D, and thence directly on the traveler via a horizontally moving hook, which regulates the distribution of the thread on the travelers or cross reeling.

It is very important to dry the silk in order to prevent the gums of the fibres sticking together and every up-to-date filature has a complete steam tubing running along the travelers and drying them while in action. 


\section{Improving the Filature}

Several fair trials have been made of the automatic reeling machines. Probably the best of all is the electric basin invented by an American, Mr. Serrell, and improved by several Italian reelers. The hand work consists of getting the cocoons ready to unwind. The end throwing is done automatically. The threads pass over a pendulum regulated by electricity in such a way that as soon as the depression of the threads indicates a falling in the size another cocoon is added to the bunch to make it up. However, up to the present, results have not been satisfactory, as it requires quite a good deal of supervision and loss of time which does not pay after all.

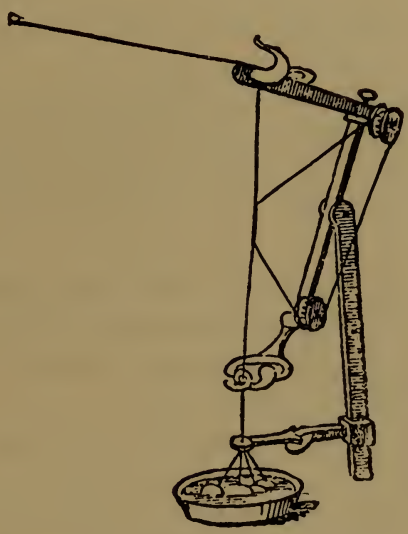

ReELing, Tavelette System

The automatic catching wheel, perfected by Mr. Camel, is among the latest improvements, and has given the best results. Instead of throwing the end toward the other running ends, it is hooked on a horizontal wheel revolving two thousand times a minute. The wheel seizes the thread and brings it into contact with the others. It has the great advantage of avoiding the coarse ends invariably obtained through hand throwing.

It is not my intention to give a course of instruction in reeling, but I will simply say that the perfection of the 
filature is till left with the reeling girl's ability. To maintain the right number of cocoons in the basin she has to use her experience and judgment. As an example, to make a size $11 / 13$ with cocoons averaging two deniers, she would have to maintain:

6 new cocoons $\ldots \ldots \ldots \ldots \ldots \ldots \ldots \times 2=12$

or

5 new cocoons $\ldots \ldots \ldots \ldots \ldots \ldots \ldots 52=10$

2 half cocoons $\ldots \ldots \ldots \ldots \ldots \ldots \ldots 2 \times 1=2$

$=12$

or

4 new cocoons ............... $4 \times 2=8$

2 half cocoons $\ldots \ldots \ldots \ldots \ldots \ldots \ldots 2 \times 1=2$

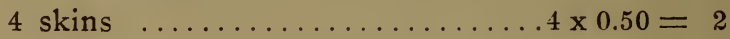

She must keep the water at a boiling point. She must watch that no dirt runs up the thread; that the twist is long enough, etc. But even the best reeling girls are not free from mistakes, and a strict supervision is necessary in all filatures.

We shall now see, taking the ordinary French and Italian filatures as a basis, what improvements could be made either in the re-reeling or the machinery that would make the best silk at a minimum of expense.

The building of a filature should be of wood entirely, similar to the Japanese filatures, but high roofed in order that the vapors from the hot water in the basins may be dissipated at once. The French four-end system is better to reel fine sizes up to twelve deniers. The reeling girl would have to prepare the cocoons and do the cleaning herself.

The travelers should not turn more than one hundred to one hundred and twenty revolutions a minute.

For reeling from thirteen deniers and above the Italian system is better: say eight ends with an extra girl to prepare the cocoons every three basins. There should be no retieing because the travelers could turn as fast as possible. but re-reeling would be necessary. In both cases automatic catching wheels should be used. 
The cost of both combinations compares as follows: lirench system (four ends), cost, per basin, per day: Working girl fifty cents, general expenses fifty cents, total one dollar. Italian system (eight ends), cost, per basin, per day: Working girl fifty cents, auxiliary girl fifteen cents, rereeling seventy-five cents, general expenses seventy-five cents, total two dollars and fifteen cents.

If the French basin is reeling nine deniers, travelers revolving one hundred times a minute, the Italian may work just as fast and produce double in weight on eight ends instead of four in any coarse size. The difference in price on the sizes makes the net profit about equal each way. Being given the above combination there is no possibility of working any better.

If we put the coarser sizes on the French four ends we lose time. If we put the finer sizes on the Italian eight cnds we cannot work it properly; the reeling girl cannot make a good. fine size with so many ends, and even if she uses four only the perfection of the thread cannot be obtained otherwise.

At present a filature is either one or the other system. Each one has an advantage over the other; they should be both judiciously used in the same filature.

The question of speed is very important, and, although it decreases in proportion with the increasing number of ends, the quality of cocoons has very much to do with it. If a good cocoon unwinds regularly at one hundred revolutions a minute and two good cocoons at ninety, two bad cocoons might unwind at fifty revolutions only, a fact which must be accounted for in the working account.

In any case, silks spun slowly come out always better than those spun very fast, because there is more elasticity and tenacity in a fibre which is given the opportunity of aggregating well. It can be watched more closely anyway, and be made considerably cleaner. In the Japanese filatures, when the travelers are revolving over one hundred times a minute the fibres are strained so as to render it impossible to avoid fine ends. In the French Cevennes filatures, travelers turn slower than anywhere else, and the silks are perfect. 
In the choice of cocoons the modern filatures have encountered a serious difficulty with dusty cocoons.

Are some cocoons fuzzier than others? The question is not definitely settled. My personal idea is that silks spun with small cocoons are more dusty than others, because, for instance, ten small Japanese cocoons make a fibre twice as dusty as another made out of five large ones. It goes to show that the largest cocoons are the best. The automatic catch wheel has the advantage of simplifying the operations greatly and should be a valuable addition to every basin.

In conclusion, I append statistics of raw silk spun in the filatures and similar establishments of the world. It is to be noted that the output in 1880 was $24,000,000$ pounds. It will soon reach three times this quantity, owing to the extension of Japanese reeling.

Statistics of the World's Production of Raw Silk for a Period of Forty Years

$$
\begin{aligned}
& \text { Average During } \\
& \text { 1881-1890 1891-1900 1901-1910 1911-1920 } \\
& \text { Lbs. Lbs. Lbs. Lbs. }
\end{aligned}
$$

Europe-

France ...... 1,316,000

Italy $\ldots \ldots \ldots 6,614,000$

$1,539,000$

$1,300,000$

800,000

Spain ....... 185,000

$7,136,000$

$7,800,000$

$7,200,000$

Hungary .... $\quad 441,000$

186,000

191,000

140,000

Russia ...... 214,000

582,000

673,000

350,000

502,000

970,000

300,000

Levant and Asia Minor-

Syria ....... 606,000

$944,000 \quad 985,000$

500,000

Turkey, Brussa 595,000

$1,153,000 \quad 1,209,000$

720,000

Greece $\ldots \ldots . \quad 42,000$

$87,000 \quad 118,000$

200,000

Balkans (Serbia, Bulgaria, etc.) $\quad 30,000 \quad 63,000 \quad 127,000 \quad 90,000$

Persia and

$\begin{array}{llllll}\text { Turkestan } \ldots & 280,000 & 340,000 & 661,000 & 570,000\end{array}$ 
Growth and Development of the Modern Filature 43

Average During

1881-1890 1891-1900 1901-1910 1911-1920

Lbs. Lbs. Lbs. Lbs.

China.-

Shanghai $\ldots \ldots .7,700,000 \quad 9,500,000 \quad 11,200,000 \quad 9,890,000$

Canton $\ldots \ldots \ldots 2,000,000 \quad 3,428,000 \quad 4,850,000 \quad 4,600,000$

Japan $\ldots \ldots \ldots \ldots .3,400,000 \quad 7,120,000 \quad 10,000,000 \quad 30,500,000$

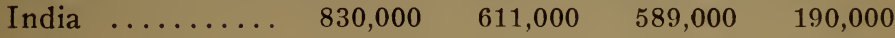

Total $\ldots \ldots .24,253,000 \quad 33,191,000 \quad 40,673,000 \quad 56,050,000$

Statistics of Asiatic silks are available for exported goods only. It is safe to add twenty-five per cent for Japan, fifty per cent for China and seventy-five per cent for India to represent the whole production. 


\section{CHAPTER V.}

\section{Conditioning, Testing and Boiling Off}

A FTER raw silk is spun and ready to be sold there is A a very important test which all manufacturers ought to have made to ascertain what quantity of moisture the silk contains. No textile fibre can absorb humidity in so large a proportion as silk and, therefore, there is a risk of buying water at the price of silk, which would be costly.

It is admitted that normally silk contains ten per cent water. The operation consists in reducing the silk to perfect dryness and adding a fixed amount of eleven per cent for allowance of moisture; if the said moisture exceeds eleven per cent plus two per cent the difference is credited to the buyer.

This ought to be an absolute rule and every bale ought to be conditioned as is done in Europe, b'it American manufacturers have their own ways regarding that question. While some are satisfied to send their silks to the conditioning house, many buy original weight, and while they never mention anything if the silk gains on the original or invoice weight, they do not fail to make a claim if it loses. As there is a conditioning house in New York large enough to accommodate everybody, it is to be hoped that in a few years from now all transactions will be made "conditioned weight."

In all the great cities of the world where silk business is done there are conditioning houses with dessicators of the most modern and accurate models. In France, Lyons, as the pioneer of all silk cities, has the largest conditioning houses, and also St. Etienne, Paris, Aubenas, Avignon, Privas, Marseilles, Valence, Nimes, Roubaix, Amiens. In Italy: Milano, Torino, Bergamo, Lecco, Udine, Firenze, Brescia, Ancona, Pesaro, Genoa, Como. In Germany: 
Crefeld and Eberfeld. In Switzerland: Zürich. In Japan: Yokohama. In China: Shanghai.

Conditioning and testing are completely treated in a recent book, "The Value of Conditioning," issued by the United States Testing Co., of New York.

\section{Boiling Off.}

To determine the exact quantity of silk which will be used in silk goods, it must be boiled off in order to extract the gum from the thread. This boil-off is necessary to obtain the beautiful brilliancy of the silk when dyed. In Europe the silk is often boiled off before it is sold, for certain qualities are liable to lose more than expected, but in America that test has not yet become popular because the sort of silks now used have a well defined difference of percentage.

\begin{tabular}{|c|c|}
\hline wh & 0 \\
\hline ans, & $21 /$ \\
\hline Italians, yello & \\
\hline Italians, & \\
\hline hina ste & $20 / 23^{\circ}$ \\
\hline Tsatlees & $20 / 24$ \\
\hline antons & $20 / 23 \%$ \\
\hline Issahs & $8 / 14$ \\
\hline
\end{tabular}

\section{Tests.}

The tests of sizing and winding of silk are made in the filatures, but when necessary to have a definite proof of the facts it is customary to have further tests made at the conditioning house, where besides the dessicators they have all the machinery for winding, sizing and even to ascertain the tenacity, regularity and elasticity, as well as the cleanliness of silk.

Although the figures as given by the official test are as correct as possible, the inspector's test is nevertheless always better, because it is made on the whole lot while only a few bales, one to four for a ten bale lot, are submitted to the conditioning house.

Outside of the personal valuation of silk by an inspector there are certain mechanical devices to ascertain the quality of silk. This is done according to European standard: 


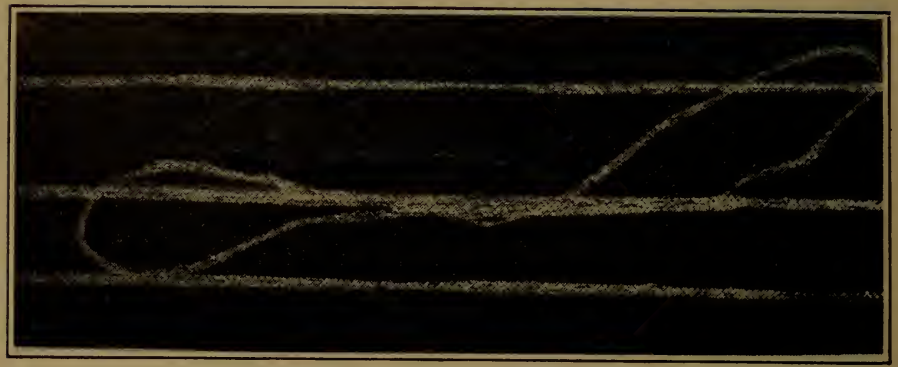

Fuzziness

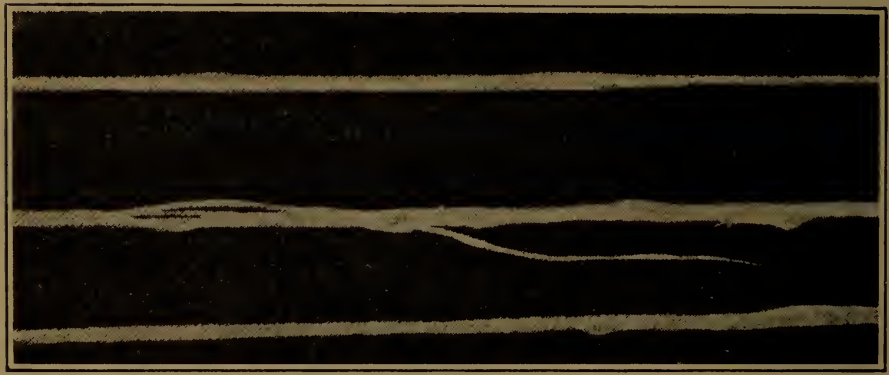

Dead End

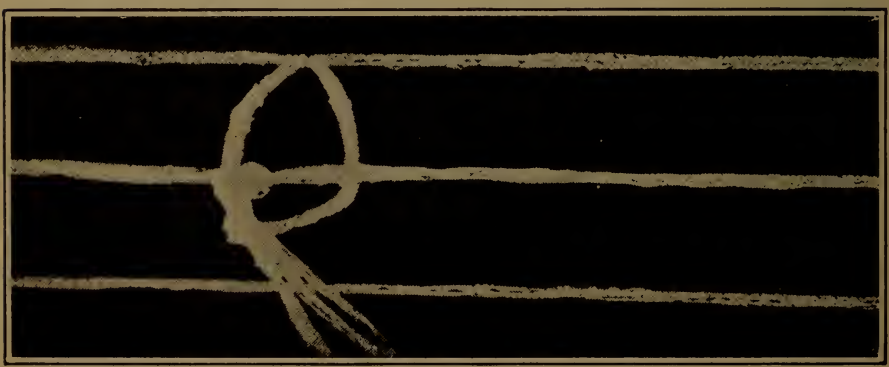

KNOT

RAW SILK IMPERFECTIONS 


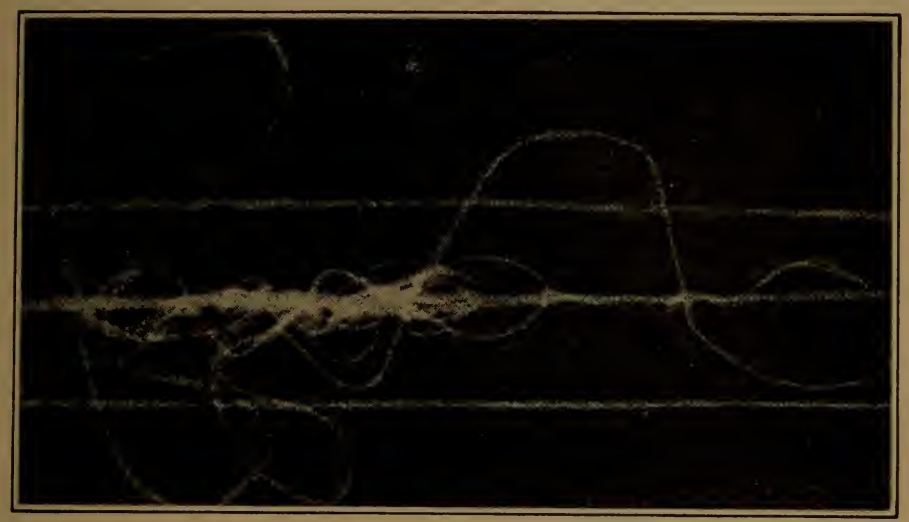

Nest

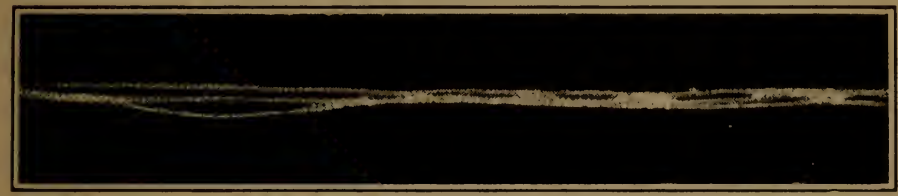

\section{LaCk of Cohesion}

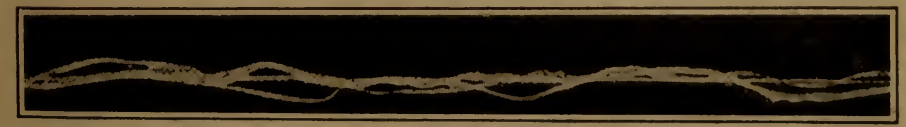

Conkscrews

RAW SILK IMPERFECTIONS 


\section{Winding.}

(Test made on fifty revolutions per minute.)

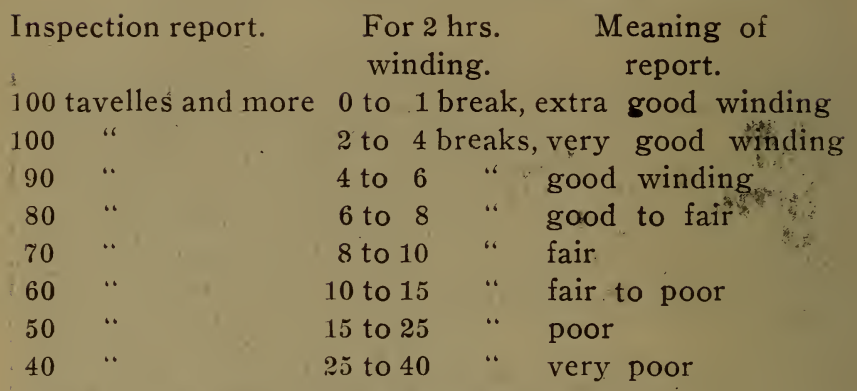

\section{Cleanliness.}

Thread absolutely pure

Only a few nibs or corkscrews

A few nibs, nests and slightly hairy

The same plus particles of cocoons

The same defects in quantities

The same in large quantities
Extra good
Very good
Good
Fair
Poor
Very poor (unfit)

\section{Sizing.}

The sizing of raw silk is obtained by selecting a number of skeins from a lot and reeling out four hundred and fifty meters of thread from each skein. The small skeins are weighed on a special denier scale and their average-must show the correct size. That is, if the silk is a $13 / 15$, the result must show a size between 13.75 and 14.25 . If the average is below 13.75 , the size is said to be $13 / 1$. fine. If above 14.25 , the size is $13 / 15$ coarse. A manufacturer ought to know that if he buys a $13 / 15$ coarse, he loses on the yardage. It is always better to receive a lighter silk. The same remark applies to all sizes.

In America, manufacturers are not generally particular regarding the question of size. It is a mistake. In Europe, where everything is figured out very fine, a lot is not accepted by the buyer unless it shows the correct sizing within a very small margin. 
The standard size is $13 / 15$ in America and $11 / 13$ in Europe.

Sizes below $13 / 15$ always fetch higher prices, say about ten cents by size. Sizes above $14 / 16$ sell at lower prices, in proportion, and according to stock on hand.

\section{Sizing Test.}

Variations of $2 / 3$ deniers on 10,000 meters; say, for instance, a Extra good

$13 / 15$ varying between 13 and

15 on the whole length

Variation of $3 / 4$ denier

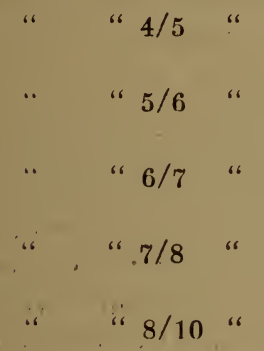

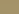


Japan-Sinshiu, Mino, Shimoosa-white.

Uzen, Rikuzen, Bushiu-cream.

Koshu-dull to very dull white.

China-Shanghai-Steam fil.--very white.

Canton-whitish to cream.

The Levant-

Salonika-light yellow.

Adrianople-pure white.

Bulgaria-cream.

Brussa-whitish to cream.

Syria, Bengal-gold yellow.

Caucasian-greenish.

When silk is old, the color is slightly altered. Dark yellow becomes pale or yellowish; pure white turns dark, with a tint of green or yellow.

\section{Elasticity.}

The elasticity and tenacity can be tested either with the hands or by a special machine called a serimeter. The combination of all tests demonstrates absolutely the quality of all silks, whether fit for organzine, single weaving or tram. A raw silk expert is the man who can, simply by looking at a few skeins representing a lot of silk, determine the grading and what it can be used for. 


\section{CHAPTER VI.}

\section{Percentage System of Inspection}

THE percentage system of inspection, as done by 1 United States manufacturers, proves to be a very correct way of ascertaining the classification of raw silk.

Thirty skeins or more are taken out of a ten bale lot and are given the usual test of winding at high speed. There is an accurate test for cohesion, elasticity, cleanliness. To this is added a sizing test, because it is the best proof of regularity. Being given a certain percentage to each quality or defect, the average gives the grading, which serves as a guide to the buyer for further purchases.

A perusal of the inspection report printed herewith on a lot of Sinshiu Extra Yodasha tells the story at a glance.

We see that the lot is very nearly as good as represented. With a better regularity in the thread it would grade up to a Double Extra. It is a proof that the choice of cocoons was good, but the reeling deficient. Either some of the reeling girls were inexperienced or unsupervised, or the reeling itself was too fast.

Approximative Inspection Percentage of Japan Silk

Double Extra A Crack chops for single

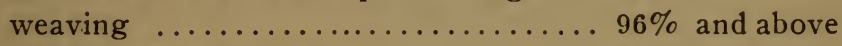

Double Extra A Cracks.............. 94\%

Double Extra A.................. $92 \%$

Double Extra B ................... 90\%

Extra A $\ldots \ldots \ldots \ldots \ldots \ldots \ldots \ldots \ldots$

Extra B.......................... $86 \%$

Best 1 to Extra..................... $82 \%$

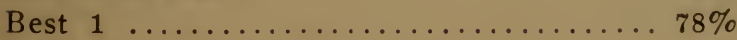

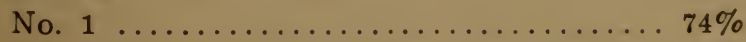

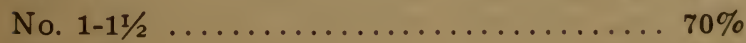

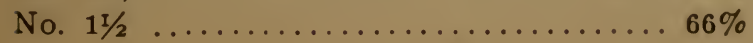


Account Post \& Sheldon Corp. Report Dace April 24th, 1919 Chop "Tennis Ball \& Racquet" Yodasha Chisagatagori Shinshu Lot No. 173

Bale Nos. 8042

Seller

Mark RSTC Stock: Japan China Ital.

Color: White Ivory Cream Yellow Lustre: VG G FG F P VP Hands: VS SKY NVY Firm Str Spg

Winding Based on 30 Skeins, 120 yds. per Minute Breaks 41 Cause Fine Ends \& Gums Gums Medium

Defeccs Found in 10,000 Yds. Estimated on Taken From 10 Skeins 10 Skeins 10 Skeins $300,000 \mathrm{Yds}$ Defects

Very Fine Thds.

Fine Thds.

Coarse Thds.

Penalties

\begin{tabular}{|c|c|c|c|c|c|c|c|c|c|c|c|c|}
\hline $\begin{array}{c}\text { Evenness Penalties } 3 \\
\text { Percent }\end{array}$ & $\begin{array}{r}300 \\
69\end{array}$ & $\begin{array}{r}150 \\
83\end{array}$ & $\begin{array}{rr}420 & 2 \\
63 & \end{array}$ & $\begin{array}{rr}210 & 12 \\
77 & 8\end{array}$ & $\begin{array}{r}120 \\
87\end{array}$ & $\begin{array}{r}210 \\
77\end{array}$ & 235 & 74 & & $\begin{array}{l}86 * \\
85 \\
84\end{array}$ & & 84 \\
\hline Raw Knots & 5 & 6 & 2 & 5 & 4 & 4 & 130 & & $\mathrm{X}$ & 82 & & \\
\hline Knots Large $x_{2}^{\frac{1}{2}}$ & 1 & & 2 & 2 & & & 25 & 12 & & 81 & & \\
\hline " V " $\mathrm{x} 1$ & 3 & 3 & 4 & 2 & 4 & 2 & 90 & 90 & & 80 & & \\
\hline Waste & & & 1 & & & & 5 & 5 & B1 & $\mid \begin{array}{l}79 \\
78\end{array}$ & & \\
\hline Slugs $\quad x_{\frac{1}{2}}$ & 1 & 1 & 1 & 2 & 2 & 1 & 40 & 20 & & 77 & & \\
\hline « V * $\mathrm{x} 1$ & 1 & & & & & 2 & 15 & 15 & - & & - & \\
\hline Bad Throws x1 & 2 & 1 & 3 & & 1 & 2 & 45 & 45 & & $\begin{array}{l}76 \\
75\end{array}$ & & \\
\hline $\begin{array}{l}\text { Corkscrews } \times 1 / 20 \\
\text { Split Ends }\end{array}$ & 8 & 3 & 7 & 6 & 6 & 5 & 175 & 9 & 1 & $\begin{array}{l}74 \\
73 \\
72\end{array}$ & 74 & \\
\hline 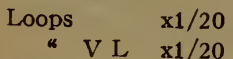 & 11 & 8 & 6 & 8 & 10 & 11 & 270 & 13 & & 72 & & \\
\hline Nibs $\quad \times 1 / 20$ & 18 & 21 & 22 & 20 & 18 & 28 & 635 & 32 & & $\begin{array}{l}71 \\
70 \\
69\end{array}$ & & \\
\hline $\begin{array}{r}\text { Cleanliness Defects } \\
\text { Percent }\end{array}$ & 56 & 46 & 56 & 50 & 49 & 60 & 1585 & $\begin{array}{r}241 \\
84\end{array}$ & $1 \frac{1}{2}$ & $\begin{array}{l}68 \\
67 \\
66 \\
\end{array}$ & & \\
\hline $\begin{array}{l}\text { Tenacity } \quad 59 \& 51= \\
\text { Cohesion }\end{array}$ & $=55$ & & $\begin{array}{l}\text { Grams } \\
\text { Strokes }\end{array}$ & $\begin{array}{l}13.83 \\
2350\end{array}$ & & Size & $\begin{array}{l}97 \% \\
100 \% \mathrm{~A}\end{array}$ & Ive. 99 & 2 & $\begin{array}{l}65 \\
64 \\
63 \\
62\end{array}$ & & \\
\hline $\begin{array}{l}\text { Quality } \\
\text { Above } \% \text { Divided }\end{array}$ & by $\mathrm{T}$ & Three & & & & & & 86 & & 60 & & \\
\hline $\begin{array}{l}\text { Hairiness } \\
\text { Humidity Dry } 70\end{array}$ & $\begin{array}{l}\text { Very } \\
\text { Wet }\end{array}$ & $\begin{array}{l}\mathrm{Bad} \\
62\end{array}$ & $\begin{array}{l}\text { Deduct } \\
\text { Relativ }\end{array}$ & $\begin{array}{l}5 \% \\
\text { ve } \%\end{array}$ & & $\begin{array}{l}\text { d } 3 \% \\
\text { Absolu }\end{array}$ & $\begin{array}{l}\text { Slightly } \\
\text { te } 5.1\end{array}$ & $\begin{array}{r}1 \% \\
\text { Grains }\end{array}$ & 3 & $\begin{array}{l}57 \\
56 \\
55\end{array}$ & & \\
\hline
\end{tabular}


With an inspection report like that, a manufacturer is able to point out to the filature what improvement may be brought to its quality. The classification of silk would be greatly improved if business was done direct with the reelers under original chop only.

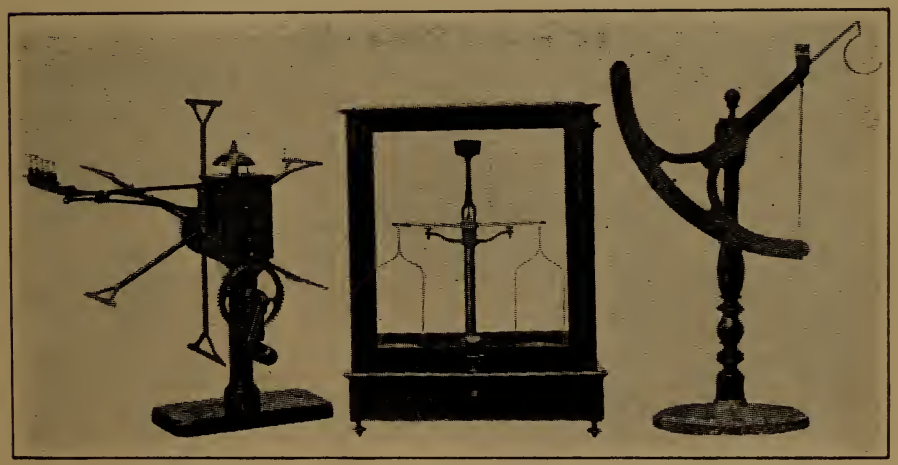

Tue Irspector's Sizixg Scales and Reeler 



\section{PART II}

RAW SILK IN EUROPE 


\section{Introduction}

If we study the raw silk industry of Italy, where that business has attained perfection, it will not be necessary for us to study it again in the other silk centers of Europe. as it would be a repetition of the same together with poorer conditions. France is the only country that could compare with Italy as to the quality of raw silk, but the production is becoming smaller and smaller. Spain and Hungary each have a few filatures which do not amount to one thousand basins altogether. Their products are consumed at home. A special chapter will be devoted to Lyons as the leading market of the world for silk goods. 


\section{CHAPTER I. \\ The Raw Silk Industry of Italy}

D EFORE entering into details of the organization of B Italian filatures it is necessary to say a word about the different provinces devoted to the great industry and how it has been developed to the present high standard of production. If Italy now ranks third as to the quantity of marketable raw silk and first as to the quality, it has come only after a slow evolution during many centuries.

The studies of the climate and working methods in different centers will give us a better understanding of this vast subject.

From China, through Greece, Africa and Spain, the silk industry was brought to Sicily during the twelfth century (1130 A. D.) From Palermo, Messina and Napoli, it spread to Firenze, Lucia, Bologna, Modena and finally Lombardia, Venetia and Piedmont. From this last place it was introduced into France. Today the Italian filatures spin from ten to twelve million pounds of raw silk in the following centers:

Country.

Number Number

Piedmont.- of filatures. of basins.

Torino $\ldots \ldots \ldots \ldots \ldots \ldots \ldots \ldots \ldots, 41 \quad 2,100$

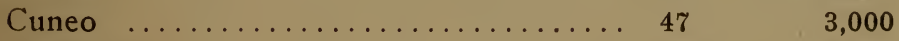

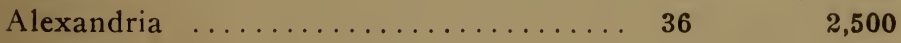

Novara $\ldots \ldots \ldots \ldots \ldots \ldots \ldots \ldots \ldots .6 . \ldots \ldots$

Liguria-

Genova...$\ldots \ldots \ldots \ldots \ldots \ldots \ldots \ldots \ldots \ldots \ldots$

Lombardia-

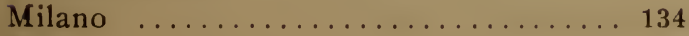

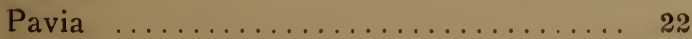

10,000

Como 
Country.

Number Number

. of filatures of basins.

Sondrio 3 220

Bergamo ...................... 88 7,500 Brescia

Cremona 42

Mantova

Venetia-

Verona $\ldots \ldots \ldots \ldots \ldots \ldots \ldots \ldots \ldots \ldots \ldots$

Vicenza ................... 46

Padua ...................... 5

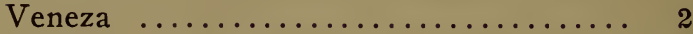

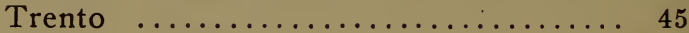

Udine $\ldots \ldots \ldots \ldots \ldots \ldots \ldots \ldots \ldots \ldots \ldots \ldots$

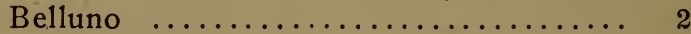

Emilia-

Piacenza $\ldots \ldots \ldots \ldots \ldots \ldots \ldots \ldots \ldots \ldots$

Reggio ...................... 2

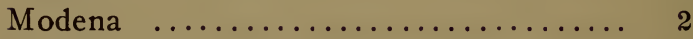

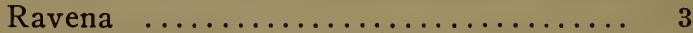

Forli

Toscana-

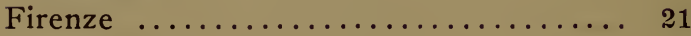

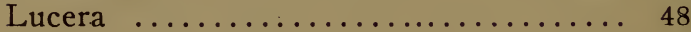

Arezzo

Umbria-

Peruggia $\ldots \ldots \ldots \ldots \ldots \ldots \ldots \ldots \ldots \ldots \ldots \ldots$ Marche-

Pesaro ...................... 45

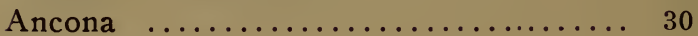

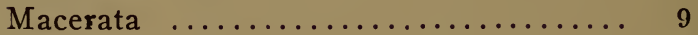

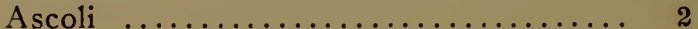

350

450 2500

390

150

2,200

3,000

50

225

600

650

550

95

\section{Campania-}

Caserta $\ldots \ldots \ldots \ldots \ldots \ldots \ldots \ldots \ldots \ldots \ldots \ldots \ldots$

850

850

200

50

\section{Calabria-}

Cosenza .................... 16

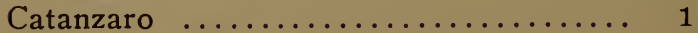

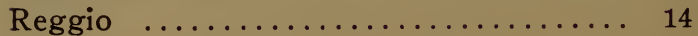

900 


\section{Cocoons}

Before going into details of the filature itself it is necessary to say a word of the cocoon business.

Formerly there was a sufficient crop of cocoons in Italy to give plenty of work to all the filatures, but the importation began as soon as the basins became too numerous. At present some $11,000,000$ to $12,000,000$ pounds of dry cocoons are imported annually, viz.:

\section{Yellow-}

Salonika, pure yellow, gives very good silks.

Adrianople, pure yellow, gives very good silks.

Servia, Bulgaria, pure yellow, gives very good silks.

Greece, pale yellow, very good for fine sizes. (The pale color is on account of the sun warming instead of steam warming.)

Hungary, bright yellow, very gummy silks.

Syria, Smyrna, Cypress, light yellow, give good silks.

Brussa, Caucasus, Persia, Turkestan, scarcer and inferior quality.

\section{White-}

Adrianople, very white, very good quality.

Brussa, white to whitish, good quality.

Caucasus, Persia, Turkestan, whitish, coarse sizes.

China, Shanghai, very white (Woo-Sie, Showshings), used mostly in fine sizes.

Cantons, Tussahs and Japans are not imported any more.

The market for cocoons takes place before or during the crops. In the first case contracts are made in a form showing the locality where the cocoons have been hatched, their quality and the approximate production expected from them. In the second case contracts are made upon sampling.

\section{Price Conditions}

The price of cocoons is said to be final when it is made without taking into consideration either the expected re- 
sults or the price fixed officially by the Chamber of Commerce.

The referendum price; with or without premium, is fixed by the Chamber of Commerce of each market (the premium may vary from five to forty cents per pound of fresh cocoons). The conditioned price is made according to what the raw silk turns out to be on the four to one basis (four kilos cocoons equal one kilo raw silk).

The price of the Sericultural Association of Milan was formulated in 1911 for the first time and is tabulated according to the average of prices paid for raw silks, quality sublime, size $10 / 12$ and 14/16 from April 15 to August 15 . Sometimes contracts are made half one way, half the other. The dry cocoon market is invariably established on the four to one basis, although the final value rarely turns out so; but if the result is inferior to four kilos the seller obtains a bonus; the buyer is allowed a rebate if the result proves more than four kilos.

Weight tests are carefully made at the conditioning house from the results obtained in three different filatures that have each been given four kilos of cocoons to spin. The decision of the conditioning house is without appeal.

For a number of years most of the filatures have owned dessicators for drying cocoons. It has advantageously replaced the hot room of old, which took a long time to do efficient work and was never satisfactory. The dessicators mostly in use are those of Bianchi, Dubinichiesa, Pellegrin, Beretta, etc. They all heat up to two hundred and seventy degrees Fahrenheit. The chrysalides are killed within two hours. In four hours the cocoons loose twenty per cent. of their weight. In sixteen hours they are completely conditioned, having lost two-thirds of their original weight.

As we shall see later in our study of spinning, the weight of the thread varies with the quality of cocoons. The selection of cocoons has the utmost importance for the combination of sizes.

Following is the different weight (deniers) obtained from cocoons of several countries: 
Qualities-

Maximum Minimum Average

Yellow Piedmont ............ 3.77

2.08

3.06

Yellow Cevennes ............. 3.65

2.30

3.03

White Persians .............. 3.54

2.12

2.87

Yellow Adrianople ............ 3.68

2.11

2.84

Yellow Toscan .............. 3.83

2.05

2.81

Yellow Salonica

3.35

2.22

2.73

Yellow Greece ............... 3.31

1.94

2.61

Yellow Hungarian

3.66

White Turkestan $\ldots \ldots \ldots \ldots \ldots . .3 .59$

1.99

2.64

White Japanese ................

3.20

2.01

2.68

White Chinese

2.54

1.92

2.12

$1.48 \quad 1.96$

The maximum of weight comes out of the exterior of the cocoon, the minimum from the interior. The boiling off of silks made out of Italian yellow cocoons is sometimes as much as 23.50 per cent. and white cocoons 22.25. The yield (rendement) of cocoons has much importance in the silk industry as it is taken as a basis to establish the cost price according to the amount of work that will be required from reeling girls to spin a quantity of raw silk with as little waste as possible.

The production may vary from two hundred to six hundred grams of silk per basin and the waste from fifteen to one hundred per cent. The best quality of silk would then be obtained from cocoons giving the least quantity of waste and that problem is the most important for a filature manager who is looking for profits.

\section{Site of Filatures}

Italian filatures, as a rule, are built very much in the same style and their organization is said to be quite uniform. The very modern ones, of course, work on a more rational basis and employ the latest devices for the production of the best silks in the most productive way. Improvements lately have been directed to the regularity in the size, better winding and principally larger production.

In general, filatures are situated in villages as near as possible a river, not only on account of the power which can be procured from water, but also because the quality 
of running water is superior in the treatment of cocoons. It is necessary that the service of reliable reeling girls may be found in abundance in the villages surrounding the filature. The number of basins varies from fifty to three hundred, but the average is around eighty.

We shall now look into a filature reeling classical silks and see how work is organized in all branches, mentioning at the same time other improvements which are not to be found in this particular filature.

In order to follow every detail we shall thus divide our study: Machinery, water, cocoon warehouses, filature, silk warehouse, waste warehouse, organization, employees and bookkeeping.

\section{Machinery}

A filature of eighty tavelles does not require a powerful steam engine. The transmission, steam heat and other necessities do not take more than twenty-five horsepower, using about one thousand pounds of coal per day.

In some filatures driven by electricity, travelers are worked automatically, so that the winding is regulated according to the speed desired. A pump usually brings the water up to the roof in a large tank, and from there it is distributed hot or cold to the basins.

Apart from driving the travelers, the steam engines furnish considerable power used either in the filature itself or in the cocoons or raw silk warehouses.

\section{Water}

In the yard near every filature, a reservoir, about fifty yards square and two yards deep, contains water irrigated from the river or from a well. This water must be filtered before using in the spinning process, as its purity and quality have the most powerful effects on the silk. A good water must be soft without alkali, and its dissolvent properties very marked. Distilled water is supposed to be the best, the direct result of its properties being to give a hard natured touch to silks unwound in it and preserving all qualities of elasticity and nervousness of the thread. The 
waters of Japan, in the Koshu district, are ideal in this respect.

As water has not only a direct action on the fibrose but also on the mineral substances in the silk, it may be necessary, if the water is not soft enough, to immerse in the reservoir a quantity of straw, the properties of which will collect and precipitate the heavy salts. Waters rich in carbona are treated by oxalic acid; waters saturated with sulphates or nitrates are treated by a solution of ammonia.

In many filatures a mixture of crushed chrysalis and water is poured directly into the basins to soften the threads and prevent an excess of mineral substance. In the filatures spinning low grade silks a composition of glycerine and soap is mixed with water to help unwind cocoons of poor quality without adulterating the raw silk.

\section{Cocoon Warehouses}

Dry cocoons are kept in large rooms, packed tight in bags of about one hundred pounds each. Each day a quantity of cocoons is taken to another room where the numbered baskets of the girls are lined on the floor. The weight of each basket is taken accurately, and its contents are supposed to be transformed into a corresponding quantity of raw silk.

In some filatures reeling extra grades, cocoons are poured on a large piece of tin with holes of several sizes, in order to divide them into piles of large and small ones, before the distribution. Baskets full of cocoons are placed near the reeling girls, and are replaced with new ones as soon as empty. At the end of the day whatever is left in the last basket is brought back to the warehouse and credited to the reeling girl.

Before sending the cocoons to the filature, a careful selection must be made, and all imperfect ones are turned over to the waste silk industry.

Cocoons are rejected on account of the following defects:

Open cocoons-due to some imperfection in the work of the worm.

Dead cocoons-when the chrysalis has died inside before terminating its work. 
Dirty cocoons-due to the putrefaction of a dead chrysalis inside.

Unfinished cocoons-called chiques; they can be unwound if properly handled.

Double cocoons-due to the work of two chrysalides spinning together in a large cocoon.

The above cocoons being eliminated, a choice is made according to size and color, so as to obtain homogeneous work in the basins.

\section{The Filature in Italy}

Basins and cocoon beaters are placed in line, usually in two parallel rows, with a few yards space in the middle. Large windows allow the sun to give plenty of light and at night a lamp is placed above each basin. If the basins are grouped in bunches of twenty to thirty, it is easy with several transmissions to give different velocities to the travelers. Also steam and water can be distributed according to the kind of cocoons used and the quality wanted.

In the old filatures one cocoon beater served four basins; at present some filatures have one to every two basins, and others, one to every basin, which increases sensibly the production, since the reeling girls have always cocoons ready to unwind, and no time is lost in preparation. A very young girl can take good care of two basins.

In some of the very latest filatures the cocoon beaters are separated from the basins in a single row, and the reeling girls, instead of sitting with their backs to the travelers, actually sit in front of them and give better attention to their work, but at the same time, they cannot attend to the retying of broken ends, and some other girls have to attend to the work.

The cocoon beaters are provided with an automatic brush, turning in the basin where cocoons have been placed in very hot water. After revolving some twenty times, cocoons are cleaned of the first thread (frisons), and the girl pulls out the clean ends to a fixed length until she has in hand a bunch of cocoons ready for the spinning girl. Formerly, cocoons were beaten by hand with a little broom, which method, however superior in workmanship, was too costly on account of the number of girls required for that purpose. 
It is the duty of the cocoon beater to mix in the basin, before collecting the ends, old cocoons, which for one reason or another, did not unwind well with new cocoons; also to see that the water in the basins and the steam are properly distributed.

It is out of the basins used for cocoon beating that the "fumana" (heavy smoke) issues, and not only humidifies the room, but also penetrates the silk, rendering it very gummy and hard. In order to fight that dampness, steam-

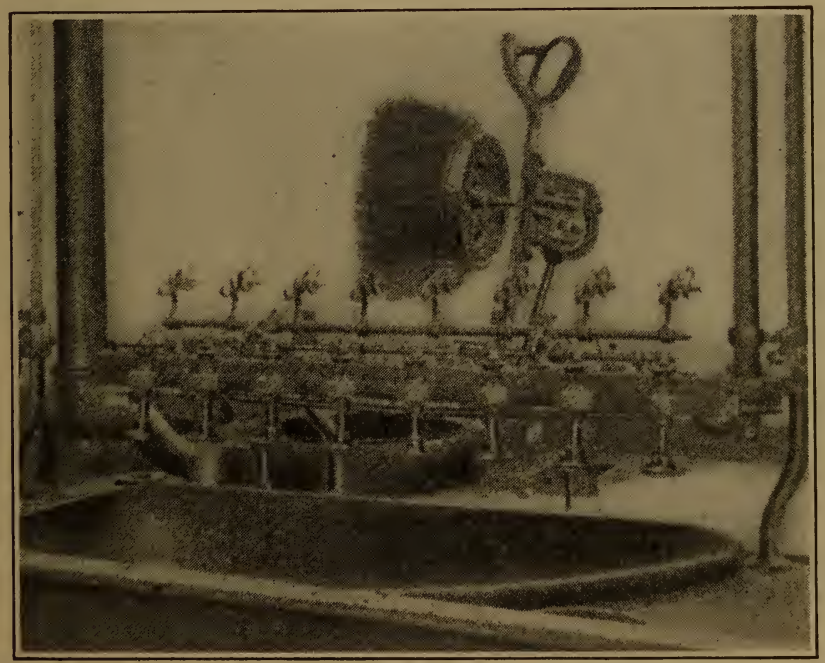

Automatic Cocoon Beater and Catching Wheeis

heated tubes are run above the beater and alongside the travelers.

The reeling basin itself is of ovoidal form, and contains water at sixty centigrades. If cocoons are very dry then a higher degree of heat is required. The heat of water is always fixed according to the speed of travelers.

In general, basins are six ended, but some new ones have eight ends. The latter may give a larger production, but require first-class cocoons only. Above the basin, at a distance of about five inches, there is a glass button with a very 
small hole in it. In that little hole the several threads unite and come out on the other side a uniform thread. The Chambon filature system is not used any more, but the tavelettes system, with self-crossing, is adopted everywhere.

We shall not describe the principle of the tavelette reeling again; suffice it to say that the crossing of that system does not allow any gross irregularities in the thread to pass; it polishes around the ends perfectly, and takes out a large quantity of water. A good crossing must be of two hun-

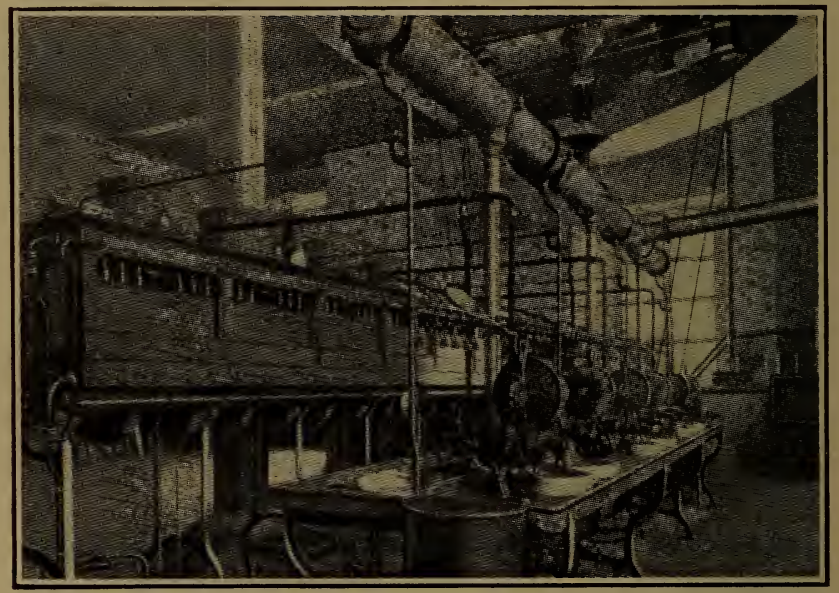

Italian Basins and Travelers in Cases

dred turns and seven inches long. The crossing can be made automatically, but most of the reeling girls can do it themselves just as quickly. The travelers are placed in a case behind the basins, one traveler to each case working independently of the others. Each traveler communicates with a pedal under the basin, so that if one thread is broken the traveler can be stopped, while the others keep working, until the broken thread is found and retied.

In nearly all filatures a number of girls look after the broken ends, saving considerable time to the reeling girl, as the threads must be crossed again, as well as retied. The sizes of travelers vary; three sizes are mostly used: meters, 
$1.20,1.50$ and 1.80 . The speed is regulated generally from eighty to one hundred revolutions per minute.

The automatic end thrower is not used very much. It consists of a little wheel placed directly above the glass button and turning at considerable speed. It catches the end, cuts it sharply and adds it to the other end. However, good reeling girls prefer the old system of throwing the ends with the fingers, and hardly miss as much as the automatic wheel.

Another improvement consists in winding the silk directly on bobbins instead of travelers, in order to save time at the mill, but it has not been found very practical as yet.

In general, for every twenty basins a girl is placed behind the travelers, and kept busy cleaning the skeins that have been stopped for retying. During the spinning some travelers are selected here and there and brought to the office so that the size can be tested and corrected if anything is wrong. This is done right along and no chances are taken at any time of the day.

Raw silk is taken from the travelers in hanks of different weights. Those for throwing purposes are made up in skeins of fifty grams. For weaving and exportation, skeins of eighty to one hundred grams are the accepted staple. The reeling girl, after completing a hank of silk, must fix the beginning and the end of the thread with a little string of schappe, so that it can be easily detached at the mill.

Each reeler must take the hanks herself to the mill warehouse and hang them on hooks corresponding with her basin number. If the raw silk is for immediate throwing purposes, the reeling girls make the skeins themselves, otherwise the skeins must be examined, cleaned of all dirt. irregularities, corkscrews, etc. Hard gums must be rubbed out. When the silk is to be exported to America, a special thread of cotton (capiure) is inserted with a metallic comb. This process is said to be "American style." Several filatures are now re-reeling their silks in view of exportation to America. This improvement is being adopted as fast

as possible all over the country. Silks are never packed in books like those from the Far East, but are simply bunched in bales of about two hundred pounds. 
Besides the sizing machine, many filatures are equipped to inspect the winding, cleanliness, regularity of raw silk, together with its specific qualities.

In the silk industry, waste silk (cascami) represents quite an important branch. The frisons are the result of the first beating, and are by far the best of all wastes on account of the lengthy ends of very good silk. Every ten or fifteen basins a girl collects those frisons and removes the chrysalis and other dirt attached to them. By pulling on those ends a length of one yard and a half is obtained. These long fibres are then brought outside and exposed to the sun.

Pierced cocoons are collected from the bottom of the basins, where they have naturally fallen. The ricotti are the cocoons which, although nearly entirely unwound, have still a little amount of silk around the dead chrysalis. These ricotti are placed in a barrel and boiling water is poured over them. A man then turns a stick inside for hours until all the chrysalides drop to the bottom; the barrel is emptied and the silk matter collected, placed under a press to dry and again exposed to the sun to bleach it.

The following percentage of waste is obtained out of Italian cocoons:

Frisons, twenty-five per cent.; Pierced cocoons, twenty per cent.; Ricotti, fifteen per cent.; Dry chrysalis, twenty per cent.

\section{The Reeling Girls}

There are only a few provinces where good, reliable reeling girls can be found, and such provinces are those that for many centuries have applied themselves to the raw silk industry. The day may come when the scarcity of help will result in a decline of the industry, such as happened in the reeling centers of France. It takes many years before a girl becomes expert in the art of reeling, and before working at the basin she must be on the cocoon beaters' staff for two or three years. She is given afterwards a couple of ends to take care of until she is able to fill the position of firstclass reeling girl at a six or eight-ended basin. In old times, girls were admitted to the filatures at the age of 
seven or eight; now the minimum age allowed by the law is twelve, and regulations are very strict on the subject.

Reeling girls, it must be said, are becoming very scarce since other industries, especially cotton, are making them greater inducements, such as less work and higher salaries; and as in silk reeling, the workmanship cannot be replaced by machinery, it has been found every year more difficult to obtain the necessary help to run the filatures in full.

Other industries, with modern machinery not requiring personal skill in the different processes can afford to pay more by being able to produce more. The filatures have been forced to raise the payroll of their employees. During the last fifteen years the salaries have advanced fifteen per cent., while at the same time, the length of working hours has diminished twelve per cent., which means an advance of two to three lire per kilo of raw silk. According to the last official statistics, the amount of salaries paid to reeling girls is fifty million lire per annum.

Twenty years ago the reeling girls had to work some sixteen hours a day. At present the working hours are distributed thus: From six to eight A. M., work; between eight and eight fifteen, breakfast; from eight fifteen to twelve, work; between twelve and one twenty P. M., lunch; from one twenty to six twenty P. M., work, or about eleven hours of work. The reeling girls are paid twenty-eight cents a day, the cocoon beaters, and those in care of waste silk twenty-two cents, those in charge of the silk warehouse thirty cents, and the superintendents from sixty to seventyfive cents:

The simple enumeration of the above salaries shows how useless it would be to try to raise cocoons and open filatures in America. Girls of ability, working hard eleven hours a day for twenty-two cents, are not to be found on this side of the water. The reeling girls, who live near the filature, are allowed to go out at stated hours, but those who live in surrounding villages usually go out in the evening only. Girls living at a distance go away on Saturday evening and return the next Monday. In such cases the manager must pay for the trip. They are fed and sheltered at the filature, and about six cents a day is deducted from their salary. 
The daily food consists of about half a pound of bread, with soup, spaghetti or polenta and vegetables. Working girls are paid once a month, but upon request advances are accorded to them. The help recruiting takes place during July and January, but in both ways the employer and employee need only eight days to cancel the contract. There are two hundred and forty working days in a filature, deducting holidays, and a period between the fifteenth of June and the fifteenth of July, during which the crop is ascertained.

It must be noted that during the last decade girls have been getting more difficult and unmanageable. The director and superintendents must be very careful in their remarks and treat them with care and discretion, otherwise they very quickly leave the place for another, for they have no trouble at all to find work at once. As in all other industries, they are organized in unions, and are always ready to strike in order to obtain higher wages and better treatment.

During the work hours, it must be conceded, the girls are very diligent, and it is customary to hear them singing popular songs that help the tedious hours to fly away, thus stimulating themselves to work faster and better.

There is one thing which has not yet been applied to the filature; it is paying the people according to the quality of work they turn out. No doubt some girls are more experienced, produce more and better than others; at the same time they are not paid any better. The manager probably finds it easier to make an average, the superiority of one balancing the imperfections of the other.

\section{Insurance}

All the working people in the filatures are insured by the company against accidents. It is a law of the state, which costs about seventy cents per annum, per head. In case of absolute disability resulting from an accident, within the filature walls, the insured person gets a sum amounting to six times his annual salary, with a minimum of three thousand lire. In case of partial disability, the minimum is five hundred lire. In case of temporary disability, half the 
daily salary is paid the injured person. In case of death the family gets five times the annual salary.

\section{Supervision}

In order to supervise efficiently a filature, an experienced woman is needed to every thirty to thirty-five basins. She must walk all day in front of the basins and see that the reelers and cocoon beaters work diligently, that the water is at the right temperature, that the exact amount of cocoons making the right size is always kept up in the basins. She must keep on record all observations coming from the office relating to size, regularity, winding, cleanliness, according to the results shown in the journal as to production and waste. The superintendents have been, as a rule, employed in filatures many years before securing such a position and are necessarily very experienced in all branches of the industry.

\section{Direction}

One good director is enough to manage a filature. $\mathrm{He}$ may probably need a bookkeeper to keep the journal and supervise the weighing of silk and cocoons. The director is all day long in the filature, and besides making frequent tests of the newly reeled silks, he also personally supervises the work of the reeling girls. The average salary of a director is something like ten dollars per week.

The Associazone Serica of Milano has an evening course on silk for young people who want to find positions in the filatures. At present there are only about twenty pupils. The Associazone Serica also secures positions for the graduated students. There is also a model sericultural and silk manufacturing college in the ideal city of Como.

\section{Finance}

We shall now enter into the details of the finances, which will serve as a basis to give an exact idea of cost prices.

Taking a seventy-basin filature we have:

Seventy reeling girls.

Thirty young girls to take care of the cocoon beaters.

Four girls to inspect silk on travelers. 
Eight girls for waste silk in general.

Two girls for sizing.

Five girls to inspect silk and clean it before packing.

Two girls to make and weigh the skeins.

Two girls to weigh cocoons.

Two superintendents.

Two men for machines and general work.

The figures may vary according to the manufactured article, but the above will cost an average of lire 2.40 per basin, and per day. Besides that, general expenses include renting, direction (lire 0.65 to 0.80 per basin), insurance, taxes, water, lighting (figured on two hundred and forty working days), 0.80 per basin; coal, 45 cents per basin. That is:

Workmanship ....... Lire 2.40

General Expenses .... $\quad .80$

Coal $\ldots \ldots \ldots \ldots \ldots \ldots . \quad .45$

Lire 3.65 per basin and per day.

Between one filature and another the cost may vary something like fifty cents, more or less, according to the kind of silk produced, and also the conditions under which the filature is working.

Once the cost of each basin is figured, it is easy enough to establish the profits, according to the prices of cocoons at four to one (four kilos cocoons = one kilo raw silk) at a price of say seven lire per kilo; deduction to be made of the sale of wastes.

A variation in the daily production and in the quantity of waste makes, of course, a great variation on the cost of reeling. Thus we see cocoons that can be reeled at the cost of nine lire, others at seven lire, per kilo.

Cocoons giving the smallest daily production are always those that make more waste.

Naturally to the above expenses the reeler adds a few small ones, which must be added to form exactly the price at which he can sell with a profit. The reeler generally 
finds a benefit in what gains he may obtain over the official valuation of the cocoon's quality, but it is usually the filatures reeling Classical and lower grades, who get such profits, while those making the highest silks for raw weaving have to figure on a loss from the official valuation.

\section{The Journal}

All the operations of the filatures are kept accurately in the journal, the book in which every working day of every person connected with the mill is recorded, and the whole is totalled at the end of each week in a way showing pretty well the progress accomplished. Through the journal, the director can see which one of the reeling girls is defective, also which one works in a superior way; it is a great help in making the right observations. It shows the quantities of merchandise used and in stock (see tables A and B).

\section{How to Keep the Journal}

Frisons, production today, Kilos............\% Frisons, production previously, Kos............

Total

Bassinés, production today, Kos............\% Bassinés, production previously, Kos.............

Total

Ricotto, production today, Kos.............\%

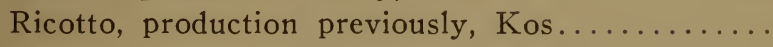

Total

Lot of cocoons, No...... Kos..............

Cocoons spun today

Balance

Production of silk today, Kos..

Production of silk previously, Kos............... 


\section{Observations}

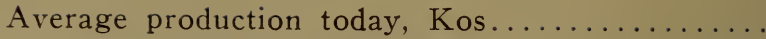
General production today, Kos. Production by each reeling girl, Kos...

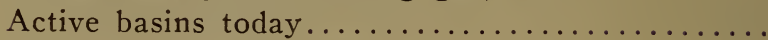
Active basins previously... Consumption of coal, Kos... Coal previously used, Kos Light used

\section{Weekly Report}

Working days Previously

Total

TABLE A.

JoURNAL OF THE FILATURE.

DATE.

WoRKING HouRs.

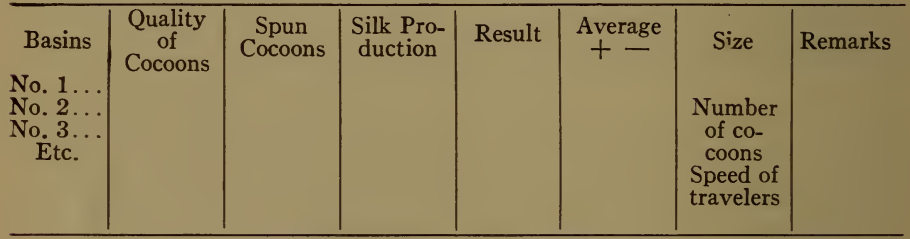

TABLE B.

WEEK No

FROM

$19 \ldots$

\begin{tabular}{|c|c|c|c|c|c|c|c|c|c|c|c|}
\hline $\begin{array}{l}\text { Date } \\
\\
\text { Monday } \\
\text { Tuesday } \\
\text { Wednes- } \\
\text { day } \\
\text { Etc. }\end{array}$ & $\begin{array}{l}\text { Quality } \\
\text { of co- } \\
\text { coons }\end{array}$ & $\begin{array}{l}\text { Active } \\
\text { Basins }\end{array}$ & $\begin{array}{l}\text { Spun } \\
\text { Cocoons }\end{array}$ & Size & Size & Size & Size & $\begin{array}{l}\text { To- } \\
\text { tal }\end{array}$ & $\begin{array}{l}\mathrm{Va}- \\
\text { lue }\end{array}$ & $\begin{array}{l}\text { Pro- } \\
\text { duc- } \\
\text { tion }\end{array}$ & $\begin{array}{l}\text { Waste } \\
\%\end{array}$ \\
\hline
\end{tabular}

General Observations on the Silk Business in Italy

The reelers who have money or credit with bankers usually work their filatures for their own account. In that case, during July they purchase cocoons for their year's 
production, or they purchase cocoons for a few months only, taking their chances as to the possibilities of buying later on dry Italian cocoons or imported ones.

We may note that the White Italian cocoons which were formerly very much appreciated for their fine quality and brilliant color have almost disappeared. In a large lot of yellow cocoons representing fifty bales, there might be found enough white cocoons to spin a couple of bales. Those white cocoons are resold to filatures who make a specialty of spinning white cocoons into sizes $8 / 10$ and the like, for muslin and very fine organzines. Some important French houses in Milan are doing a very large import business in Asiatic whitish cocoons, which are kept in quantities at the conditioning warehouse. Outside of that, all transactions are understood to call for yellow cocoons.

The reelers who have not a sufficient capital or do not care to speculate, work their filatures for the account of other people:

First-At a fixed price for each kilo of silk produced.

Second-At a fixed price per basin and per day.

In the first case the firm for whom the reeler is working furnishes the cocoons and a fixed amount of silk is to be returned to them. If more silk than expected is produced it is the reeler's profit; if the contrary happens, the difference is debited against him. The fixed price is understood for every kilo of raw silk, all wastes becoming the property of the reeler. In that kind of contract, engagements last for months and sometimes a year, several prices being, of course, agreed upon, according to the quality of cocoons and the size to be spun.

The reeler must guarantee the quality, size, winding, color, and is liable to be asked for a rebate in case of deficiency.

In the second case, the firms for whom the reeler is working also furnish the cocoons, but the reeler must return not only the silk, but also all waste, without guarantee of production, quality or size.

The above kinds of contracts are quite in favor, when the price of cocoons compared with the price of silk leaves a profitable margin, but when the cocoons are too expensive 
in comparison to the price of raw silk, the reelers working for the account of others do it at a very small profit, and even no profit at all. Still they prefer to accept that rather than close the filatures altogether, because the reeling girls would desert the place and go to some competitor.

There is now a good organization of silk dealers who are ready to store silk and cocoons for the account of reelers, and to advance in cash seventy-five per cent on the value of silk, permitting them to continue working when business is dull. Such houses have the same organization as commission houses in New York. Many reelers, instead of doing business direct with a bank deal directly with those commission houses or some silk merchants, who, for a commission of one per cent furnish the necessary money to run the filature, but in that case the filature is absolutely under the control of the commission house, and all contracts and sales are made through it. That is the reason why many raw silk merchants have the exclusive sale of several filatures, which they are at liberty to dispose of to the best advantage on the markets of the world.

The reelers who own filatures far from the silk markets usually have an agent in Milano looking out for their interests, and acting as a commission broker. Although many large filatures deal directly with buyers in Lyons, Milano or New York, most of them prefer doing business in Milano through the silk brokers.

The recognized commissions are:

For fresh cocoons, one cent per ko.

For dry cocoons, two cents per ko.

For raw silk, six cents per ko.

For waste silk, two cents per ko.

Engaging work for a filature, four cents per ko.

All brokers' commissions are payable net cash the day after the silk conditioning, or when the dry cocoons are delivered to the buyer. Very rarely one month is allowed when sales are made directly to the manufacturer. Deliveries are made bale after bale, and payment accordingly. Once in a while a large filature delivers five or ten bales at a time, but it is the exception unless for shipment to America.

It is only when the silk is contracted for forward delivery 
that it may be rejected for inferiority after inspection, otherwise the buyer must accept the silk as it is.

All transactions are made according to the market rules, and may be referred to the Silk Association, the decision of which is without appeal. 


\section{CHAPTER II.}

\section{Sericulture and Filatures of France}

$T^{T}$ is localized in the southern part of the country, the 1 largest centers being the departments of Ardeche and Gard, where the climate is temperate and labor cheaper than elsewhere.

Cocoons are excellent and belong to the four molting species.

Filatures reeling Cevennes cocoons are producing the very finest raw silk in the world, especially adapted to fine sizes, such as $9 / 11$ and $10 / 12$. However, the crop is rather short; labor is too high. The quantity of cocoons raised in France is far too small to accommodate the filatures.

Cocoons are imported from Turkey, Greece, Bulgaria, Syria and the Caucasus and kept in storage in Marseilles until brought up to filatures over the country.

The distribution of filatures is as follows.

Departements (Districts) Filatures No. of Basins Ardeche ................ 51

Bouches du Rhône.......... 4

Drôme $\ldots \ldots \ldots \ldots \ldots \ldots \ldots \ldots \ldots . .19$

Gard $\ldots \ldots \ldots \ldots \ldots \ldots \ldots \ldots \ldots \ldots \ldots \ldots \ldots$

Herault $\ldots \ldots \ldots \ldots \ldots \ldots \ldots \ldots, \quad 17$

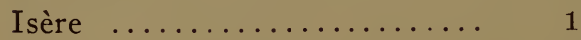

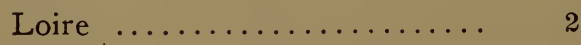

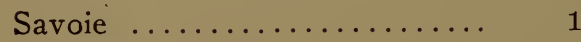

Vaucluse $\ldots \ldots \ldots \ldots \ldots \ldots \ldots, \quad 12$

6,000

$4 \quad 550$

1,000

$54 \quad 5,700$

$17 \quad 1,400$

$\quad 100$

190
1

$1 \quad 60$

$12 \quad 1,000$

161

16,000 
There are still a number of establishments in the Cevennes districts that are mounted according to the slow Chambon system of reeling, but during the last twenty years, very modern machinery has been installed in new buildings, such as the eight-ended basin with catching wheels and automatic cocoon beaters. 


\section{CHAPTER III. \\ Lyons, the City of Silks}

$\mathrm{F}^{\mathrm{RANCE}}$ is the second nation (America being first) in

$F$ respect to the quantity of manufactured silk goods, but she is still first as regards quality, taste, and splendor of production.

The annual output of silk goods in France amounted, previous to 1914, to one hundred and thirty million dollars, almost all of which is the product of the looms of Lyons. As the export of silk from France reaches eighty million dollars, which is larger than any other product, it is easily seen that Lyons contributes even more than Paris to the wealth of the country.

It is highly interesting to study the reasons for the supremacy of Lyons over such markets at Zürich, Milano, and New York, and I will try to show why that advantage is maintained notwithstanding the ever increasing competition.

Anybody entering the offices of the average silk manufacturer in Lyons would be surprised to see a couple of small rooms and a magasin or wareroom, with a few clerks about, looking after some bundles of silk. It will take many years before any Lyonese dares to open an office as sumptuous as those displayed by our New York manufacturers.

The Lyons manufacturer is like a publisher; both of them edit the work of others after a careful consideration of their merits and chances of success. The freedom of such a manufacturer is his strength; for he does not control the looms working for him; he simply gives his orders outside either to some mills or to private weavers. Having nothing to do with mill management or supplying the looms with work, he can keep better posted and follow the 
trend of fashions more closely. If he starts on a fabric and its vogue is short-lived he is always in time to catch the new fad and recognize his mistake. Thus, he is in a much better position as regards the course of fashion than his American, Swiss or German competitors.

The American manufacturer, with an enormous and always increasing number of looms, turns out silk goods by the mile, whatever the fashion may be, and if suddenly the demand ceases, an enormous quantity of goods is left on his hands, which it is impossible to sell, or which must be sacrificed at a great loss.

In America, if a silk concern makes money, it very quickly starts building up an additional plant for an increased number of looms. Building more factories is, no doubt, considered a sign of wealth, but, on the other hand, if business is bad, some additional capital is called in and the company builds just the same. There are already in America enough looms to furnish silk dresses for every woman in the land, but, nevertheless there are all the time announcements to the effect that ground has been broken for additional silk mills. Is there no limit to the capitalists, who place their hopes in the silk business? It is all right to add a few looms when the country is prosperous, but keeping up the building of mills simply means that many looms will stand idle when bad years come.

In Lyons the people are more conservative. Every now and then a new mill is built, and the venture always attracts the comments of all. The policy of running a few looms all the year 'round evidently pays more than having only half the quantity in action. The Lyons manufacturer has an unlimited number of partners viz.: the designers, the mill owners, the finishers, etc. All these people, although not being directly associated with him, have an interest in keeping him well posted, in suggesting, and creating for him whatever will bring business. $\mathrm{He}$ is at liberty to pick up what pleases him best, distributing to one mill his orders for satins, to another his orders for taffeta, and attending to the financing and selling end himself. The commission houses of America can be compared to this only in the light that they may be financing several silk enterprises, such as 


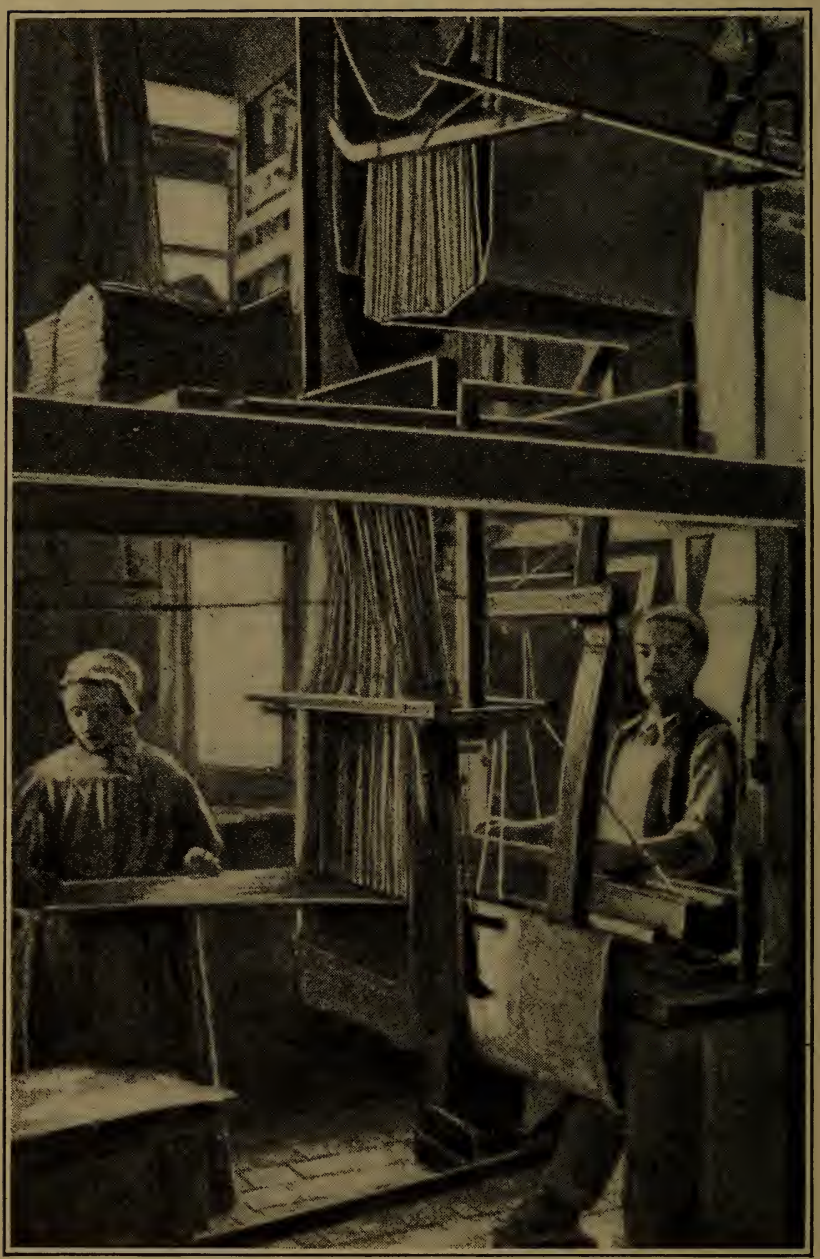

A Jacquard Hand Loom in Lyons, France 
broad silks, ribbons, velvets; but they do not profess to know much about manufacturing, and are satisfied to see that their money brings in as high a rate of interest as possible.

I will name at once the most important factor of the silk business in Lyons-the silk merchant. The organization of silk merchants in Lyons is the most powerful in the world. Even the Milano market, now handling more raw silks, is practically controlled by Lyons banking establishments. The raw silk merchant needs a large capital because most of the time he is owner of some filatures in Europe, and also an importer of Asiatic raw silks.

In Lyons, as well as in Milano, the silk merchants sell on a one hundred days' basis, discount allowed if paid in ten days, six per cent per annum. It is a safer business than the extended credits allowed to almost everybody in America. Silk is always sold conditioned, except for some wild species, and, indeed, conditioning is absolutely the root and foundation of correct raw silk business. It is most surprising to note that only one-third of the silk coming to the New York market is actually conditioned. No manufacturer in Lyons would accept a pound of silk before it was duly weighed, conditioned, sized, tested as to elasticity, tenacity, and very often a boil-off test is requested. After all this is done, he knows what can be done with the fibre. This conservatism pays in the long run because the variations in such a costly material may amount to important gains or losses.

It must be said also that the sales of twenty-five bales of raw silk in Lyons are less numerous than those of fifty on the New York market, the bulk of transactions being limited to lots of a few bales, and, of course, manufacturers can follow more closely the quality of their purchases.

Until 1875 the looms of Lyons were exclusively worke' by hand. At present there are yet about 15,000 jacquard hand looms in Lyons and surrounding villages, making special kinds of goods, mostly high class brocades. In more recent years, especially the last two decades, a number of manufacturers have built large mills in order to weave 
larger quantities of pile fabrics, but the majority of manufacturers are still placing orders outside "a façon."

The finishers and dyers of Lyons have helped materially to make their city the foremost in silk manufacturing. They have a recognized superiority over the dyers of the world. It is a superiority gained by hard work, because these dyers, whose names are known everywhere, actually started from the bottom, working to the top by hard, energetic work, and the millionaire dyers of Lyons are not at all ashamed to soil their fingers, and work among their men. I would not be surprised if nine out of ten of the finishing and dyeing plants of this country have been started, and, if not owned, have prospered through the hands of skilful Lyonese.

With such a prodigious activity of manufacture in Lyons, its silks most naturally find their way to Paris and foreign countries. At certain times of the year, buyers from England, United States, Russia, and Germany come to the streets near the Place des Terreaux to buy millions of dollars worth of novelties that will rule the fashions from Paris to Timbuctu. What an inventive brain those manufacturers must have, when foreigners are always ready to copy, imitate, and finally produce in enormous quantities at cheaper prices the wonderful fabrics created by their imaginative genius! Every season's product must be absolutely different from that of its predecessor, so that the buyers may always be interested and enthusiasts over good selling prospects.

In St. Etienne, near Lyons, there is also a vast industry specialized in ribbons, but owing to the intimacy of the business interests of both cities, their products are always counted together.

The export of silk from Lyons, through that city or Paris in 1910 was: $\$ 32,000,000$ to England, $\$ 14,000,000$ to United States, $\$ 3,000,000$ to Switzerland, $\$ 3,000,000$ to Belgium, $\$ 2,000,000$ to Germany, $\$ 2,000,000$ to South America.

How long Lyons will retain her present supremacy over her formidable competitors is a hard thing to guess. Silk manufacturing is growing in such enormous proportions in the United States, Germany, and Switzerland, that perhaps 
they may manage eventually to put the French out of business through cheaper workmanship and larger output. The economists say that the silk business in Lyons has not progressed during the last decade, but they still recognize that it is in Lyons alone that can be found the highest grades of silks and the most beautiful designs (one has only to pay a visit to the Lyons Art Museum to be convinced of this assertion). The royalties and courts of all nations, for their pageants, cannot find elsewhere silks sold at hundreds of francs per yard and worth it. 


\section{CHAPTER IV.}

\section{The Levant}

W

HETHER in Europe or in Asia, Levantine raw silks are practically controlled by Europe, since over half of the cocoons are exported to France and Italy.

Conditions in these various countries are very bad at the present time, when one knows the amount of persistent labor and skilled supervision spent by the Turkish Government and French investors to bring the production to what it was previous to the Balkan war of 1911 .

From the official records I find that the yearly crop of fresh cocoons from 1900 to 1911 gave an average of forty million pounds in Turkey alone.

After the Balkan war, 1912-1913 returned thirty-two million pounds.

The 1914 crop was partly destroyed by diseases and after that the great war made things worse.

The 1915 crop yielded eighteen million pounds.

The 1916 crop yielded fifteen million pounds.

The 1917 crop yielded twelve million pounds.

The 1918 crop yielded ten million pounds.

The 1919 crop yielded seven million pounds.

The 1920 crop yielded six million pounds.

What are the reasons for such a decline in the crop of cocoons?

The worst is that mulberry trees have been destroyed by the Turks in the proportion of sixty per cent and used as fuel all over the country. The leaves of a mulberry cannot be picked to feed the silkworms before the tree is five years old! We must figure then that should political conditions give farmers confidence enough to start growing mulberry trees, it will take many years before the crop of cocoons comes back to what it was in 1911. 
It must be explained that mulberry planters and hatchers of cocoons are all Armenians or Greeks; that is, Christians. They are the only intelligent and efficient workers in the country of the destructive Turk.

Following the murder of so many Christian families, the cutting down and the burning of mulberry trees, more than fifty per cent of the farms and hatching houses and sixty per cent of the filatures were destroyed and the material burned as firewood.

Since 1918 most of the farmers, instead of growing mulberry trees, have found it more beneficial to grow tobacco and cereals.

\section{The Crop and the Cocoon Business}

The Near East crop of cocoons comes out by the end of June. That is three weeks after the Japanese crop and six weeks after the Canton crop.

The filatures begin reeling in July.

Previous to 1914 a large part of the cocoons from Adrianople, Salonika, Syria and Bagdad were exported to Europe, mainly to Marseilles.

French steamers calling at several of the seaports where cocoons could be shipped, made it a rule to take same as part of the cargo at reduced rates, and reduced rates were necessary, for it takes a few pounds of cocoons to cover a large space.

These cocoons were brought to Genoa or Marseilles and French and Italian filatures made up the deficit of their own crops with Levant cocoons.

Adrianople white cocoons reeled in fine sizes were always considered the best in the world for that purpose. Cocoons from other places used alone or mixed with natives producd some very fine raw silks. In fact Brussa silk proves to be of a better tenacity than Japan's and boils off two per cent less. Its color is somewhat grayish and does not compare favorably with the brilliant white of the Japanese product.

The main cocoon markets are Brussa, Moudania, Ismidt, Ada Bazar, Biledjick, Adrianople, Salonika, Batoum, Beyrouth, and Smyrna. There and around are gromped most 
of the filatures. All the Caucasian large gummy cocoons are used at home. The better ones of regular size are exported.

Evidently the best Turkish cocoons are to be found in Brussa where stand also the best filatures. When it is possible to bring Caucasian or Bulgarian cocoons to Brussa, there will be a possibility of making an excellent quality of raw silk out of them.

Unfortunately the Turkish government insists upon an import duty of eight per cent on cocoons and through this stupidity some filatures must remain idle through lack of cocoons, the eight per cent duty added to the cost of transportation making prices prohibitive.

It is a question whether Syria will remain part of the Turkish Empire or not. At any rate, raw silks reeled out of Syrian yellow cocoons are of a low quality, not very much above what is commonly known in New York as a Japan No. 1.

The Syrian (Liban) filatures have been engaged for years into reeling fine sizes $(9 / 11,10 / 12,11 / 13,12 / 14)$ exclusively for Lyons manufacturers. In the size $13 / 15$ and re-reeled the silk might be good enough for a fair organzine.

\section{Filatures}

The production of raw silk previous to 1914 was 12,000 bales of one hundred kilos, equaling about 20,000 Japanese bales.

In 1919 the quantity was reduced to three thousand bales of one hundred kilos of which no more than one thousand bales (say sixteen hundred bales-Japanese) were fit for export in all sizes.

Before 1914 there were one hundred and forty filatures in the Brussa district; there are now about fifty. In Brussa city there were thirty-nine filatures before the war. Only fourteen worked in 1920 and in April 1920 only two were in operation. It is expected that the fourteen filatures will resume work next July.

In Syria there were about one hundred filatures before 1914. Thirty of them are still standing but are not working all the time. 
During the wars the filatures which had not been destroyed by the Turks were operated under the supervision of German business men but no attention was paid to the quality or size and it became a rule to reel a sort of $14 / 17$, size of which ran from nine to twenty-four.

After the armistice, French firms who have long had extensive interests in filatures and cocoon business in Turkey, sent again their representatives to Constantinople and have met with the utmost difficulties in dealing with the reelers. Add to this the bad faith of dealers, the robberies, the travelling difficulties, the postal restrictions, the shortage of labor, not mentioning the poor qualities of raw silks.

\section{General Conditions of Filatures}

All the filatures in the Near East are modern and employ the Italian system of reeling said to be (a la tavelette) from four to six ends. The very latest improvement was brought to Brussa by a Swiss with an eight-ended reeling machine. The silk is neither cross reeled nor re-reeled but goes straight on the travellers with one or two, rarely three, lacings. The size of the skeins now universally adopted is fifty centimeters, that is like the standard American skeins minus the cross reeling.

Steam is obtained from wood, but when a few years ago, coal was imported at a low enough figure, it was substituted for wood. At the present time wood is again to the fore. Several filatures would like to change to gasoline motors, as American oil is now sold at a price low enough to eliminate the burning of wood. The filatures work ten hours per day, producing about five hundred grams of silk per day and basin. The average number of basins per filature is sixty, so that a filature of sixty basins produces about two bales of one hundred kilos per week of six days.

A native superintendent receives Turkish $£ 50$ per month. The head reeling girl receives fifty piastres per day and a first class reeling girl thirty. Each filature has the necessary apparatus for the packing and testing of raw silk.

In Brussa, the filatures which are situated near the mineral springs make a superior quality which was known 
before the war as Grand extra but now the poor help has brought down the gradings considerably.

Sizes from $16 / 18$ up fetch the same price. Sizes $14 / 16$ and $13 / 15$ usually cost fifty piastres more per kilo, and finer, another fifty piastres. All depends on the condition of business at the time of purchase.

\section{Quality and Prices}

The best cocoons and most modern filatures being in Brussa, it is interesting to compare the quality of these silks with the products of other countries. The so-called Grand Extra of Brussa has never equalled an Extra Classical Italian, a double Extra of Japan or an E. Wo of China. But many French or Italian filatures have reeled Extra Classical out of Brussa cocoons because when it comes to skilled work and perfection of reeling, the Armenians or Greeks employed in the Brussa filatures are very much lacking in ability and do not seem to be able to equal European girls.

The silk called and sold in Lyons as Brussa Premier Ordre (first class) is very similar to an Italian Best Classical or if especially well reeled, to a Japan Best Extra or N. Y. XXB. During 1919, no more than three hundred bales of real first class silk were reeled in Brussa in 13/15. The quality commonly offered was no better than an Extra Japan and in the sizes 20/22 and 24/26 some four hundred bales could have been exported to America in competition with Japanese and Chinese filatures, especially as prices for a long time were very much lower than those of Japan and China.

When the map is revised once more, the following centers will prove interesting for American investors, to build up again the raw silk industry in the Levant:

Greece-Adrianople and Salonika.

Bulgaria-Brussa (seaport, Moudania).

Syria-Beyrouth, Bagdad.

Caucasus-Batoum.

Persia-Reck (Province of Erivan).

Cyprus. 


\section{Filatures in Turkey}

City

Aslan bey

Bardizak

Beyrouth

Biledjik

Brussa

Keupleu

Ortakuy

Saida

Senyut

Tripoli
Ada Bazar

Lefke

Number

6

1

3

14

16

40

15

3

8

4

3

1

114

\section{Filatures in Greece}

City

Adrianople

Number

Athens

3

Galamata

7

Lepante

3

1

2

Patras

2

Sparta

1

Syra

2

Volo 



\section{PART III}

RAW SILK IN THE FAR EAST 



\section{CHAPTER I. \\ Raw Silk Inspection in the Far East}

THE position of the silk buyer and inspector in China and Japan is very different today from what it was a few years back.

Sixty years ago steamers called only now and then at the ports of Yokohama, Shanghai, and Canton, conveying orders for many hundred bales at a time to be bought or shipped within a year. The established representative houses had plenty of time to go into the country to buy, assort and inspect the lots of silk which were scattered all over in small quantities. The cost of raw silk was ten dollars or over. Buying commissions were no less than five per cent. A very close inspection of the raw was necessary because of the rough process of reeling, making lats very mixed in color, size, cleanliness and quality. Fraudulent matters as lead, dust, even stones were sometimes concealed in the skeins or hanks, so that practically every pound of silk had to be opened and viewed closely. Silk was bought then for gold or silver in cash, for there was no such banking organizations and letters of credit as today.

Later on, with progress, steamers called oftener, and the first filatures in the European style were opened under the supervision of foreigners. Japan sent a number of students to Lyons to learn the art of reeling in the greatest silk center. A number of French inspectors went to Japan and helped in the management of the first filatures. These students worked in filatures and later on brought to Japan complete apparatus, exact copies of the European systems, and a model filature was built, where the native girls could be trained in the reeling of silk. 
At the same time, instead of the three or four companies that, besides tea, mattings, and other sundries, used to expor.t silk, other companies opened branches to inspect silk exclusively. The British were the first to establish a bank in Hong Kong, a step which was quickly followed by other nations in the open ports.

With the increase in demand for Asiatic silks, the natives started hatching more eggs every year, and the farmers began to turn out a few more pounds of silk every season. At the same time the value of the article began to decrease and competition being keen in buying centers, the commissions had to be reduced. The buyers no longer needed to go into the interior to buy and inspect the raw, as filatures placed their interests in the hands of commission houses who could better conserve their interests on the spot. Native reelers sold their little output to large associations, who simply assorted the silk to send it on the markets under several gradings to be sold at a certain limit. Such silks were later on re-reeled to obtain more regularity in the quality.

Thus the Shanghai tsatlees were improved into crossreels and new style re-reels, steam filatures under supervision of skilled Italians, ranked equal to European filatures. Tussahs were improved from an almost unutilizable thread, into a very good article.

In Canton the "paquetailles" made up of an impossible mixture were improved as to reel $11 / 13$ deniers currently. Re-reeling was introduced to respond to the American demand. The filatures gave the best results, according to the class of cocoons, and could be improved only by an extra rereeling as done in Japan.

Japan, in her wonderful civilization, took every opportunity to improve the best of her revenues, and even that remnant of old times, viz.: the Kakedas, can be relied upon to give good satisfaction. Such improvements could not be done without many changes in the course of business, until transactions became more and more difficult and buying almost impossible without speculation.

In Canton the silk firms are well established on the Island of Shameen, where all foreigners live. Each firm, besides 
offices and lodging, must own a large storage, called "godown," where inspection is made, and a full staff of native employees, including a compradore (cashier, acting as banker, usually a rich retired merchant; he gets a commission on everything), a silk superintendent, and a number of coolies, whose work is to take care of the go-down, reeling machines and charcoal fires, which must be kept burning all the time, even in the hottest days, as the climate is so damp that the silk absorbs a large percentage of moisture. All the men, either to reel the silk at the windingtable or to pack and carry the bales, are provided for by the silk merchants.

These silk merchants, each one of them being agent of a number of filatures, call on the foreign firms every day. The language spoken between them and the buyers is a mixture of English and Chinese, called "Pidgin," as, for instance, to say: "Do you want to buy twenty bales of No. 1 Pit Cheong Ling, spot delivery," this is what you hear: "Suppose you wantchee twenty bailee taiyat Pit Cheong Ling, my can bling chop chop this place."

However, the difficulty lies elsewhere. Formerly business was on a steady order and commission basis, and every firm was almost certain to figure on two per cent. to three per cent. net profit on the whole business, but since speculation on the part of some strong organizations started, buying has become very difficult. Some firms not only buy against orders, but in expectation of a rise, to resell on the market. These firms are crowded all day with silk merchants, while small firms hardly have a chance except if begging for offers. Necessarily commissions have been reduced to a very small margin.

The Chinese are very reliable, and their word is as good as gold; that is, no contract need be signed between buyer and seller, whether for prompt or future deliveries.

The difficulty is that Cantonese filatures are irregular. A perfect lot of Hau King Lon might be followed by a lot of inferior quality. Some XXA fall easily to XXB grade, and vice versa. This fact has been ascertained several times. Still the American consumer sticks to chop ticket, even if he is told that another chop comes out better. 
I remember an instance when I cabled a customer that a lot of Hau King Lon was a poor winder, and that I could replace with Kum Lun Tai, then an XXB, which was exceptionally up to crack chop. The customer insisted on getting the Hau King Lon, and was very sorry when the silk proved bad on the looms.

It is a mistake to think that silk inspection is carried on in Canton by merely kicking the side of the bales. There is no article of merchandise that demands a closer inspection than Canton silks on account of the perfect similitude of all grades. The books are all of one and the same cream, shining and soapy color. It is only when the skeins are opened that the cleanliness, uniformity of the thread and quality are detected. Almost every skein must be inspected to get rid of the uneven ones, as there are sometimes any amount of fine ends. A full two hours' winding is necessary to report the right number of breaks. As there is no conditioning house worthy of the name there, any mistake on the inspector's part might prove very costly.

The American buyer, by insisting on securing the chop ticket, is standing against a good inspection, and runs the risk of getting an inferior choice which the inspector will ship at his express order, notwithstanding that lots sometimes classified in the lower grades could be found to fulfill the requirements.

The speculators have naturally an easy job securing the best lots on the market, leaving other buyers to fight over what remains to be sold. Another difficulty is the varying silver exchange, which is always an important question in cabling firm offers.

Barring these difficulties, Canton is still one of the producing centers where an enterprising firm, with a small capital, but good customers, can make a good living. The amenity and truthfulness of the Chinese dealers account for this.

If conditions in China, are getting very hard on account of speculation and keen competition, the position of the silk inspector in Japan can only be said to be worse. The staff of a silk house is more numerous, as every working hand must be provided by the firm. As in China, the silk dealers, representing a number of filatures, call on the 
buyers, and conversation is held in Japanese, or through an interpreter and reporter called "Banto." Inspection in China and Japan does not differ much, technically speaking. Most of the time the silk is in stock on the market and is brought to the inspection rooms as soon as purchased.

In Canton, silks are conveyed from the country on armed junks and delivered to the customer in shirting bags. Bales are made of about ten books, weighing $1062 / 3$ pounds, or eighty catties. In Shanghai the customary weight of bales is one picul. In Japan silk comes from the country in boxes of about sixteen books each. One bale is made up with twenty-eight to thirty-one books, weighing around one picul (132.277 pounds). These books are piled up in the inspection rooms, and a number of skeins extracted at the inspector's choice from the whole lot to make the winding and sizing tests.

Afterward if the results are satisfactory, the inspector standing in front of the window specially constructed to get the full benefit of the light, inspects every book of silk, one after the other. He has then a chance to detect the different shadings, and by opening skeins now and then, to judge if the quality is satisfactory, that is, good enough for the desired purpose. If inspection is passed the lot is weighed at once.

In Canton, where there is no conditioning house, the dealer usually makes the weight full. In Japan, silks are weighed very strictly, as the conditioning house makes a free test for the buyer, and any loss of weight is made good by the seller. All silks, being accepted, are paid for at once.

If the silk is not satisfactory it can be refused; it formerly had to be replaced by the seller, but at present handlers rather suit themselves, according to the tone of the marke.t.

When buying a certain class of goods, and in the event of a purchase, the silk usually responds to the classification. In China, no samples are required. In Japan, it is very seldom, except when contracting for futures, duly signed and dated, that a lot of silk is bought without seeing a sample. I may mention here that many dealers are strict with their 
engagements, and that a lot bought from them, is at least equal to sample; but how many disreputable ones carry on a shameless business by substituting lots of inferior grades having no resemblance whatever to the sample on which classification the lot is bought! This is indeed the manipulation of employees and brokers, as in most of the cases the manager is a respectable man who ignores these proceedings; but nevertheless such abuses tend to throw much discredit on the Japanese character. Another trouble comes from the reelers themselves, who are getting more and more careless in keeping the standard of their brands. Certain chops cannot be relied upon twice as giving the same results. In order to produce more, they work too fast in the filatures, and all supervision has been dropped. I refer only to silks under the grade of Best I Yokohama classification, for the upper grades, especially the Extras, are still up to their reputation, mostly on account of the perfect cocoons used.

In the lower grades I have seen silks of a grade poorer than No. 2 Sinshiu, offered under a nice chop and blue strings as a No. 1 filature. There is evidently a belief among the Japanese dealers that once in a while such rotten stuff will be accepted and shipped when nothing else can be found.

Where the small silk buyer receives the hardest blow is in his competition with the Japanese speculators and handlers of the raw on consignment, and for the account of manipulators in the interior. The big manipulator, as usual, is little by little getting rid of his small competitor. After reducing their profits to the bone, until they are nearly starving, the small firms, one after another will be compelled to leave the place clean for the Japanese bankers, who will always have enough money to finance the business so as to produce the best revenue for themselves. Especially is this so as silk is Japan's most important article of export and is productive of more wealth for that country than any other article of merchandise.

Would the trade gain by such an elimination of competition? It may save one or two per cent. on the commission, but there being no competition, the necessity of a direct 
inspection would be eliminated and consequently the grading of silk would have to be determined on this side of the water by the buyer himself. I will point out in another chapter the disturbances created by the workings of the Yokohama Silk Exchange, and shall only add that the manipulations related above on the part of some unreliable dealers might be on account of unfortunate speculations, for almost all dealers gamble more or less openly and the fluctuations of the Bourse have much to do with raw silk transactions.

Thus business conditions are becoming very difficult in the Far East for foreigners. Taking in addition the lower salaries paid to silk men and the cost of living becoming higher every day, it goes to show that China and Japan were happy lands some years ago, compared to the present time. The Japanese, at least, are beginning to find out that within a few years they will control entirely their national industry. 


\section{CHAPTER II.}

\section{Japan}

I.

\section{Japanese Filatures}

I $\mathrm{N}$ order to give the reader the clearest possible view of silk reeling in Japan, it is perhaps well to relate a trip made in April, 1908, by the author, accompanied by a friend, to Kofu, where the well-known Koshu silks are reeled for the American mills.

We took the seven A. M. train at Yokohama and reached Shinbashi Station, Tokyo, at seven forty-five A. M. The trolley car carried us across the city to Uyeno station where we took the nine A. M. train.

From Tokyo to Hachioji (another large silk center) the scenery is made up only of plains, covered with rice fields, The wide plain is left behind and a long tunnel entered, which cuts through the Kobotoke pass. Emerging on the other side, we enter the charming valley of Katsuma-gawa. After another long tunnel, the peaky hills and tiny hamlets on the right bank of the river Tsuru-kawa present a series of charming glimpses all the way. At Saruhashi, perpendicular cliffs frown down upon the dark emerald stream. which is narrow and deep at this point. Then, at Ozuki, we enter the valley of Hanasaki-gawa, passing by villages devated to the breeding of silkworms. The natives make use at the same time of the many streams to drive their looms and throwing plants.

Passing through the tunnel of Sasago (three miles), we enter the province of Koshu and suddenly obtain views of granite ranges hitherto unseen. Mount Fuji is visible now and then over the tops of a range bounding the plains to the south. Mulberry trees and rineyards are extensively 
grown here. We noticed with pleasure that mulberry leaves were only beginning to sprout and that the freezing had occurred much too soon to do any harm to the young vegetation. We did not think it possible that an accurate report could be made on the crop before the middle of May, and the rumors which had been cabled out during April had no foundation whatever.

Kofu is only seventy-six miles from Tokyo. It is encircled by a barrier of lofty mountains 6,000 to 10,000 feet high, and an extraordinary amount of tunneling has had to be resorted to, with the result that much of the beauty for which this route was formerly noted has been sacrificed. There are no less than forty tunnels, with an aggregate length of twelve miles out of the fifty-three miles traversed between Hachioji and Kofu.

Outside of Kofu, places like Mitake, the gorge of Akawara, as well as the granite mountain of Kimpuza, would suffice to make the trip worth taking. Kofu is the capital of the province of Koshu (Chinese name) Kai (Japanese name), prefecture of Yamanashi, with 39,000 inhabitants. The climate is temperate in winter, but on the nineteenth of April it was like a summer day. We arrived at four P. M., a long and tiresome trip for the distance, and stopped at a Japanese inn, called Bosenkaku, in the public garden.

Springtime is the holiday of nature in Japan, and nothing in the world can be compared with the beauty and poetry of that inn among cherry blossoms.

Owing to its large industry in raw silks, Kaiki (a thin silken fabric used for the lining of dresses and for bed quilts) and beautiful rock crystals, Kofu is a rich city. There are several banks, supported by wealthy citizens.

The silks known as Koshu are well liked by American manufacturers, and nearly every pound manufactured in that district is exported to New York. Europe does not like Koshu silks, because their color is too dark; they had rather buy Sinshiu silks, which, as a rule, are very white. All filatures at Kofu and surrounding villages have been long established; the names of Yajima, Wakao, Koseisha, Kononsha, Kinposha, Hakureisha, Koyokan, Fusosha, Asahisha, Yamatogumi, Yawata, Kusanagisha, Mitsubishi, 
are well known to the trade as standards of high grades. Being closely in touch with the American market they have always done their best to bring out the latest improvements for the benefit of their customers, although they seem to be still under the impression that quantity pays more than quality.

We visited several filatures; the Yajima, one of the largest, was reeling at top speed a low grade to be exported under the chop "Kyoseisha" as a quality equal to New York No. 1. The cocoons used were from the autumn crop; the thread seemed very dirty and irregular. The Japanese reelers make only two distinctions in the crop's season. When spun from cocoons raised during May and June, silks are called Aru. They are by far the best. When spun from cocoons raised in autumn, silks are called Aki. No raw silk is sold in Yokohama as summer or winter silks. Accordingly, reelers apply different chop tickets to silks of spring and autumn.

The system of reeling adopted is now completely "a la tavelette," because the twisting does not require so much supervision when running more than four ends in each basin. Only in one or two cases there was an extra girl to prepare the cocoons (blaze out and draw the first thread) for every two basins; otherwise, each girl does that work herself.

In the Kusanagisha filatures (fifteen hundred basins), they were reeling the "Gold bag" quality out of dry spring cocoons. There was a little less speed in the travelers. By examining a few skeins, we convinced ourselves that the silk of Koshu stands as the perfect representation of the hardnatured silks so sought after in America. It certainly comes from a quality of cocoons which are also to be found in Shimoosa, Hitachi, Kasuza, Yashiu, Djoshiu, etc. They contain a larger percentage of fibroin than cocoons from any other district. Notwithstanding the proverbial irregularity of Koshu silks (due, no doubt, to the lack of supervision in the filatures), the fibres have more tenacity and wind better than other silks of equal quality, and they are so firmly spun that they always make a good organzine. The faults are the dark color and the dustiness of the 
thread, which makes it difficult for it to rank equal to the best Oshiu Extra. The latter have not as much strength in the thread, but are much whiter, cleaner, and always show a perfect regularity in the size.

We saw several other filatures which are all of four hundred to fifteen hundred basins, with latest improvements - steam engines and electric lighting ithroughout. We were at all times kindly entertained by the owners of the places, gentlemen of education and refinement. At our request, we were shown every detail in the manufacture. One fact impressed us more than anything. All, except the steam engine and the tin lining of the basins, was built of wood. Everything-the walls, the frame work, the reelers, the testing machines, the scales, etc., etc.,一was made as simply as possible of solid wood setting, each piece fitting in the other without a nail or screw. This, of course, we had seen in small filatures, but were indeed surprised to find the same cheapness of construction in such important establishments. Evidently, in Europe, a large amount of money invested in heavy buildings, steel apparatus and expensive machinery, could be saved by building cheaper factories where, after all, the quality of work, skill and workmanship speak better for the sale of the goods than costly basins. This is one of the tricks young, practical Japan is teaching old Europe.

We also noticed in every office a telephone connection with Yokohama, so that every little move on the latter market can be talked over. Such up-to-date equipment is rarely seen in Europe either. Any respectable town in Japan could not do without a Race Course and a Bourse nowadays. The small Silk Exchange at Kofu follows closely the Yokohama quotations in reference to the Yokohama Silk Exchange.

Most of the Kofu filatures, especially at the beginning of the silk season, are in activity every day from five A. M. to eleven P. M., these eighteen hours' work being cut down by five or six times a ten to twenty minutes' interval for meals and tea distribution, which is provided by employers. The girls are paid from fifteen to twenty-five cents a day. We asked several girls how they liked 
their hard work. They replied: "Amari suki degozaimasu" (We like it!) But one must go far to see a dissatisfied Japanese. They have a good deal of the old Chinese philosophy, especially in the country.

In each filature the work was thus divided; first the reeling; second, the re-reeling (while the re-reeling is done, a little skein of four hundred and fifty meters is taken from the reel and later on attached to the big skein in order that the denier weight of same can be ascertained); third, putting ties or capiures; fourth, hanks inspection (a very light and superficial examination merely to see that capiures are fixed right); fifth, folding into skeins; sixth, weighing the little skeins obtained during the re-reeling, so that corresponding big skeins weighing too much more than the standard size may be put aside.

Once we waited to watch the size testing, and saw that some skeins weighed as much as one denier out of the size, which was supposed to be $13 / 15$. The man wrote down the name of the reeling girl, but did not put aside such skeins; they were simply mixed with others. From this we understood why the Koshu Extra shows sometimes a variation of $6 / 7$ deniers in the size. The reelers ought at least to make a choice and keep the $12 / 14$ and $14 / 16$ skeins together, respectively. It might take some time to complete a bale of such sizes, but the regularity of the $13 / 15$ would be saved. The skeins are packed into square books, stringed, labeled, covered with thick paper, and put in boxes of sixteen books each, ready to be shipped to Yokohama.

Besides the rooms occupied by the above operations, there are several offices where a number of clerks work. Also, a large space where, at meal hours, straw mats are laid down and the girls called to eat their fish and rice. At such moments the room is crowded with hundreds of girls, seated closely and making up in noise what they were compelled to keep back while at work-a regular bird cage. The meal finished, they rush back to work. The place is left just as clean as before-the floor varnished; not a stain to be seen. We admired the scrupulous cleanliness of the Japanese, with his bare feet and chopsticks. Twenty European girls, eating in the same room, would 
have soiled it so as to require a complete cleaning up afterwards. Cleanliness is a rule in Japan, and is kept strictly in the filatures. Notwithstanding their arduous work over boiling water, the girls' clothing is always neat and decent.

Near the main building there is a fireproof house to keep the dry cocoons. There is also sufficient room for selecting cocoons. In some places quite a quantity of silk waste was laid open on the ground to whiten and dry. Some women were employed outside to reel out double cocoons

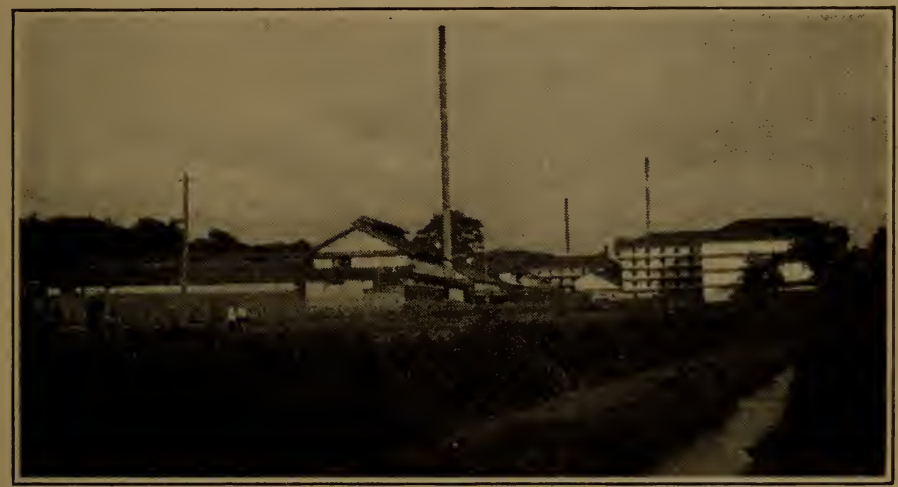

Outside View of a Japanese Filature

into tamaitos (douppions). In one instance the whole apparatus consisted of one basin containing cocoons and the girl reeling the coarse threads around her fingers.

To see all the Kofu filatures would take at least a week, so we were contented to see a few of them. We were very glad in the evening to reach our hostelry, where an almost boiling bath was awaiting us to relieve our fatigue. And at dinner time, with some local silk men, seated on the tatamis, looking through the open sliding windows we breathed the cool, perfumed breeze of the night, while the moon was shining on the beautiful cherry blossoms. The moon rays illumined the miniature lake in the garden below, where enormous red fishes jumped out of the water like silver. The servant girls brought us raw salmon, pickled 
turnips, extraordinary dishes, and plenty of rice wine. But we were looking at the scenery all the time. No wonder the Nippons are happy in their dreamland. A strange and sweet music came from behind, and, there, kneeling at the door, were geishas, without whom no entertainment is complete.

Note, 1921.-Since the above was written, much improvement has been introduced in all filatures of Japan, especially as regards supervision. Several Kofu filatures have improved their grading to Double Extra.

\section{II.}

\section{The Silk Exchange}

One of the unpleasant experiences of the silk exporter in Japan is to discover, on reaching his office in the morning, that the "jo ichi ban" No. 1 Filature, equal to Sinshiu Okaya, is quoted at the Bourse, ten yen or more above the closing price of the previous evening; next, his "banto," Japanese employee, will rush in: "Sir, Messrs. So and So and Messrs. An Other \& Co. have received large orders from America, the Japanese firms are in the market (they are always) and the Silk Exchange is going up rapidly."

This report is the same in every exporting house. If you have a fresh order or an old one which you were holding back in the hope of a decline, you will most of the time cover yourself at once, very glad if you do not pay the advance. Your neighbor thinks himself wiser, he buys twice as much as his orders amount to. The next man buys without orders at all, and some others place an order at the Silk Exchange, expecting a further advance.

Very quickly prices jump higher and higher. You did well to cover yourself and you now regret that you did not buy more. You smile over your lunch, but at two P. M. you find that your "banto" is also smiling.

"Bourse down yen five."

"Why?"

"Messrs. So and So are cancelling all their purchases."

"What about An Other \& Co.?"

"They did not buy, waiting for lower prices."

"And the Japanese?" 
"They bought at the Bourse this morning at yen nine hundred, but are reselling all they can, now, at yen nine hundred and twenty."

A.t four P. M. quotation has declined to yen nine hundred and ten, and finally comes down to the starting point, but the next morning it is up again, and so on.

The above story happens when the market is quiet, but when there is real buying the excitement and the way the quotations are pushed up at the Silk Exchange are impossible to describe. In fact, there is so much speculation going on at the Bourse that sometimes the real prices find difficulties following it. During the year 1907-1908, the Yokohama Silk Exchange had to close its doors the day speculation pushed the quotation up to yen seventeen hundred, when yen fifteen hundred could not be obtained for spot silk. The same thing was repeated during 1920, when a fictitious value of 5,000 yen was given.

Transactions are made in two ways: Either ready or three months' deliveries. A brokerage of yen two is paid on each bale for ready and yen four for three months deliveries. No deposit is asked up to three bales and about yen ten per bale above this number. The delivery of goods is optional. Two or three large Yokohama firms speculate against actual deliveries, but the bulk of business is for cash.

Some of the large Yokohama firms find a substantial food at the Bourse for their speculative spirits. It is very easy for a large firm when receiving a good-sized order to hold on to it, and buy at the Bourse first at current prices. The second thing is to get in the market and to start buying. It is understood that prices are very sensitive to the advance. Such a large firm getting in the market will drag along other firms with ready orders or sometimes without. The dealers are asking more money and the Bourse leaps upward. The originators of the advance have now covered themselves, and, according to circumstances, cancel at once or later their contract with the Bourse and pocket the difference.

There is no doubt that such an institution is demoralizing, 
and it is with the utmost difficulties that silk buying is effected at Yokohama.

Filature men in the country are constantly speculating, and you discover that a lot of silk has been sent to the Bourse when it should have been sent to you, or, when you expect a silk equal to chop from some one, you only receive a second thread because the first thread has been delivered to the Bourse. Your customer wants a filature of summer reeling, and you answer that there is only an autumn reeling to be found, but three months later one of your competitors ships the same summer reeled chop which has come out fresh from the Bourse.

These happenings and many others make it difficult for the silk inspectors to keep well posted on the innumerable Japanese filatures. A badly regulated market is always perturbing, because the slightest news, the smallest purchases, are sufficient to send the Bourse upward, and when the market is dull, prices come down just as quickly.

The only remedy would be to close the Yokohama Silk Exchange altogether, but, of course, this suggestion could hardly be realized among Japanese merchants, as there is hardly one of them who is not constantly gambling on the Bourse. Even the poorest salesmen combine to buy or sell a few bales, and it is really a sight to see at Yokohama, when the market is excited, in every firm, Japanese or foreign, the rooms where the "bantos" and salesmen meet, transformed into gambling dens.

This state of affairs is to be deplored, for the firms who are not speculators have no other means of livelihood than their knowledge of the thread.

III.

\section{Silk Waste}

The silk wastes of Japan are divided into innumerable varieties resulting from the differences in the reeling processes of each district as much as from the manipulations of native middlemen. Following is a description of the qualities mostly dealt in: 


\section{Noshiitos}

Kikai Noshis are a steam waste ahout equal to Italia: frisons, but with more "nerve" and without any silky appearance. The color varies from white to dark gray, according to the amount of oily matter and chrysalides mixed in. The color can be improved by opening and drying in sunlight.

The Kikai Noshis vary greatly with the districts and are divided into several qualities from Extra to No. 4.

They are usually sold at the proportion basis, say, sixty No. 1, thirty No. 2 and ten No. 3, with an allowance of five per cent. for dust on the cost price. The Kikai Noshis. good for export, are by valuation order:

Oshiu Noshis.

Hossoris.

Hachiojis.

Sinshiu Noshis.

Djoshiu Noshis.

\section{Kikai Kibizzos}

The Kibizzos are a kind of steam waste in which the fibres are rolled in little balls mixed with long fibres and a little percentage of sundry waste. That kind of waste is largely exported to England and America.

\section{Zaguris}

These are the product of hand filatures. They contain more silky matter than other kind of waste, but more dust at the same time.

\section{Mawatas}

Mawatas are the product of double and pierced cocoons opened, washed and worked into a mass very much like bourrettes.

\section{Hiras and Neriwatas}

The cocoons once dropped at the bottom of the basin are picked up to be dried, the chrysalides taken off and the remaining dried white and mixed up with all the silk waste outside of Noshiitos and Kibizzos left in the filature. Such 
waste contains as much as ten to fifteen per cent of dust and is sold at a very low price. The value of that waste increases in proportion to the quantity of "bassinés" (partly unwound cocoons) found in each lot.

The only qualities brought to New York for the use of the spun silk mills are Noshiitos and Kibizzos in the best choices, say, Extra and No. 1. The schappe industry is growing in America and the home product can compete fairly well with the threads imported from France and Italy. A good future is predicted for this industry, and the

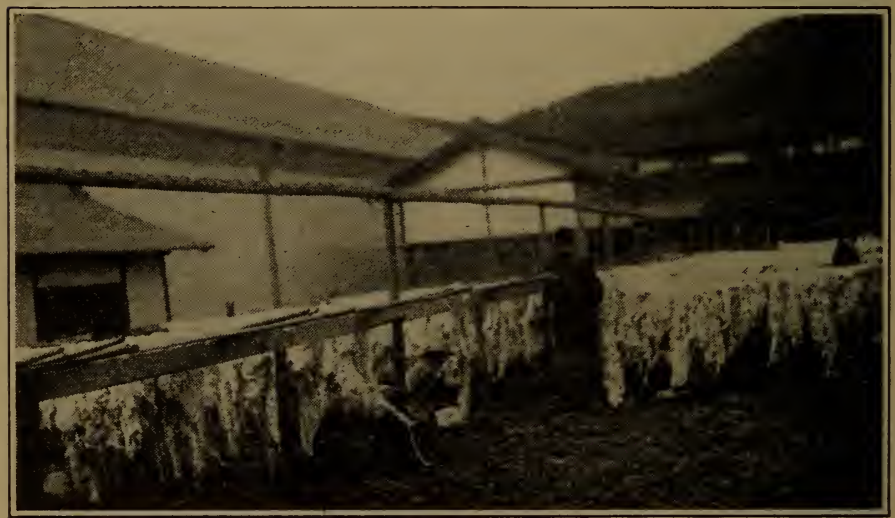

Silk Waste Drying in a Filature Yard

import of silk waste (Japanese and Chinese) is growing every year. There certainly would be a larger import of Japan waste silk to America if it did not contain so much adulteration, such as hair, rope, matches, filature refuse, which are to be found even in the best grades and prove very troublesome to the mills.

IV.

\section{Re-Reels}

We have seen how Japanese filatures, after being spun in the usual process, that is, mostly "a la tavelette," pass through a re-reeling department which is not part of the European filatures. 
Let us now study the Japanese Zaguris, which are known in the trade as re-reels. Most of the large re-reeling establishments, like Kanrasha, Usuisha, Shimonita, Kosuisha, have opened their factories in cities where the larger part of the inhabitants are farmers. They all, more or less, produce cocoons and cultivate mulberry trees. For instance, in Mayebashi, an important place of $3 \pi, 000$ souls, the houses are mostly farms, where some hands can be spared at home, and it is among those hands that Zaguris are spun. If you go through the small muddy streets of the town, you will see in nearly every house an old woman working over a small basin full of water, kept boiling over a charcoal fire. She is turning the wheel with one hand, and reeling the thread with the other.

Some farmers provide their own cocoons, but usually the factories buy from them and make a selection according to quality and color, and then each basin is again provided with cocoons to be spun in a certain size. If, according to the factory test, five cocoons are necessary to spin $13 / 15$, a general order is given to all hands to use five cocoons. Now most of the women employed by the factories are very experienced; they are old women, who cannot be used in outside hard work, but there is no doubt that their ability and attention is much above the average of the young girls in the filatures, and the employer is pretty sure to get a good silk from them, that is, as much as the deficient machinery will permit. From the above, it seems that by giving good cocoons to experienced hands, Zaguris ought to be better than filatures, and it has been actually a mistake of some to believe so. It would be nearer the truth to say that such good workmanship prevents them from being too bad because the reeling machine used to spin these Zaguris cannot and never will produce a standard thread like filatures.

Let us describe it roughly: A small basin is placed directly above the fire, which cannot be kept uniform in temperature. The water may be from cold to boiling, and consequently the cocoons will unwind more or less easily, and the color of the thread will differ at the same time. Besides, there is no twisting whatever, as in any systematic 
filature. The thread is roughly turned around a couple of hairs nailed to one side of the basin and goes directly on the wheel. If the twist gives elasticity to the thread it also makes it regular, and the process of passing it through the hairs may be useful in stopping the loops, nests and sundry dust, but it does not in any case improve it. When the small winder is covered, it is taken to the factories, where the same process as used in filatures is gone through, that is, re-reeling from the small winder into a larger one as fast as possible, so that the fine ends do not fail to break and are at once retied.

A small skein of four hundred and fifty meters is taken

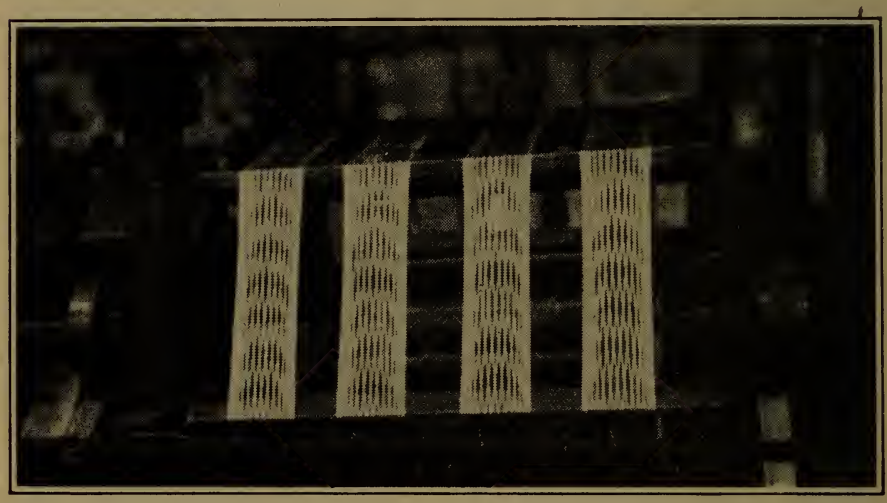

American Standard Re-reeled Skeins

from each tavelle and carefully weighed, so that three or more selections are made according to size. Then another selection is made according to color, and the most regular skeins are packed and shipped as best and the others as lower qualities, and that is all-no cleaning, no special process to improve on the regularity. An exporter asked the manager of one of the leading factories why no special care was taken in the production of his silks. His answer was: "We have no time, and our customers are satisfied with our products."

"Have you never tried to improve your chops by careful cleaning and also with some kind of twisting apparatus attached to the basin?" 
The man took him to an abandoned room, where he saw a few cleaners formerly ordered from Zürich.

"We used them for a season," said he, "but we lost time and money, as our customers from America did not give us a cent more for our trouble."

It would not be right to say that re-reels are superior to Japanese filatures, but one thing can be said in safety: It is that the cocoons used to make Zaguris are especially good, and, being reeled by clever hands, they produce a very nervy silk, giving splendid winding and filling well in the goods. It remains to be said that the improvement needed to make of them a silk equal to the filatures (double extra grades excepted) rests with the customer, who should be willing to pay for the extra work of cleaning, and perhaps it would be an easy matter to improve the reeling machine by adding to it a simple system of twisting.

The leading re-reeling establishments are the Usuisha, Kanrasha and Shimonita, who are now combining in a large corporation to control at least fifteen thousand bales of raw. The time is not distant when the re-reels as a special article will become a thing of the past. They are now offered on the market as regular filatures, and as the largest part of such silk goes into tram, manufacturers are well satisfied.

\section{V.}

The Crop and How it is Manipulated

Almost every season, at a certain time, there are rumors circulated on the New York market, tending to show that the stock of raw silk in Japan will not be sufficient to cover the needs of the American and European consumers. Any one who has studied closely the Yokohama market for the last decade will not pay any attention to these false rumors, which only have the result of frightening importers and forcing some excitable manufacturers to false steps, to be regretted later on.

The idea of this chapter is to throw a light on the question of crop and stocks in Japan, so that any discussion on the subject may be based on logic and facts. 


\section{The Crops}

It is between the first and the fifteenth of May that accurate news of the crop's condition. can be ascertained. According to vegetation the mulberry leaves come out after May 1, and the quantity of eggs put into incubation is known around May 15 . There is a large crop of spring cocoons, the first choice of which is reeled all year round, but mostly during the summer. The autumn crop is reeled in winter, and together with polyvoltins and second choice cocoons in spring. But as nine-tenths of the filatures are now working all the year round, the terms summer and spring reeling are beginning to be a thing of the past, and I hope will soon disappear from the New York market.

The statistics show very plainly that the export of Japanese raw silk is increasing at a rapid rate. The Japanese, backed by the Government, are using every bit of the soil for mulberry trees. During the last ten years, the Japanese crop has increased by 100,000 bales. There is no shortage in sight for many years to come.

It was in 1907 that a shortage was really felt; prices went up to nearly six dollars per pound for Japan raws on the New York market, and even at that price it was hard to obtain any. In Japan the sellers had almost nothing to offer and were holding what they had on hand at fabulous prices.

It lasted about one month, and behold, at the first sign of weakness, when the American mills got tired of paying fancy prices, silk arrived in Yokohama from the country in amazing quantity. After repeated advices that no more Japan silk could be had, it was coming as fast as could be. Some had been kept secretly in the filatures, some had been reeled out of Chinese cocoons. At any rate, the market began to come down by leaps and bounds. Such differences as one hundred yen per bale on the same silk were recorded in one day. Again in 1920, owing to some extraordinary speculation and a false idea that the crop was exhausted, prices reached seventeen dollars a pound. As soon as the demand ceased, the market jumped down, and a decline of ten dollars was recorded in four months, with plenty of silk in stock. The Japanese have always 
managed to meet the demand, however great. So-called shortages are usually due to speculation or manipulation.

\section{The Question of Stock}

When one hears about the stock in Japan he may be quoted, say ten thousand bales. That figure is wrong, for it includes only the silk known by the several dealers of raw silk in Yokohama. Supposing that these dealers show the figures according to their best knowledge, they never know exactly what stock the reelers are carrying in the country, and silks that have been offered on a flat and declining market quickly disappear as soon as there is a firm tone. And when the reelers refuse to sell, it looks as

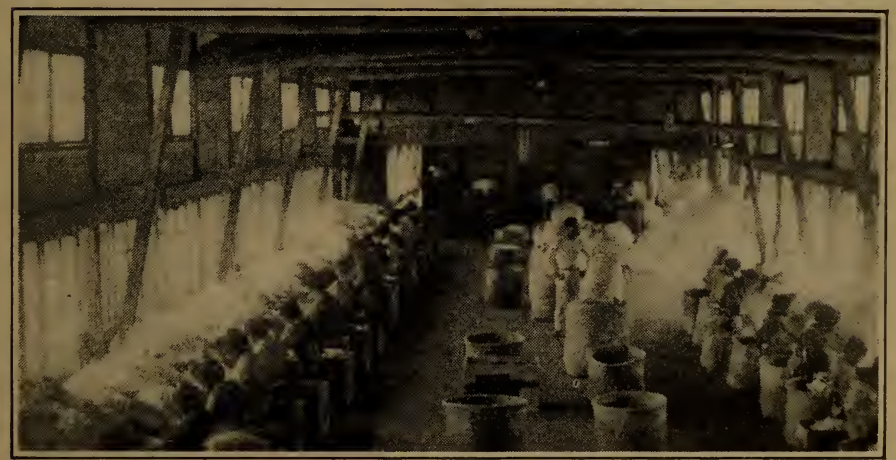

Selecting Cocoons in Japanese Filature Warehouse

if there was no silk to be had, hence a reduced stock. Let the market be weak again, and the stock will come out larger than ever.

\section{Cocoons From China and California}

We have seen before that in case of extreme want, the Japanese filatures have purchased cocoons from China. During 1918-20 several thousand bales reeled out of Chinese cocoons were shipped to New York. There the crops are unlimited, and if the mulberry trees were cultivated to the same extent as in Japan there would be enough 
silk produced in China to supply the whole world. However, the Chinese are lazy and they have not yet grasped the fact that they could make more money out of silk.

On the other hand, the Nippons without loss of time have started raising cocoons in Korea and also in California. There are very few people aware of the fact that a quantity of cocoons raised on the Pacific Coast is sent yearly to Japan and reeled there. Some lots of silk sent to New York are spun out of American cocoons!

There is no reason why California cannot raise a great quantity of cocoons and sell them to other countries since reeling here is too expensive. There is now an active society called the Sericultural Association that is studying the question of hatching silkworms and many thousands of mulberry trees are growing at Rutherford, Napa County, Calif. The Society intends to start reeling on a small scale, as an experiment, with the co-operation of young students from the Agricultural School.

If Japan can get these cocoons from different sources beside her own, there is very little chance that the crop over there shall ever run short.

\section{Some Qualities May Run Short}

This is the only danger that may result from a quality being in demand in excess of production. There is a tendency in Japan to reel a good part of the XX grade in sizes from $16 / 18 \mathrm{up}$, in order to compete with the Italian silks. The quantity of best extras Japans being also limited, a large call for both fine and coarse size outside of $13 / 15$, would most probably reduce the stocks to very small quantities. These shortages would occur only in the case of extraordinary demand in a year of prosperity, such as we see only once in a while.

\section{How to Figure on the Yokohama Stock}

The quantity of old silk available in Yokohama at the opening of the new crop must be added to it, so that if the promised crop for a season is 170,000 bales, we must add what is left over from the previous season, say, five thousand bales, altogether $1 i 5,000$ bales. When business 
is brisk, figures given by the Yokohama dealers are always below actual quantity, and ten per cent must be added to the visible stock. Never, at any time during the season shall that amount be forgotten.

By keeping in close touch with the statistics of export, the stock in Yokohama, the approximate quantity kept back in the country and the total amount of silk to be exported during the season, there is a better chance of getting the right figure than by listening to various rumors that are never very accurate, if not based on reasonable facts.

\section{VI.}

\section{Inspection}

It seems that foreign silk inspectors in China, viz.: Shanghai and Canton, have an easy job purchasing from stock or contracting far ahead with Chinese merchants. Without any sort of contract, except merely a clapping of the hands, the goods agreed upon always come in time and up to sample. It is the main reason why Chinese silks are sold in New York under the merit of their name, and very rarely do we see well-known brands come out inferior to their usual standard. Even when there is a real inferiority, it is due more to the defective crop of cocoons than to bad workmanship or manipulations in the filatures.

In Japan the silk inspectors face the real difficulties. Firstly, the market is practically in the hands of the large speculators, who naturally have control of the larger part of the filatures. Secondly, raw silk is becoming more and more an article of gambling through the handling of middlemen and the operations of the Silk Exchange. Thirdly. transactions between buyers and sellers have reached the acute point where transactions are not based on confidence. just as if each party was trying to do the other. Fourthly, when the market is active and prices advancing, contracts duly signed with the filatures may be considered as naught. as reliable dealers are getting to be an unknown thing. Fifthly, many Japanese dealers have adopted private chops. similar to those used by New York importers, with the only 
difference that while the New York importer invented the private chop to put his personal guaranty on the quality of its deliveries, the Nippon middleman simply covers rejected goods in order to be able to sell them again. $\mathrm{He}$ also sometimes buys a good lot, usually sold as a certain grade, and tries to sell it as a better silk under a new chop. Thus names of new filatures are multiplying faster than

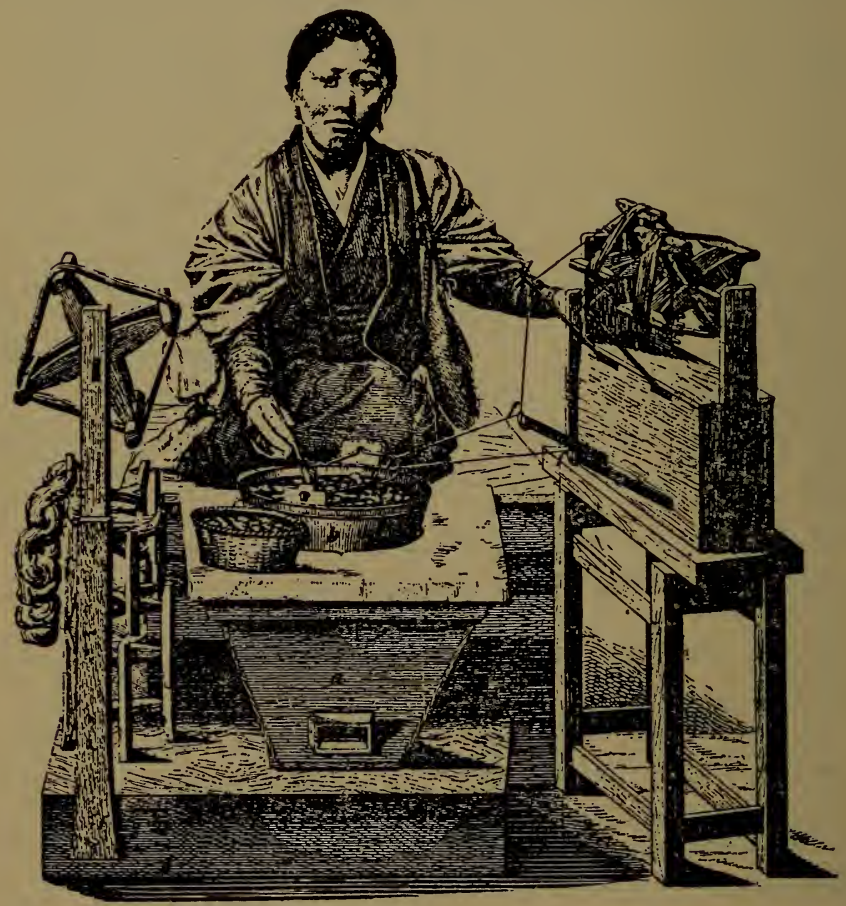

Japanese Country Reeling

potatoes in sunny Japan. Sixthly, two-thirds of the Japanese filatures have no standard of quality, and can be classified only after a very careful inspection.

An inspector told me that, having bought a ten-bale lot of well known chop, he had to reject it on account of the quality, the nature being very streaky. The seller took back the silk and replaced it the next day with another 
lot of a different brand. The inspector found the silk pretty much the same as the first lot, and in fact, it was the same, as he learned later from one of the coolies. Of course, he did not accept the silk, but it is said that such tricks succeed more than once, especially with a rising market, when the buyer has no choice of replacing. There is, of course, an old game which, it must be said, is not in favor either of the buyer or the seller, and which is practised by almost every. one with a very few exceptions. In such a case the shrewdest and most experienced get the better of the others. It is done in some such way as this: The Japanese seller delivers a lot of silk which is supposed to be equal to sample. If the market comes down, and the lot is not good, the seller is only too glad to replace with another; but if the market goes up he simply refuses to replace unless at an advanced price. The inspector revenges himself as follows: He buys a quantity of silk, part of which has not been ordered by New York. If the market goes down he rejects what is not wanted, under the pretext that it is no good, whether true or not; but if the market goes up he very quickly accepts the whole quantity and ships it to best advantage.

One of the worst troubles is when filatures refuse to make deliveries in proper time against signed contracts. It is always a matter of "cancel the order if you cannot wait."

The Yokohama market is so sensitive that sometimes the purchase of a ten-bale lot pushes up prices five yen. In China we see often the reelers selling at the same price continually during several days. When the silk men's guild decides to sell, the reelers will all sell at the same time, at a fixed price for each grade. After that, they may sit still during several months. It is that old basis of organization and ancestral reliability which guides the Chinese and they do not have to live on credit like so many Japanese reelers. They will sometimes advance their prices only when the stock is reduced to a certain point. Hence, firm offers for several days which they are willing to make. In Japan, firm offers are given for twenty-four hours in a flat market; but as soon as some excitement 
prevails, offers are not good for five minutes. With the system of telephoning to the head office, and from there to the country, the reelers and sellers get so excited that they sometimes absolutely refuse to sell at any price. An inspector who does not know the game is hand-tied and cannot buy anything if he does not take it upon himself to jump at whatever is offered.

From the few above facts business in Japan appears to be indeed very difficult, and only those who are perfectly acquainted with such dealings and customs have a chance to compete. On account of the manipulations taking place before the silk reaches the warehouse, the inspector must know his silk thread perfectly, because if he relies on the chop only, he might accept anything. Most of the foreign inspectors in Japan are men of long experience, having learned during many years how to deal successfully with the filatures. Even then they have difficulties.

The European firms who are sending very young and sometimes inexperienced men at a low cost to buy their raws in China do not dare to place their Japanese interests in other hands than those of first-class business men, for otherwise, they would stand a chance of getting a few gold bricks.

\section{VII. \\ Private Chops}

There is a burning controversy between the buyer and the seller about the chop question in Japanese raw silks. The consumer insists upon getting original chop, the importer insists upon using his own brand. Which of them is right?

The question lies at the producer's door, for he is the only one responsible for the trouble.

Supposing we are placed in the position of an honest importing house whose rule is to guarantee the inspection of its silks. With the conditions existing now in Japan, there are hardly ten chops that are given an invariable classification in New York. A manufacturer will call a chop Extra, another Extra to Best No. 1 and the next man Best No. 1 only. The importer takes note of every manufacturer's view of his inspection and starts writing down the names of 
chops with their different classification, but when such chops are coming from Japan sometimes as Extra, sometimes as Best No. 1, it becomes so complicated that the importer gives up the game altogether, and rather than have more trouble simply accepts the shipper's own classification or establishes a system of private chops. Being given a number of qualities, samples are made up at the beginning of the season showing what the qualities are going to be all the year round regardless of seasons. A chop is chosen to cover each quality, whether a lion or an elephant is of no interest as long as the importer knows that under his private chop of Extra he shall always get an Extra silk.

All silks which are not Sinshius are wrongly called in New York either Kansai or hard natures. It would be better to sell silk according to the grading of the Silk Association of America, simply mentioning on the contract of sale whether the silk is of hard or soft nature because Sinshiu is not the only district where soft nature is to be found. At the same time there are some hard natured silks in Sinshiu. In fact, what most of the manufacturers understand by hard nature is a silk similar to that spun in the Koshu district.

Now using a flag or a turtle to represent each grade is of little interest as long as the silk is always kept under the same standard. The work of the importer would be to take care that a grade is fit for each one of his clients in order to be able to provide them regularly with the same quality. $\mathrm{He}$ would gain steady customers for his private chops.

\section{VIII.}

\section{Is the Standardization of Japan Raw Silk Possible?}

At the present time, no recognized classification of Japan filatures exists.

Several times, under the leadership of the Silk Association, leading manufacturers have gotten together, and an official Mission even went to Japan to tell the reelers all the improvements they should make and how wise it would be to deal direct with filatures that would maintain a correct grading of their silks. Outside of much talking, nothing practical has ever been accomplished, and it is the belief 
of many that the question should be left in the dark.

In the previous chapter, I mentioned the question of private chops. The first step to be taken is to eliminate all chop tickets and to attach to each skein a little slip bearing simply the quality and size. For instance, Extra 13/15. No one can make a classification according to chop tickets because they are continually changing. Possibly as many private chops as originals are in circulation in the New York market. Some of them cannot be distinguished from the originals.

The next step is to recognize only one classification, while there is supposed to be the Yokohama classification and the New York classification, and almost every importing house has a different idea of what grading should be. This one calls this chop an Extra and the other one a Double Extra.

A long experience has shown me that there is just a narrow margin between the following grades but that margin exists, and I urgently ask that it should be officially recognized.

Special Double Extra or Cracks

Double Extra A

Double Extra B

Best Extra

Extra

Best No. 1 to Extra

Best No. 1

Number 1

Number $1-1 / 2$

I was the first in 1910 to classify Canton silks with the favorite chops of each grade. This grading has been generally taken up.

The Silk Association of America should appoint, every year, a number of experts, who would select in October a few filatures, or chops, if such are still in existence, as representing the quality of such a grade. The grading could be based on the percentage system of inspection if desired.

All rames of districts, such as Kansai, Sinshiu, etc., ought to be eliminated, because they mean nothing, but the words 
"hard nature" could be mentioned in contracts when such is the case according to the buyers' requirements.

Should any disagreement occur between the buyer and the seller, the case should be referred to the Silk Association, and one of the experts would be called upon to compare the samples with the standard quality.

A manufacturer knowing which grade fills exactly his requirements, would try to buy as much as possible from the dealer who can furnish it.

It is probable that the Silk Association would not have to decide very often upon diversity of opinion concerning a quality of silk, because manufacturers are generally satisfied in their dealings with importers and most especially those who own inspection departments. Nevertheless such cases may happen, and it is a pity to think that there is practically no standard-no official grading-by which a quality may be recognized. All other textiles of the world have their standards. Silk stands alone as a pure gamble with which one has to take his chance.

\section{IX.}

\section{How to Improve Japanese Raw Silks}

Silks coming from Japan to this country may be divided into three classses, that is, silks for organzine, silks for tram and silks for single weaving.

Organzines are Double Extra, Extras and Best No. 1. All of them make the warp of broad and narrow fabrics. Trams from No. 1 and below make good to ordinary filling. While the distinction is not noticeable in organzine, two distinctions are made in the tram stock, viz.: silks of hard or soft natures. Hard nature silks are called here Kansai, that is, more or less, all districts except Sinshiu, which is supposed to produce silks of poor elasticity and rather hairy. Mino and part of Bushiu ought to be included with Sinshius as soft-natured silks. There are, however, many other districts where hard and soft-natured silks are found simultaneously, and it is more a question of quality of cocoons than a question of district. 


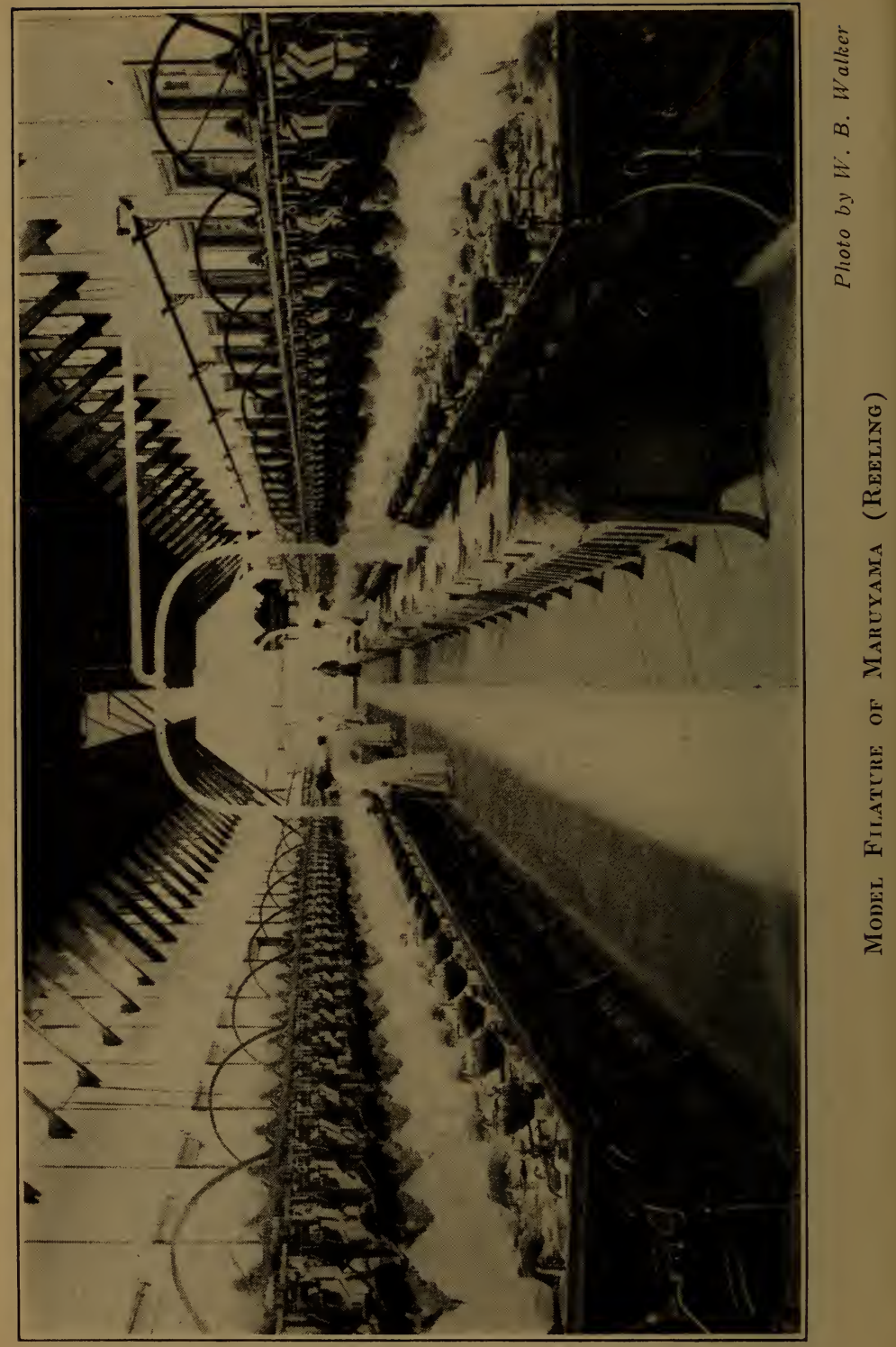




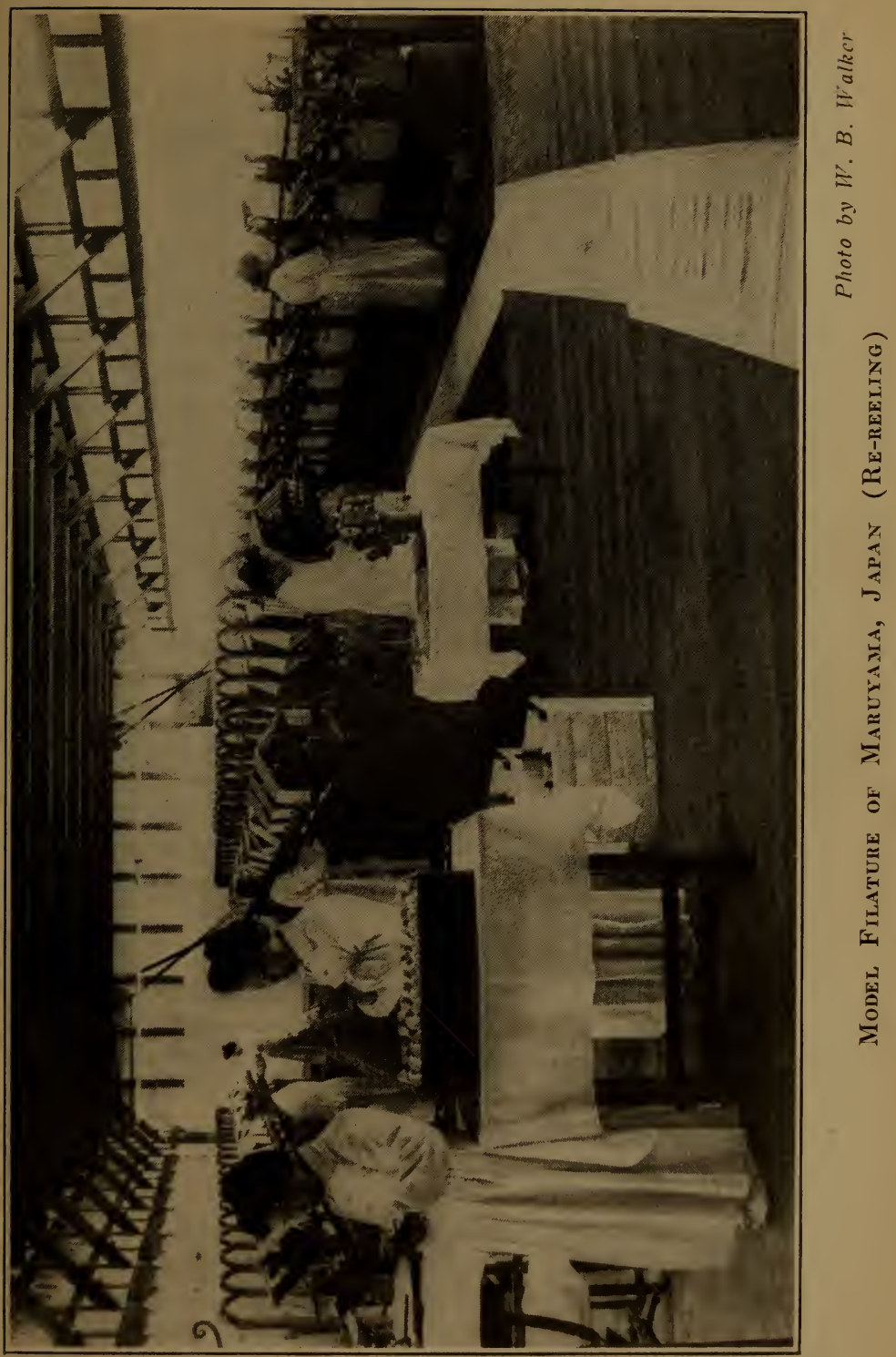


It has been asked many times if the best grades of Extra Japan could ever replace Italian silks in the large field open to them and almost exclusively as silks for raw weaving.

A silk for weaving in the raw calls for:

Perfect winding and even color.

Regularity of size, variation three to four deniers.

Much strength and elasticity in a round, nervy thread, and a very long crossing. Only a few Japanese establishments can fill the above requirement, but a great improvement is shown daily in both white and yellow silks by leading filatures.

At all events, supposing the Japan Extras are much cheaper than Italians, and a manufacturer starts using Japans for raw weaving. He may do so for a while and be successful with a couple of lots but then, all of a sudden he will not be able to get the silk because the production of such Extras is small, or is sold otherwise, or has declined in quality; while on the other hand, he can provide himself all he wants in an invariable grade from Europe. Of course, that costs him more, but he is sure of what he is getting and in a steady way.

In order to have some chances of competition, the Extra filatures of Japan must first reach the standard of Kawano and Sanin, buying the best cocoons obtainable and employ only first-class reeling girls under strict supervision, and try to obtain perfect regularity in the size. When manufacturers find that they can buy in Japan all they want for single weaving, Italians will have little chance. Japanese reelers must understand that it is in the Extra grades that their successful expansion lies.

The faults usually found in Japan Extras are: irregularity of size, unevenness, flat threads and cork screws. There is always a small amount of fine ends. The remedies are: slower reeling, long twisting evenly maintained on the tavelette, perfect choice of cocoons, selected for the whole production at the beginning of the spring and autumn crops.

Below the Extras, we have the Best No. 1, which are good winders. These silks, sometimes spun from very best cocoons, show the worst defects, as streakiness, poor color, 
many fine and coarse ends, dirtiness and the most awful irregularities in the size. The reeling is always too speedy, and also, even in the best filatures, many reeling girls are quite inexperienced; add to this the lack of supervision, and you have silks of undoubted good winding showing variations in the size of six or seven deniers.

Formerly the Yokohama Best No. 1 was not supposed to be sufficient for organzine, but since a couple of years some chops have been accepted by the throwsters as good for such employ. However, it is when we come to No. 1 and below, that we find the greatest variations in the quality.

There is absolutely no established standard for every filature, and it is impossible at present to obtain three deliveries of one and same quality out of any chop of No. 1 Kansai. Now this is the worst defect of Japan raw silks. No reliability in the quality is what will always make the American buyer hesitate to pay the full price, or the price asked by the reeler for the real value of his silk. The buyer feels that he is taking a chance, even when accepting a wellknown chop, because he has been caught too often through poor deliveries. When every reeler in Japan guarantees the year's production equal to two standards (say summer reel and autumn reel) every season, he will not only establish for his filature a reputation of reliability, but the American buyer will be glad to pay a premium in order to secure his silks.

One of our leading manufacturers finds it to his benefit, for special purposes, to contract for the whole production of certain chops, as the "Gunze," and pay the market price at delivery time. Evidently those filatures reel their best at all times, and other filatures would do likewise if offered work on the same basis. Unfortunately, most of our manufacturers do not possess the same facilities and must take their chances according to business. The amelioration must come from Japan, not from America. The latter country, as said before, will certainly reward the former as soon as it is found that filatures can be trusted.

Little may be said of the Japanese zaguris or re-reels, because hand-reeled silks cannot very well be improved, and as far as re-reeling is concerned, the Japanese have attained 
a high degree of perfection. I would advise that more care be given to the selection of skeins according to sizes.

With the extension of silk reeling in Japan, filatures are found everywhere, but the silks most perfectly adapted for this market are those of Oshiu for Best Extras, Koshu for Extra to Best No. 1, and to a less extent Bushu, Mino and Sinshiu, where the cocoons are not so good. This is said in a general way, for excellent chops are reeled in every district. All filatures ought to be of good color, even in size, nervy, and must have a round thread. Perfect winding is always required; this is the principal and most-important condition. Even the lower grades, $i$. e., below filature No. 1 , must wind at least $60 / 70$ tavelles; better grades must give one hundred tavelles.

The clever Japanese have obtained good winding out of their filatures by re-reeling them. It is a mistake to rely on the re-reeling only, because it does not improve on the quality. The silk being re-reeled at full speed, the fine ends are evidently broken and retied, and while it may look well on paper to see that the silk winds one hundred tavelles, once viewed closely, it is found that the thread shows great irregularity. The improvement must be accomplished while the first reeling is done.

Double or three-thread silk, as quite often happens, should be avoided as much as possible. Some Double Extras have a tendency to show too many corkscrew fibres. In filature Extra, one color only is expected, as near white as possible, and not several colors in a lot. The Koshius are rather dark in color, some quite brown, due to the large percentage of mineral coloring in it; it is all right if all of one color, because those of too dark a hue can be dyed black.

The size of filatures $12 / 14$ or $13 / 15$, unless otherwise ordered, should average 12.75 to 13.25 and 13.75 to 14.25 respectively. In Extra filatures, the variation in the size must not be over four deniers; in filature Best No. 1 not over five; and below from five to seven.

Some American manufacturers have started using finer sizes as $10 / 12,11 / 13$. A considerable quantity of these are spun in Japan for Europe. The filatures which will soon improve their qualities and obtain very good winding will 
stand a fair chance of finding a steady call for these sizes in competition with Europe.

The question of improving common Sinshiu filatures must be laid aside, because in filatures reeling No. 1 and lower, it is only a question of fair production. No matter how good cocoons are, no Extra silk can be obtained from poor winding and inexperienced help.

High-class filatures are intended for and must be fit for organzine. Double, fine or split-ended silks are death to organzine. After perfect winding, good color and perfect evenness of the size is a very important matter indeed, and many a superior parcel is emphatically condemned if the size is irregular.

European requirements are quite different in this respect, because in Europe raw silk is but rarely sold to manufacturers direct, generally to dealers and throwsters, who have both time and cheap labor at their command, and can sort the silk according to the size of each separate skein. Cleanliness comes next in importance, because we have no cheap labor in this country that would enable us to clean silk as they do in Europe. The question of twisting is invariably one of the defects of low grades when the thread is flat and uneven.

Many lots are lousy, $i$. e., containing minute particles of cocoons, which do not take dye and give the woven cloth the appearance of being dusted over with a pepper castor; this fault is-bar none-the most serious defect of any raw silk.

Streaky silk, as found sometimes in Koshius, is not very objectionable if pointed out in the inspector's specification, but it becomes very serious if the silk is dyed and woven without foreknowledge and thereby produces streaky goods.

So many lots are sold on this market without adequate or sufficient details of their qualifications that it is safe to point out that when a lot goes into work and proves to be inferior to sellers' representations or classifications, an allowance of fifty cents per pound does not compensate the manufacturer for his trouble and actual loss.

In order to improve filatures in Japan, I offer the following humble advice. It is the result of the close study of the 
conditions of silk reeling in Japan, as well as in Europe, in connection with the American market. Being given a modern filature of a large number of basins, "a la tavelette," I suggest:

1. That two choices of cocoons are made-once in spring, once in autumn. That each choice be divided into two; first-class cocoons, second-class cocoons, or four grades altogether (instead of buying cocoons from everywhere and at any time, as it is currently done.)

2. The reeling girls to consist of two classes of womenthose very experienced to reel the best grades of each season, and those of little experience to reel second choices-there being four grades of silk, one label or chop to be applied once and forever to each grade (instead of changing every season, as some filatures do).

3. Two reeling girls, to be provided with an extra girl to prepare the cocoons and take general care of the basins while the reelers are busy. One forewoman for every ten or twelve basins is necessary to see if the silk is properly reeled, viz.: if the twisting is long enough, $8 / 10$ inches, if the number of cocoons in the basins is always kept to the average sizing point, if the basins are kept evenly warm, if the silk is properly cleaned and retied when broken, etc. In fact, supervision cannot be dispensed with in a filature aiming to make a perfect silk.

4. Restrict the daily work of women to nine hours above eighteen years of age, and to eight hours below that age, because it is impossible for a tired mind to perform properly such a delicate duty as watching the tiny threads.

5. The speed of the travelers must not be too fast as is the case in most Japanese filatures. The desire to make more and sell more than they are really able to make properly is the cause for an extra speed given to the wheels. This is the worst mistake of all, because when the fibres are given too much tension they lose their elasticity, and while the Koshiu silks, although reeled very fast, are of such a good nature that they still retain a good strength, the same cannot be said of other silks. Hence the extraordinary irregularity of Japanese silks. The writer has seen many a Yajima, a Kinposha, a Koseisha, with irregularities of ten deniers 
in a lot averaging $13 / 15$. These very good silks are often barred the name of Extras on account of this defect.

6. The sizing must be done very carefully, and any skein that is not strictly one-quarter denier above or below the fixed size must be eliminated from first-class silks.

7. Re-reeling, although not strictly necessary, does away with gums, and is a guaranty of perfect winding.

8. After four lots of the initial four spring choices have been reeled, it is necessary that the filatures maintain the same standard throughout the season. This also applies to autumn silks. It can be done by comparing right along the silk while it is reeled with a sample of the standard lots.

Thus it will be known that, for instance, the Yiroshiya chop reel:

One "Gold stork" chop Extra spring cocoons, of first choice by first-class reeling girls, valued at yen one-thousand per picul; one "Silver stork" chop No. 1, spring cocoons of second choice by second-class reeling girls, valued at yen nine hundred and fifty per picul; one "Gold fox" chop Best 1 autumn cocoons of first choice by first-class reeling girls, valued at yen nine hundred and eighty per picul; one "Silver fox" chop No. 11/2, autumn cocoons of second choice by second-class reeling girls, valued at yen nine hundred and thirty per picul. Comparing the above fixed prices with those of other chops it will be possible once and for all to establish a classification of Japanese chops, for a classification of the same today is, with the exception of very few chops, as false as useless. I do not deny that some very well managed filatures have already adopted some of the above suggestions, although not all of them; neither is this article sufficient to treat the question completely and without reserve. In the raw silk business much can be said in word or in writing which cannot be practically accomplished.

There are also the difficulties arising from the business itself, as, for instance, the mistake made by the American manufacturer of purchasing in speculation, without knowing exactly what he is going to get against a certain grade, varying widely in the mind of the silk merchant. Another mistake is to try to buy silk at a price he knows very well is 
much too low to obtain the real quality. These and many other erratic dispositions of the buyers have disconcerted the Japanese reelers more than once, and are the direct reason for their having tried to replace quality by quantity. However, our mills are the first to suffer through that state of affairs, and now beg the reelers to establish a standard of perfection not yet obtained in Japan. Because the Japanese are courteous, as much as winners in many games, including business, they will no doubt astonish us with their perfect raw silks before long.

The preceding was printed in a number of "SILK" in 1910 , and circulated in Japan through the press of that country; the following completes the subject.

It is gratifying to see the Japanese reelers doing their utmost to improve on the quality of their silks. Indeed, since "SILK" took up the question of improving the filatures in Japan, two years ago, there is a marked improvement in the thread and the classification of the raw.

The time is not very far off when Grand Extras $13 / 15$ will be spun in quantity sufficient to be currently reliable for single weaving. Now a fair quantity of Extras is spun in coarse sizes, viz.: $16 / 18$ to $28 / 30$, thus entering into open competition with Italian yellow and white silks.

It is true that in the matter of high-class silks, such as Grand Extra, Piedmont, Friouls and Cevennes are still in the lead; but it is only a question of time when such high qualities will be dispensed with, and some Japans giving almost the same results will be used instead at much lower price. In the fine sizes such as $10 / 12,11 / 13$ and $12 / 14$ deniers and finer, a fair quantity is already exported to America. Should this country take up largely the manufacture of goods requiring those sizes, Japan can provide all that is wanted.

\section{Cheaper Raw Materials Demanded}

Thus it seems to me that the further we go the more we see the consumption of Japan silks increasing while Italians are losing ground every day. As aforesaid the first reason is that the quality of Japans is improving, and some manu- 
facturers who used to buy Italians are now buying Japans; the second and main reason is that they are cheaper.

With the fierce competition of the near-silk, mixed silk and cotton manufacturers and the tendency in this country to manufacture low-priced goods for a consumer unwilling to pay the value of silk, manufacturers have now to figure on low-priced raws, and, of course, Italians cannot compete in that line.

Outside of Chinas and Cantons, which are specialties, Japan raws are now the New York staple article; and a Japanese crop of 300,000 bales will be just enough for the continuously increasing consumption. 


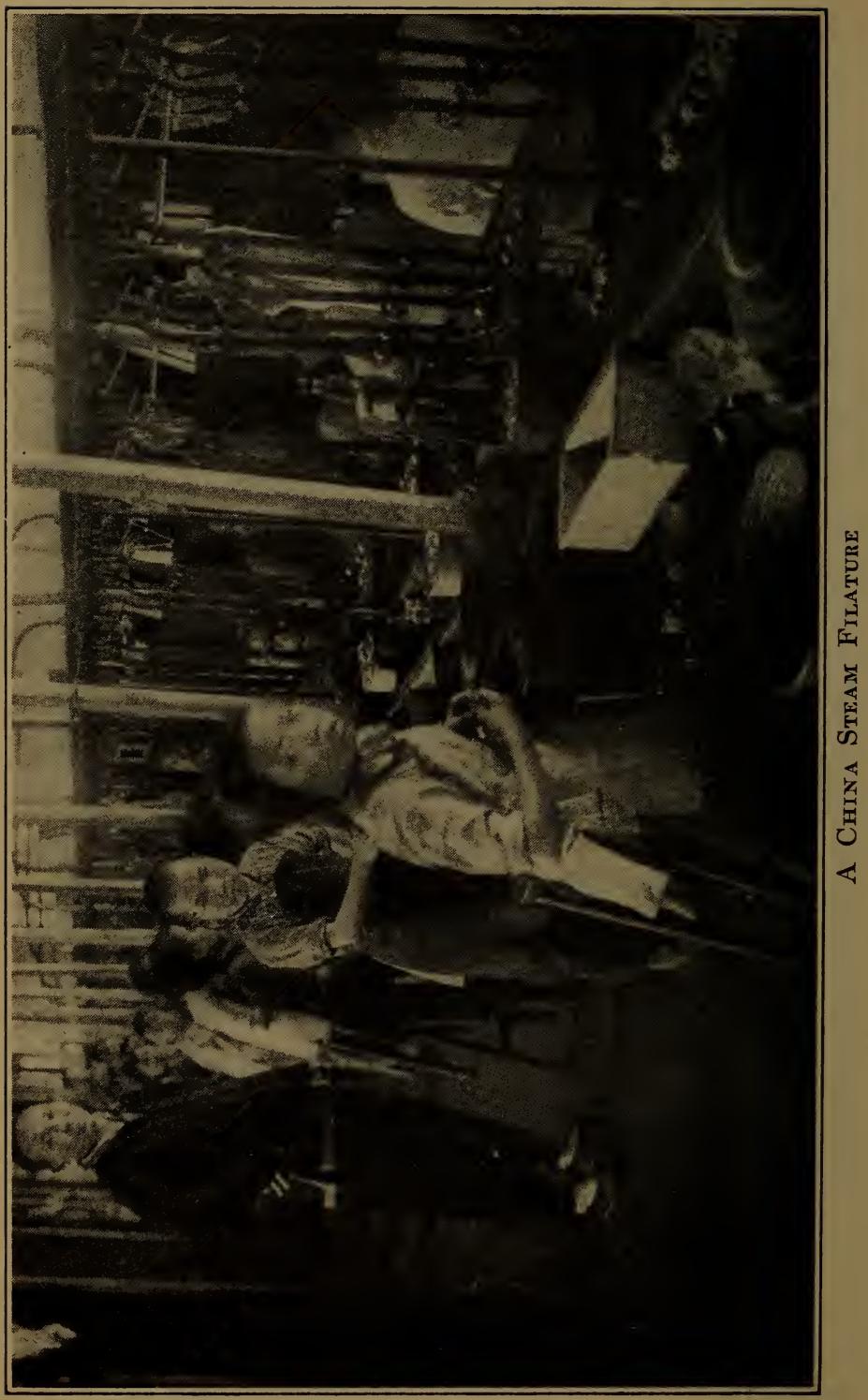




\section{CHAPTER III}

\section{China}

I.

\section{The Shanghai Market}

$7 \mathrm{HE}$ Pacific steamers do not come in sight of Shanghai, but anchor at Woo Sung, ten miles below, at the mouth of the Blue River. Shanghai is reached either by steam launch or via the railway.

Steaming up the Houang Poo River, we pass the extensive docks and some filatures, but it is only when the city appears, with its cosmopolitan activity, its fine foreign buildings, that we feel we are indeed in a civilized town, representing fairly well a diminutive New York, contrasting in its splendor with the poor, dull native surrounding villages, purely Chinese. We may compare Shanghai to New York, not only on account of the great business activity shown in every line of import and export, but also because the foreign population is so very cosmopolitan. There, out of 10,000 white people, we see representatives of all nations on the face of the earth. Add to this the luxuries of the West, magnified by more freedom, and the large banks, offices, clubs, newspapers, theatres, and you have a delightful modern city.

To describe the variety and the enormous trade of Shanghai would require volumes, but the most important is the raw silk business.

In Shanghai we find a great number of different silks placed on the market, silks differing not only in quality and sizes, but also in appearance, color and packing. Silks from different provinces, from Nanking. Hanchow, Chefoo, etc., are marketed in Shanghai. Formerly, fifty years ago, raw silks were brought from the interior in irregular bunches or hanks (grappes), named according to 
the district in which they were spun. Today some grades are still sold the same way, but they are relatively in small quantities, in comparison to silks spun expressly for export purposes.

The silks called steam filatures are those reeled according to foreign fashion, using the latest improvements, in several cases under the supervision of foreigners, like the "Soy Sun" and "E. Wo." Indeed, so-called steam filatures Extra are superior to the best Japans.

The first filatures in the European plan were introduced in China sometime around 1880 , and the new style was quickly taken up by Chinese capitalists. At present some steam filatures may be compared with the best Europeans for perfection of machinery and spinning improvements. Nothing can be said against cleanliness and supervision, because the best steam filatures employ or have employed foreign superintendents. The quality of these filatures compares very well with the Japan silks of the Oshiu provinces. The fibre has more tenacity, but less elasticity, because it contains more mineral substance. The color is of brighter white than Japans. It has been found, however, that Chinese silks of medium quality lose more than Japans in the boil-off; consequently, on account of this defect preference is given to Japans on this market, unless Chinese are offered at a cheaper price. The real market for Chinese silks in general is in Lyons, where every kind of raw enters into fabrics, some too expensive to use in our silk mills, and some lower qualities, the winding of which is very poor. Tulle manufacturers in Tarare (France) use Chinas Extra in a size as fine as $9 / 11$.

The next silks of importance are tsatlees, viz.:

Ordinary reel.

Cross reels (Grant system).

Improved reels or Shanghai re-reels.

Tsatlees are simply hand-reeled silks, packed by different associations. The first-named rarely come on this market, because of their poor winding; the second are wound again into cross-reels expressly for export, and the Shanghai re-reels being further improved into perfect winders, 
large quantities of them are taken up by the sewing silk and the wash fabrics trade.

The improved tsatlees are sized regularly enough around $18 / 20$, but the others are coarser. The tsatlees have an exceptionally brilliant white color. They are packed in books like steam filatures.

Concerning other kinds: The Hangchows are poorer grades than tsatlees, bad, to very bad nature, sold in books. The skeins are of medium size, $40 / 60$ deniers in large hanks, weighing three pounds.

Hanchow, Shinyang, are made up in skeins of heavy sizes, from 50/200 deniers. The above are not packed in books, while the Woosies, although of about the same nature and reeling, are made up that way. The color is rather whitishgray. That kind of silk, once cross-reeled, would have a good chance to compete with tussahs when they are scarce or held at extravagant prices.

The Heineens hand filatures are sold either ordinary reel, cross-reeled or in books.

Green and white Kahings, yellow and white Meeyans are exported in quantity to Europe, especially to the Swiss mills. They are rough, coarse silks in loose skeins. The Shantungs and Minchews steam filatures produce silks of good quality, spun from yellow cocoons. Some of the filatures have been improved by re-reeling under the name of "Japan style." However, they are only offered in small lots of $13 / 15$ size, therefore, not very interesting for export to America unless the regularity is greatly improved. Coarse sizes are obtained from primitive country reelers.

Other raws, known as Wooyungs, Wanchews, Wongyis, Pachows, Szechongs, are all yellow silks of coarse size.

The Tussahs (chief producing center, Chefoo), are exported to New York in large quantities.

The call for mixed goods of silk and tussah, cotton and tussah, and other combinations, and the taking up of such fabrication by many manufacturers, has caused quite a vogue for the brown thread.

The Tussahs are spun from wild cocoons found on the oak, plum, and trees other than the mulberry. The cocoons are large and gummy. The Chinese have a peculiar way 
of getting rid of such gums by allowing the cocoons to soak in manure; hence the sui generis smell of tussah silks. But a more unpleasant experience awaits the tussah waste inspector when he has to taste with his own palate whether the waste is overcharged with salt or not!

Now there are filatures turning out silks perfectly clean and regular, considering the difficulty of spinning. They are reeled, four, eight and sixteen cocoons. The best grades of tussahs shipped to America average thirty-five deniers.

Apart from the tussah filatures, numbering nearly one hundred, there are also tussah natives and tussah waterreels. Those spin silks from fifty to three hundred deniers, the former in ordinary skeins, the later in skeins three times larger. They are also employed in America for the manufacture of rough fabrics, in concurrence with doppionis, but before they can be introduced in the warp they must be re-reeled. That is why these grades reach this market via Europe, where they are worked cheaper, ready for use, either in the skeins or thrown. The low grades of tussah filatures can also be used here if properly re-reeled.

All Shanghai silks are sold according to choice and chop, in bales of about one picul. The payment is made in taels.

The merchants or their agents call personally on silk buyers and exporters. There is a Chinese guild (not silk exchange) which regulates the quotations according to demand, production and fluctuations of the silver exchange, which is of great importance in China, where the monetary system is on the silver basis.

On account of the diversity of silks to be found in Shanghai, not speaking of the silk wastes, which inspection is very complicated, it is probably the most interesting market in the world for the raw silk student and inspector. At least, he may choose to be in a real western city during business hours, and at other times in the heart of Chinese life a few minutes from his office, beyond Bubbling Well Road. 
II.

\section{Raw Silk in the Canton Province}

As done previously for Japan filatures, I shall relate a trip to Macao in the province of Canton, which will give the reader a good idea of the raw silk business in South China.

Of all South China, the only filature that does not send its silks to Canton for inspection is the filature at Macao. The foreign buyers, as in days of old, have to make the trip especially for the purpose, and it gives them the opportunity of a very interesting journey.

Leaving Canton at seven A. M. on the little British steamer "Leun Shan," we come down the River Si Kiang via Whanpoa, and leaving Hong Kong at our left, we reach the open sea, navigating among a number of diminutive islands, the refuge of poor fishermen, whose numerous junks are all about. At noon we perceive the old lighthouse Guia, the first one built by Europeans on Chinese soil. Below, the semi-circular Macao bay appears, looking like a diminutive Monaco.

The Portuguese city is built on the flank of a mountain, on which summit the old forts are seen. The hotels and dwelling houses facing the sea, with their broad fronts and verandas painted in light rose, yellow or blue, present a charming view to the eye. We want to disembark at once, but the tide is always low on the Portuguese shore, and our steamer, turning the Boa Vista point brings us in full view of the old Chinese port, situated exactly on the other side of the mountain, showing a rare contrast of dirt against the pure beauty of the Portuguese coast.

We land at two P. M. and take lodging at an antiquated Chinese hostelry. Rickshaws, similar to those used at Shanghai or Yokohama, carry us along the narrow, filthy streets of the Chinese town. We pass the beautiful residences of the rich Cantonese merchants, who make of Macao a place of leisure. We see the numberless gambling houses which cause the city to be called the Chinese Monte Carlo, and the handsome revenue the Portuguese 
Government gets from each "fantan" is well appreciated in Lisbon.

Leaving the large and crowded Chinese city, an extraordinary sight awaits us on the other side-that of a little provincial town transplanted from Europe to China-old houses of the last two centuries, and except a few officials and the soldiers, a funny mixture of Portuguese and Chinese people, half castes of many generations old. Large and well-kept roads, public gardens, many Catholic churches and convents in the style of southern Europe; now and then Portuguese soldiers in gallant service uniforms of khaki. We pass the giant door of the ancient Cathedral San Paulo, half burned down by the mob years ago; the beautiful, silent and evergreen garden where Camoens wrote the Lusiades; the remains of the extensive prison house, where slaves were kept and exchanged when Portugal was Queen of the sea, and Macao called, by the great navigators, "Pearl of the Orient."

The Macao filature is not a first-class one. The quality of silk made there is but an Extra A. The building is entirely of wood. Judging from the appearance of its walls, it must be a hundred years old. The steam engine is near the entrance, and quite a quantity of steam waste is drying nearby. Some women are working the waste outside, opening same with large wooden hammers.

Let us observe, in passing, how waste silk is worked up in South China. The frisons obtained from the basins are in great quantity and very silky on account of the nature of the cocoon itself. These frisons, once dried, are distributed in small bundles to a number of women usually working at home. Each woman, laying the frisons in front of her, beats them hard with the hammer, so that the fibres, becoming soft, lose part of their gums. A long beating opens them perfectly. The woman, using her fingers, cleans and loosens the silk, making it perfectly neat. It looks then more like cotton and is very white. When she brings back the bundle a certain percentage of weight is allowed on each bundle for loss in dust and chrysalides. The loss is never of as much consequence as with Shanghai or Yokohama wastes. 
This quality is called by inspectors steam filature waste, opened, but an equal quantity is also sold unopened, with a difference of eight to ten Mexican dollars per pound. Nearly all of the waste business is in the hands of large manipulators, who buy the silk directly from the filatures and mix it themselves for their foreign customers.

Perhaps Canton is the only place in the world where no inspection is passed on silk waste by the foreign merchant as to quality, he being satisfied to see grosso modo if no straw or other stuff is shipped instead of silk.

In every case, the dealer guarantees not only the weight, but the quality, and is held responsible for any claim received within three months from the European or American buyer. In fact, the waste is classified like raw silk, and there is a difference of a few dollars per picul between one name and another on the same class of goods.

Coming back to our subject, there were about two hundred basins in the filature. The reeling system used was "Chambon two and four ends." Water was kept boiling in the basins, and the place, being unventilated and quite dark, it was not easy to distinguish what was going on in that heavy mist.

Notwithstanding the heat and absence of fresh air, the reeling girls were neatly dressed, using with dexterous hands a couple of chopsticks to pick up cocoons, follow the end and do other sundry work around the basins. The travelers were turning no more than $80 / 90$ revolutions a minute. The cocoons were of the small, hairy kind, without any consistence whatever.

Let us say here that the reason of the difference in the quality of Cantonese cocoons is entirely on account of the weather. The mulberry trees are especially strong in South China and cannot be affected by any variation of soil or weather, but the worms have a tendency to be lazy and sick during the hot days. The three first crops occur during the rainy and damp season of March to June, and the hatching houses cannot be protected from dampness. July to September are warm and dry, and the next crops are considerably better, the cocoons being less hairy and more consistent; but the best cocoons are hatched during 
the temperate weather of October and November, when the fifth and sixth crops are obtained. Sixth-crops are nearly equal to the northern cocoons, and would give the best results if they were reeled better.

The silk, being already dusty, and, further, reeled in dampness, cannot fail to show hard gums, especially on the spots touching the travelers. The cross reeling has been introduced only in one or two filatures and in the re-reeling establishments. To get rid of the gums, the great objection to Canton silks in America, every pound of silk ought to be re-reeled, and, if possible, cross-reeled, as pointed out by the Silk Association of America.

The Chinese are so slow that it takes years to induce them to make a change in their modus operandi as long as there is money to be made with an old system. It will probably be fifty years before they introduce the direct cross-reeling in their filatures. However, for a couple of years such reelers as Wing Cheong Sing, Tsung, Wai Hang, etc., have been reeling from selected cocoons with experienced help only; the price paid for their silks is over five per cent higher than for regular XXA crack chops. All filatures reeling for Americans have also adopted a smaller skein and gums are less hard than formerly.

After the reeling, the hanks were examined, made into skeins, sized and, according to the choice of cocoons, labeled first or second choice, then packed into bales of ten books each.

From Macao the silk is shipped on one of the steamers going to Hong Kong direct. When the inspection is made in Canton, the silk is conveyed from the country on junks, via the rivers and creeks. Those junks carry on board a couple of loaded guns and soldiers, armed to the teeth, in fear of the numerous pirates infesting Kwang Toung, who would find an easy market for the precious thread.

Work begins at five A. M. and continues during twelve hours. Each girl receives her bowl of food every three hours, and gets anywhere from ten to fifteen cents a day.

In Macao the Chinese are well used to strangers. We remember once in Lak Low, a small place quite far from Canton, while we were looking at the work of the reeling 
girls not an eye did we perceive raised to look at us; but once we got out of the place, turning suddenly, we saw a thousand eyes piercing every crevice of the old building, and we felt that the whole working crowd must have jumped from their seats and crushed themselves against the walls to peep with curiosity at the foreign devils.

In the Kwang Toung province there are about five hundred filatures of twenty-five to three hundred basins, including re-reeling establishments and assorting houses, where the hand-reeled silks are packed under the name of "Markets." Some filatures reel only for America (four corners) in the size of $14 / 16$. Those reeling for Europe (six corners) reel from $11 / 13$ to $30 / 40$. Such sizes as $18 / 20,20 / 22$ and $22 / 26$ have been introduced to America with good success. Occasionally a lot of $10 / 12$ is put on the market in Canton. That size has even been obtained in "Markets." The latter sell under a two, three or four kind standard, several sizes being sold together. The field for Canton silks is becoming larger in America on account of the tendency to use that thread to make wash fabrics of mixed cotton and silk, otherwise it is only used for crêpe and velvet.

The proprietor of the Macao filature invited us to a cup of tea in his office, which was furnished in a rather rudimentary way, consisting of a pile of old books, a counting board and a few chairs.

In the evening he took us to his private house, a real palace, where pavilions of gold and lacquer were distributed among the flowers of a marvellous garden. The dinner was served in a room of rose and white marble, decorated with odorous tea flowers dyed in different colors. As the fifty-ninth course was placed on the table the sing-song girls were yelling to a gong accompaniment, and our host had forgotten us in the opium fumes; we left the place in the early morning.

Out in the night we had at our right the European quarter, small, dark, and silent and at our left the contrast of the Chinese city, with its enormous activity, thousands of lights moving in the darkness, the distant music of the flowery restaurants, the immense red signs of the gambling 
houses-all the strange, emotional noises of an unknown world.

\section{Remarks on Canton Silks}

Perhaps no mulberry tree in the world is subject to as many calamities as the Cantonese. It is very small and grows everywhere, among rice fields, in marshy lands and along dirty creeks. Floods, typhoons, winds may come or the soil be washed away; if any diminutive piece of land is left over, the mulberry tree is there pointing its green leaves to be picked. The lazy Chinaman just comes to collect the food for his worms at the proper time. $\mathrm{He}$ could grow twice as many mulberry trees; he could improve them by working on a good piece of land. No! $\mathrm{He}$ is too slow for that. The tree has to live by itself; it will grow or be washed away. Nobody cares.

The Cantonese silkworms are like rich mandarins, fat and lazy. No change of climate affects them. Overfeeding or dysentery are their common enemies. They start making their cocoons in the same lazy way, and before they are settled to neat work they spit any amount of thread which has no consistence. That is why the Canton cocoons are so weak and produce so much waste.

It is certain that would the Cantonese pay more attention to the growing of mulberry trees and hatching of eggs, they could not only improve on their cocoons, but double the production, which has been stationary for a number of years, with a small overproduction some seasons and a large curtailage the next ones. This is when flood after flood has washed away the trees and turned them absolutely roots on top.

A Cantonese filature is a place of antiquity and dirt. Some of them use the "tavelette" system, but most of the filatures use the "Chambon $2 / 4$ bouts," because the hand filatures were improved by Frenchmen. The reeling girls are very clever. They do not throw the end with their fingers, but with chopsticks similar to the ones used in China to take food, and the way they twist, clean and follow up the thread with these tiny pieces of wood is wonderful. The water is usually kept boiling in the basins. 
Comparing the Cantonese with the Japanese filatures we see that the latter are clean, neat, ventilated, and in most cases lighted with electricity. (In the filature Kusanagisha at Kofu, Kai, an electric lamp is hanging right over every basin.) A Cantonese filature looks as if it has been in existence for centuries, the only thing recalling present times is the steam engine. Dirty walls, dark rooms, stingy oil lamps hanging from the ceiling,-it is a sight that recalls at once the conservative people of South China. How different are the Chinese of the north. They have been quick in placing their interests in foreign hands. Their now successful filatures on the European plan are reeling the finest brands that can be produced in the Far East. But nobody can induce the Cantonese to change his slow way. $\mathrm{He}$ does not care for wealth. He wants to manage his own business. He thinks that he will always be able to resell his products to his friends, if not to others.

The Cantonese raw silk is dusty and weak, the color is whitish to cream, the thread is generally very spongy and soft, so that it dyes perfectly. In Europe it is used currently in raw weaving, but American manufacturers cannot afford to work it that way.

In Europe, where labor is cheap, they use all Canton silks with profit, especially the kind called "paquetailles," or hand-made silks. They are usually sold under a threesized standard $11 / 13,13 / 15,14 / 18$. Some filatures are even able to make a four-sized standard, including $10 / 12$, which is very remarkable for such rough silks. Where European throwsters find their profit is in making a further choice of these kinds, enabling them to benefit by a larger number of fine-sized skeins than they are supposed to get.

The Canton silks cannot be compared with any athers. They are altogether inferior to China steam filatures and Japans in every way, not only because the cocoons are poor, but because no trouble is taken by the reelers to improve on their chops. However, the filatures are very faithful to their standard, and the buying is done, excepting when purchasing a new chop, without seeing the sample; simply on the chop's reputation, and whether the market goes up or down, the silk inspector is always certain to receive the silk he has 
bought; that is as it ought to be. If to the mind of the Chinaman his silk is not up to the grade, then only will he submit a sample for the inspector's approval. Such faith in the seller renders business easier and John Chinaman has the reputation of an honest tradesman in all the Far Eastern ports.

\section{New Style Cantons}

In the first (1913) edition of this book, page 125, I pointed out the great improvement that might be brought to Canton filatures by building re-reeling establishments, in view of increasing trade with America. This idea was taken up during 1918, probably under the leadership of a large Japanese organization, and the first lot of Canton re-reels or new style was received in the New York market in the Autumn of 1919.

After the silk has been reeled in the regular way, it is taken to a re-reeling establishment where it passes through the Grant cross-reeling process at a very high speed. Gums and weak spots are eliminated. American standard skeins are packed up in books and are worth nearly a dollar a pound more than old style skeins.

While Canton silk has a nature all its own, with careful reeling and cleaning, and the size being changed from $14 / 16$ to $13 / 15$, it bids fair to compete with low-grade Japans in piece dyed goods. Fifty per cent. of the crop is being re-reeled for American consumption.

III.

\section{Sericulture in Indo-China}

Sericulture is much in favor in the French Provinces of Indo-China, which include Tonkin, Annam, Laos and Cambodge. The mulberry tree is cultivated there from the sea to the mountains of the central section. The soil is so rich that usually the tree attains a height of six feet but a few months after the seeds have been put into the ground. The leaves can be picked at once and the natives are able to collect them during the period between April and November for the reason that when a tree has been 
stripped entirely bare of its leaves they grow again in a few days. It is an easy task to hatch the worms at all times and sometimes one hatching is started while another is in action.

The silkworm races are, of course, polyvoltins, the eggs hatching from eight to ten days after the laying down. The cocoons are never suffocated as often happens in the modern filatures of Europe and Japan, but reeled fresh. The hatchers sell some of the cocoons to dealers who resell them to filatures; while other lots are reeled in the homes and in the most rudimentary way. The whole apparatus. consists of an earthenware basin containing boiling water heated over a fire made of straw, as wood is far too expensive to be used for fuel.

The reeler, kneeling down before the basin, throws into the water some twenty to thirty cocoons and beats them with a pair of chop sticks until she has separated the waste from the cocoons. This ancient and.rather stupid way of treating the cocoons makes a considerable quantity of waste, and the result is that over thirty pounds of cocoons are often necessary to reel a single pound of raw silk. Furthermore, the reeler does not bother herself about the number of cocoons used in making the thread which is invariably irregular in size. The thread is wound on a small hexagonal winder without any crossing whatsoever and dirt and irregularities and double ends are the rule and not the exception.

Thus, the raw silk produced on these farms by native hands cannot be exported, but is consumed by the natives themselves and in many cases has to be re-reeled before it is used on the looms. The women handle the silk without the use of winders, simply reeling the silk on bobbins according to the thickness of the threads, a process to which they get accustomed to the extent of unerringly judging the threads as they pass through their fingers. With such irregular silks the natives, however, managed to weave all kinds of goods like taffetas, crepes, brocades and grenadines.

Such are the primitive ways of reeling found in IndoChina and in general in all of the provinces of China proper. 
and especially in those distant from the important centers, such as Shanghai and Canton, where the operators of the filatures have adopted foreign methods and improved machinery.

In 1904, a silk inspector from Canton, Mr. Emery, obtained a subsidy from the French Government, together with a tax exemption on all the mulberry trees grown upon Indo-Chinese soil.

Notices were distributed, printed in every language spoken in Tonkin, Laos and Annam, giving precise information to the farmers as to the growing of mulberry trees and the hatching of cocoons. To start the enterprise, several millions of silkworm eggs were distributed free to all who could be induced to engage in the work.

The cost of a reeling basin was two dollars, but all machinery was imported from Italy and France.

There are now several filatures, altogether one thousand basins, in Nam-Ding and Tai-Bing, producing a silk which is slightly superior to the Canton silk as to its nature, but greatly superior as to workmanship. It is appreciated on the Lyons market, the season's output being practically sold in advance.

This success was achieved without a large capital, but like every French enterprise, by constant plugging, small profits to begin with and plenty of governmental help.

It may serve as an illustration to American capital that silk reeling may be taken up and worked out to be a profitable enterprise as long as labor is cheap, plentiful and climatic conditions are right. 


\section{PART IV}

THE NEW YORK MARKET 



\section{CHAPTER I.}

\section{Improving the Raw Silk Business in New York}

UTSIDE of the season of great prosperity, which some say occurs every seven years, if you ask anyone connected with the silk trade, "How is business?" you will probably receive the same monotonous reply: "It is bad and getting worse."

There used to be a time, say twenty years ago, when silk men were pretty well satisfied with the business. Things were going on smoothly, profits were plentiful. Nowadays it seems that everybody, from the raw silk dealer to the weaver, is only too glad to make a living and the profits made out of the silk business do not justify the enormous capital involved in it.

There are many reasons why the silk business has a hard struggle for life. Of course, competition is keener than formerly; with the continually increasing number of looms in the mills, it takes a very prosperous year and fashion favoring silk to keep them all busy, and the competition is not restricted to silk manufacturers, for we have the mercerized cottons and artificial silks stronger than ever. The first to suffer by this state of affairs are naturally the raw silk importers.

This chapter is devoted to the relations between raw silk importers and manufacturers and offers some suggestions.

It is my opinion that raw silk business ought to be done on the letter of credit basis exclusively. Every firm on the New York market dealing in raw silk ought to have a branch in the different countries from which silk is imported: Italy, France, Japan, China. Instead of doing business over the counter with speculation as a basis and taking chances on the soundness of many buyers, the question of credits should be entirely left to the banks and unreliable 
customers would soon be eliminated from the face of the market.

There are, of course, very small buyers using now and then a few bales of silk. Such people would be taken care of by the thrown silk dealers as long as they could not give an order for at least five bales of raw. At the present time, I admit, it is almost impossible for raw silk importers to confine their business solely to the letter of credit basis. A,t least if there are a few firms doing so they are the exception and their success depends upon their organization on the primary markets.

The reason manufacturers buy on New York terms may be that they can discount at a high rate of interest, that they can' contract very far ahead, that they are assured the replacement from stock of lots that are not found satisfactory. The first reason does not count because buying on letter of credit basis is cheaper than otherwise since the raw silk importer mus,t take an extra commission when he sells New. York terms. Contracting far ahead is a very bad practice; it is nothing but speculation in most cases and should be allowed only when a manufacturer wants to control a certain chop or quality.

In regard to the third reason, let us say here that twothirds of the manufacturers would gladly buy against letter of credit if they knew that the raw silk dealers had the right organization on the other side and those who are known to have such organizations are doing a paying business. If the buyers know that they are going to receive from the other side exactly the quality they want they will certainly buy against letter of credit since it is cheaper to do so.

But why can't all raw silk importers confine themselves to letter of credit of business and buy directly from the producing countries? Because there is practically no understanding between the buyer in Japan (taking Japan as an example) and the seller in New York. The New York importer knows his customers. Among the innumerable grades to be found in Japanese silks nowadays he knows which quality, which lot, will fit better such and such customers. A certain Best No. 1 will do for Mr. A. and will not 
do for Mr. B. Mr. C. buys a good No. 1 for organzine and $\mathrm{Mr}$. D. wants the same to be thrown into tram. The salesman knows what kind of goods his customer is making and he sells him the raw accordingly.

Now the buyer in Japan knows nothing about it. He is asked by his New York correspondent to buy a Best No. 1 and he does so according to the old established rules that certain chops are recognized as Bes,t No. 1. Wouldn't it be better if the inspector in Japan knew the customers as well as the salesman in New York so as to ship always the quality required and guarantee the quality suitable for the use of the buyer?

Most of the time when an importer buys a lot of raw silk from anywhere he does not know what he is going to receive while he has to guarantee the quality to his own customer. He would know it if there was an understanding with the inspector providing that each lot is bought expressly for a stated customer, and to be used for a certain purpose.

It seems to me the raw silk importers ought to train their salesmen with a view of making them silk inspectors. By residing a couple of years in Japan or China and a couple of years in New York alternately, these men would be better posted and render more service than absolutely unknown inspectors from other countries. Here is a new profession for young Americans. Why not open a technical school similar to the silk institutes of Europe? Raw silk buying ought not to be a European specialty. Let Americans buy for America.

I am sure that raw silk importers having in their employ silk men of ability, knowing perfectly the requirements of all manufacturers, would be better off by sending them to Japan rather than by relying upon foreigners, who have absolutely no idea of our silk market.

The practice of raw silk inspection is not very difficult, and with a couple of years of training anybody can recognize very well the merits of silk as well as its defects, and when former experience is necessary there are yet enough inspectors in Japan to help the newcomers. If we refer strictly to buying and dealing, the American character and 
business training is vastly superior to the European. There is one thing certain; as soon as the buyer in Japan has to ship directly to the manufacturer and for a stated use, he will have to be careful, and reports of inspections will be made in such a way that the manufacturer will know the story of the silk he buys from $A$ to $Z$. It pains me to see some raw silk speculating organizations delivering lots of raw silk just as if they were Tiffany diamonds. They are all, every bale of them, equally perfect.

Here you are, Mr. Manufacturer. You may not find it exactly what you want. You may discover that it is very irregular; well, it is a matter of opinion. Just try another lot. This is decidedly not raw silk business. When the raw silk importers have their own men in Japan (and, by the way, in China, Canton, etc.), buying expressly for American requirements, there will be no objections to doing business against letter of credit.

The very small houses, those of poor standing or bad reputation will be systematically eliminated by the banks. The honest manufacturers will be served better, competition will be fairer, everybody buying on the same basis. The skill and originality of manufacturers will count first instead of the fool competition consisting of trying to sell cheaper than their neighbors, and, in order to do so, weaving unusable material. The winners will be those who, with the same material, costing about the same price, will turn out the most beautiful fabrics, the best combinations of the silk threads. Silk manufacture ought to be a work of brain and art instead of being either a gamble or a puzzle.

The golden age of the silk business may come back if we are willing to establish the whole trade on a sound basis. We are now placed in such a position that the base of it is speculation from beginning to end. There is no pleasure in a work that affords only deception and how could American silk goods have any originality when they are made by people whose main idea is to cut each others' throats!

I suggest a raw silk business conducted strictly on a letter of credit basis. If the letter of credit business is not practicable to be enforced as a rule, then terms should tend more and more to the cash transaction basis. 


\section{CHAPTER II. \\ Quilling and Coning}

\section{How to establish a Raw Silk Buying Agency in the Far East}

$A$ BUSINESS has come into existence during the last $A$ ten years and is now an important factor in the silk industry. This is the quilling and coning of silk by the raw silk importers themselves. The business has proved profitable to those who have engaged in it, and it seems that a bright future is ahead of those with efficient organizations, especially in the knit goods line.

\section{Quills}

Manufacturers of piece dyed goods, wash fabrics, insulated wire, tapestry and all mixed fabrics whether of cotton and silk or wool and silk, buy their silk on quills because their principal products are cotton or woolen fabrics which sell all the year round. When occasionally they make silk goods they cannot afford to wait for a raw silk to be thrown and so they buy the quills which are used as raw silk in stock. Wash fabrics manufacturers prepare their own warps of cotton or wool filling with bright silks like Cantons or Tsatlees. In domestic shantungs the fillings are made out of tussah four or eight cocoons and tussah natives fifty to one hundred and fifty deniers.

Quills are made either of wool, cardboard or paper. The wooden ones are returned to the throwsters after they have been once used. Paper cops are thrown away. The advantage of the former is their durability; that of the latter is the reduced freight expenses. Wooden quills cost fifty per cent. more than the paper. However, the silk either quilled on wood or paper is quoted at the same price to the buyer. The question of making aluminum cops cutting 
down the cost of freight and costing no more than wooden ones might well be considered.

The quills most commonly used by cotton mills are Canton single $22 / 26$, Canton double $14 / 16$, tussah eight cocoons 30-40 deniers, tussah natives 70-80 deniers, two threads, also $40 / 60$ to 200 deniers, Tsatlee two threads $18-20$ deniers and Japan No. $113 / 15$. The degree of twist varies with the customer. Nine tenths of cotton silk fabrics are woven thirtysix inches wide, but the quills are sold either boiled-off or in the gum; the boiled-off thrown silk loses twenty to twenty-two per cent., but the manufacturer does not get any shrinkage in his goods. That is, thirty-six inch fabrics are woven thirty-six, while with the ordinary thrown, to obtain thirty-six inches it is necessary to weave thirty-nine inches. On tussahs there is a difference of about twenty-five cents per pound between the ordinary and the boil-off thrown.

\section{Cones}

Manufacturers of silk knit goods, hosiery, ties, etc., have also found it to their advantage to buy thrown silk for hosiery, six to ten thread tram on cones of cardboard. Nearly all the knitting mills of Pennsylvania have taken up silk hosiery and buy a large quantity of tram stock (mostly Japan Best No. 1 and No. 1). It may be noted that this large consumption of tram stock by the knitting trade has been the direct cause of the shortage which occurs at certain times. The quantity of low grade raw silks imported to America has increased to enormous proportions.

In order to establish a quilling and coning business, it is necessary to have the co-operation of a raw silk importing house, a throwster and a dyer. At present the largest firms in that business are raw silk importers who own or control throwing plants. The establishment of a buying agency in the Far East is really the small end of it, as it requires little capital to engage in such an enterprise and the profits are large. Many people think that opening a branch in Japan and China involves great expense. On the contrary, a very small capital is needed, provided, of course, that the firm or representative in New York has a sufficient outlet to cover running expenses. A house not in 
position to dispose of one thousand bales of silk a year could not possibly maintain an office in Asia, but very few firms indeed sell less than that quantity. The cost of establishing a branch in Japan is as follows:

Installing of inspector $\ldots \ldots \ldots \ldots \ldots \ldots \ldots \ldots$ yen 3,000

Machinery ..................... 1,000

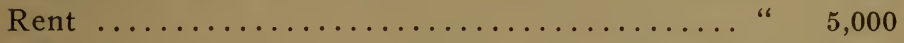

Salary of Inspector $\ldots \ldots \ldots \ldots \ldots \ldots \ldots \ldots \ldots \ldots$ " 10,000

Salary of Assistant ................. 3,000

Japanese staff $\ldots \ldots \ldots \ldots \ldots \ldots \ldots \ldots \ldots \ldots \ldots \ldots$ " 1,000

Office expense $\ldots \ldots \ldots \ldots \ldots \ldots \ldots \ldots \ldots \ldots \ldots \ldots \ldots \ldots \ldots$

Total $\ldots \ldots \ldots \ldots \ldots \ldots \ldots \ldots \ldots$ yen 25,000

The second year the expense would be about yen 4,000 less. The cash needed to open an office in Yokohama would be half the above, or about $\$ 5,000$.

Profits, 1,000 bales at yen 1,500 , yen $1,500,000$ at

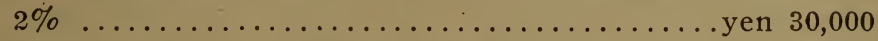

Extra profits in purchasing $1 / 2 \%$ or......... 7,500

yen 37,500

Less expenses $\ldots \ldots \ldots \ldots \ldots \ldots \ldots \ldots \ldots \ldots$ " 25,000

Net profit $\ldots \ldots \ldots \ldots \ldots \ldots \ldots \ldots \ldots$ yen 12,500

If the New York house, or importer, before making any profit on the sales gets a return commission of about $\$ 5,000$ for every one thousand bales, the establishment of a direct agency in the Far East is well worth considering. As soon as the importation reaches three thousand bales it becomes a good paying proposition even with a reduced commission of one per cent. or less. Of course, the above profits are taken to be strictly without speculation, as it may happen that an element of speculation introduced in the business may increase or decrease the profits considerably.

In China, Shanghai or Canton, expenses run about the same.

It can be seen from the above that a firm doing a strictly letter of credit business can well afford to work at 
a very small commission and still make a handsome profit as soon as the importation reaches around five thousand bales.

If the raw silk importer is also a throwster, he must own a sufficient number of spindles to be ready at any moment to take an order for a current or specialized quality. It is a fact that the cotton mills sometimes pay higher prices to the man who can accommodate them on the instant, and quill dealers are known to have missed business very often through their inability to contract for the required deliveries. It is in the throwing end of the business that capital is needed. The following figures show an approximate estimate of the cost of establishing a plant with a capacity of two thousand five hundred pounds of tram stock on quills per week, say, in two threads $28 / 30$ deniers:

\section{Winding and Throwing.}

1 Swift per week winds $1.7637 \mathrm{lbs}$. (including waste).

2,500 lbs. equals 1.7637 plus 1,400 Swifts (approximately). For doubling and winding 700 spindles.

1 Spindle (second turn) produces per day 60 grams, say, for a 55-hour week:

Second turn, 3,100 spindles.

$1 / 2$ more for First Turn, 4,600 spindles.

\section{Quilling.}

1 cop equals 15 grams silk.

8 cops per day per spindle equals 120 grams by 55 hours per week equals 660 grams or 1,530 quilling spindles.

\section{Cost (1914).}

Winder with 40 spindles costs $\$ 200$ (2,100 spindles). . $\$ 10,500$ Throwing spindles, 7,700 at $\$ 3.00 \ldots \ldots \ldots \ldots \ldots \ldots 23,100$ Quilling spindles, 1,530 at $\$ 7.50 \ldots \ldots \ldots \ldots \ldots \ldots \ldots 11,475$

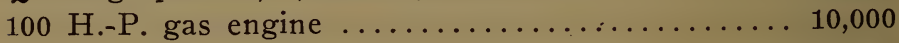
Transmission, shafting $\ldots \ldots \ldots \ldots \ldots \ldots \ldots \ldots \ldots \ldots, \quad 5,000$ Soaking and drying apparatus............... 1,000 Building and Sundries, approximating ......... 15,000 
If a number of coning machines is added, the capital involved would be large.

While the establishment of a Chinese or Japanese agency does not call for much capital, it must not be forgotten that in order to be ready for any call, the firm must carry some stock in all kinds of raws besides what is imported against contract. The whole thing means at least $\$ 200,000$ to carry on both raw and thrown silks. It would mean much less to an importer giving the silk to be thrown outside but also less profits.

The combination of profits first on the raw, then on the thrown, then on the weight, ought to leave an average of five per cent per pound. In some cases it reaches ten per cent. On the other hand, competition is already becoming very keen as the number of dealers in quills and cones is increasing all the time, but the field still is large for those, who, being well started, can follow the requirements of fashion, as at present the hosiery manufacturers require Japan tram principally and the New England cotton manufacturer requires Japan No. $113 / 15$ and $14 / 16$ and Canton $22 / 26$ double extra $B$ for their mixed fabrics, not mentioning a steady call for tussah and Tsatlee silks. 


\section{CHAPTER III:}

\section{The Making of a Raw Silk Salesman}

$\mathrm{T}$ O sell raw silk is like selling cotton or wool for a born salesman because a born salesman will make good in any line, being gifted by nature with such essential characteristics as personality, magnetism and will power. In order to be entirely successful in selling raw silk he must also possess intelligence and a fair knowledge of the subject, as to how raw silk is made and generally dealt with in the producing countries, and what each grade and size can be used for.

If he has these qualities, a man ought to be able to make large sales, provided he has something to sell. Because one must remember that if even such a well equipped man was trying to sell for a firm that was not prepared to meet all the requirements of the trade-that is, dealing in all the qualities that are in demand and carrying a reasonable stock-he would be wasting his ability and achieve no results.

Let us study the possibilities of a salesman from a manager's point of view, if we were to engage one on the spot. We have buying agencies in China and Japan and we need two young men to push the business which, for some reason, has been losing ground lately.

Several salesmen apply. Those who know nothing of raw silk we dismiss with the exception of one who has been successful in some other line, and who has impressed us with his very fine appearance and an unmistakable air of distinction and confidence. From the others who know about raw silk we select a young man who manifested an earnest desire of selling more if given a better chance. We eliminated many others who had some of the necessary qualities but not in any marked degree, and they were unable to show us either through their conversation or 
past performances the proof that they would be likely to make good.

The two young men are started at a good salary, plus a percentage on their respective amount of business, because emulation always pays a firm and a man who is interested in his own profit will work more and better than one who is limited by a fixed salary.

In distributing the customers we have wisely given to the salesman of ability (but who does not know raw silk) those who are difficult, but who rely upon themselves to select the silk they need. To the salesman who knows the possibilities of raw silk we have given the customers that have to be coached in their purchases and who need to have confidence in the salesman's knowledge before they place their orders.

Being ourselves sure of the needs of the firm's customers, we never forget to direct our two salesmen, posting them on what Mr. So-and-So may be interested in, also what might be offered at an attractive price.

The manager of a firm, the one who is the brain and buying and selling power, sometimes forgets that he is the general and that his lieutenants are practically carrying his messages. We may put down in passing the following axiom:

"It is not expected that a salesman can make good if his employer does not make good."

Our firm, as was mentioned before, has branches in China and Japan, which is the only proper way to carry on a raw silk business, and at the time we established these branches we engaged local inspectors over there, but after a few months we sent a young man to Japan from our selling staff and after two years' experience he turned out to be a very good assistant-so much so, in fact, that in the absence of our regular inspector who is now here on a vacation, he is filling the position. However, we do not expect to leave him there because he is too good a salesman to be wasted on silk inspection, but what he has acquired in knowledge of the silk, will give him a tremendous confidence which will add to his ability to sell for us. We will have him back after a while and send in his place 
our young man who needs to know what raw silk is made of. We would not do this if the young man had not proved his ability beyond question, and we know that everybody will gain by such action.

It is evident that a buyer knowing exactly what the requirements are for each one of his customers will be better posted than one who has never visited the New York market. This is why our salesmen are sent to the buying markets every two or three years to buy and inspect raw silk, and that by this continuous exchange of position they know that their customers by being better served, will place their utmost confidence in them.

We are, however, diverging from the question of salesmanship which we are here to study.

How can a salesman make good if he has only the average qualifications? If you question a very successful one, he will probably answer either that he cannot help selling, no matter what, or that he is working hard to attain success.

Now we do not believe in any of the above answers taken singly, but they are both partly true. It requires as much brain work to sell any kind of goods, as it required to construct the Woolworth Building. However big the comparison seems, if you go to the bottom of it, you will find that the salesman who understands his business and makes good, is constantly awake and planning the possibilities of further business. Another axiom that holds good is:

"A manager who treats salesmen like brainless machines cannot train good salesmen."

There is no man, unless he possesses the power of suggestion, who can sell at first sight; and no one can sell without the authority which comes from the knowledge of his subject.

To dress as well as you can and try to look distinguished is certainly good advice. A man may look like a farmer all his life if he wants to. That many buyers are impressed by the personal appearance of a salesman is a fact recognized by all.

Speak of your subject with authority. Try to be always 
sure of what you propose to your customer. See that the quality you offer is what you say it is, and that you are sure of the price. Do not give the buyer the impression that you have to consult somebody else about it because your wise buyer will think that he will get you.

Try always to know when the mills will be in need of raw silk, what they are making and what they need to make it with. Be on the spot when they are in the market.

Do not confine your study to raw silk, but study also manufacturing so that you will know better what kinds of raw silks are actually going to be used. By advising the buyer in advance it will give you a chance to sell at the proper time.

Above all study your customers. They may all buy the same thing but they do not buy it in the same way. Remember that if you are not gifted to judge a man at first sight you had better make a close study of your man so as to get as near his heart as possible.

Aside from the question that your prices are attractive and that you know all about the raw silk business, your relations with the buyers go to make the success of your firm. In America more than anywhere else, the larger part of the tremendous business transacted is between friends. Make friends then. It pays! Customers like to be called upon often and advised as much as possible. Try to give valuable information about market fluctuations and the trend of fashion.

It is better to miss a sale at the cost of giving good advice, because it will pay in the long run.

Impress your customer with the idea that you are working for his own good. Try to have his confidence so that your advice will be valuable to him and he will depend upon you to look after his interests when he buys silks from you.

Never misrepresent the goods that you are selling. Do not offer them to a manufacturer that you know cannot use them or will experience difficulties in the mill. Better use your brain and see who could use the goods without question.

Dignity and honesty are the basis of your business career 
and you should not sell what you consider is not proper to sell under any circumstances or denomination.

Remember that if you are successful now, even with all your fine qualifications, you may not be tomorrow, but that if you have a straightforward reputation you will be successful in the long run. 


\section{CHAPTER IV.}

\section{Raw Silks Used in New York}

\section{Japans}

A LL American manufacturers use Japans for their $\mathrm{A}$ fabrics. Half of them use no other silk. The following qualities and sizes are imported all the year round:

\section{Filatures}

$\begin{array}{llllll}\text { Double extras } \ldots 10 / 12 & 11 / 13 & 12 / 14 & 13 / 15 & 14 / 16 & 16 / 18\end{array}$ $20 / 22$

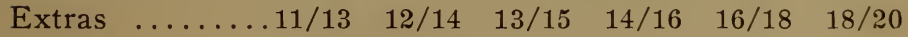
$20 / 22 \quad 24 / 26 \quad 28 / 30 \quad 30 / 32 \quad 34 / 36$

Best No. $1 \ldots \ldots 13 / 15 \quad 14 / 16 \quad 16 / 18 \quad 18 / 20 \quad 20 / 22 \quad 24 / 26$ $28 / 30$

No. $1 \ldots \ldots \ldots 13 / 15 \quad 13 / 16 \quad 14 / 16$

Above sizes apply to intermediate qualities.

\section{Chinas}

Manufacturers of tulle and mousseline are now buying a fair quantity of high-class fine-sized filatures. Coarse sizes are more reliable than white Italians at equal prices. Chinas are suitable for all purposes and superior to Japans in sizes below $13 / 15$.

Extras $\ldots \ldots .9 .9 / 11 \quad 10 / 12 \quad 11 / 13 \quad 12 / 14 \quad 13 / 15 \quad 14 / 16$ $16 / 18 \quad 20 / 22$

Best No. $1 \ldots \ldots 10 / 12 \quad 11 / 13 \quad 12 / 14 \quad 13 / 15 \quad 14 / 16 \quad 16 / 18$ $18 / 20 \quad 20 / 22 \quad 24 / 26$

No. $1 \ldots \ldots \ldots 13 / 15 \quad 14 / 16$

\section{Tsatlees}

This class of silk is bought exclusively by the sewing silk manufacturers. The sizes of the many grades are all irregular and coarse from $16 / 20$ to $26 / 30$. 


\section{Tussah}

This class of wild silk is used largely by carpet manufacturers, the cotton mills, for mixed fabrics, the insulating wire mills, and for shantungs and pongee imitations. The usual size of eight cocoons silks best grades is $30 / 40$ deniers. A small quantity of low grade tussah, native and waterreels, in very coarse sizes up to 500 deniers is imported for fancy tussor imitations.

\section{Cantons}

The crêpe de Chine and velvet mills take up the largest quantity of Cantons in size $14 / 16$, in the grades XXA crack and ordinary. New style $14 / 16$ and $20 / 22$ is used in piece dyed goods and Jacquard weaves in substitution for Tsatlees and mixing with Japan threads.

The New England cotton mills buy Canton on quills quality $\mathrm{XXB}$ in the sizes $14 / 16$ and $22 / 26$.

\section{Yellow Italians}

Two-thirds of the Italian silks imported to New York are for single weaving and enter into the manufacture of high class goods, mostly satins. The qualities called Extra Classical and Classical are reeled in sizes from $10 / 12$ to $28 / 30$ and sizes in between. Sizes $12 / 14$ and finer are used more for organzine in the better grades. Best No. 1 and Realinas are made into warps and sold on beams to the cotton mills for their mixed fabrics, the sizes ranging from $14 / 16$ and above.

\section{White Italians}

Raw silks called white Italians are spun in Italy from Levant cocoons. The best are Extra Adrianople, which are used in the very fine sizes for the same purposes as Chinas. The Brussa and Turkestans reeled in coarse sizes may be attractive if offered at prices meeting the Japanese competition. When conditions in the Near East are righted again, much can be done in sericulture and filatures in general for direct exportation to America. 


\section{CLASSIFICATIONS}




\section{Classifications}

Grades of Italian Silks Generally Imported to New York. Yellow

Per lb.

Grand Extra Classical like Caru.............. $\$ 4.30$

Best Extra Classical like Chicco Fossano.......... 4.20

Extra A, like $\quad\left\{\begin{array}{l}\text { Diana, Ello, Sormani } \\ \text { Lancenigo oro ............ } 4.10\end{array}\right.$

Extra B, like

$\left\{\begin{array}{l}\text { Chiari, Padovani, Brunich } \\ \text { Frizzi Udine, }\end{array}\right.$

Cornaredo Dubini, Palmanova. 4.00

Extra to Classical, like $\{$ Piva ancora, Arsene, Frova

$\{$ San Martino, Pordenone ..... 3.95

Classical, like

$\left\{\begin{array}{l}\text { Arzignano, Belgioioso, } \\ \text { Sanazzaro, Marcato, } \\ \text { Casalbuttano ............ }\end{array}\right.$

Best No. 1, like $\quad\left\{\begin{array}{l}\text { Artiero, Rivergaro, Vittorio } \\ \text { Cologna .................... } 3.80\end{array}\right.$

Qualities from Grand Extra down to Classical are good for single weaving. The quality Best No. 1 and lower grades like Realinas are imported only in comparatively small quantities for organzine.

\section{White}

The best cocoons from Italy, Messina and Adrianople, reeled by Italian filatures have the same grading as yellow cocoons. Whitish Turkestan, also reeled in Italy, comes to New York in coarse sizes in the qualities Extra and Classical (first and second choices). Prices compared with yellow silks, extra $\$ 3.70$; classical $\$ 3.60$.

\section{JAPAN}

In the 1913 edition I gave an extensive list of Japanese filatures, the so-called Kansai, Sinshiu and Re-reels being given separately. Since re-reels are bound to disappear and Sinshiu is generally accepted without specification, the fol- 
lowing is the correct classification of Japanese raws on the New York market:

Comparative Prices in Yen.

Grand Double Extra, like

Kawano, gold turtle

Muroyama, hive ...........yen 1000

Double Extra A, like $\left\{\begin{array}{l}\text { Hodono, dancing girl } \\ \text { Gunze, pheasant ......... yen } 980\end{array}\right.$

Double Extra B, like $\left\{\begin{array}{l}\text { Yoneya, stork } \\ \text { Yamanashi, crow }\end{array}\right.$ 960

Best Extra, like

SKinposha, kirin

\{Nanpokan, peacock .......yen 950

Extra, like

SKusanageisha, money bag

Best No. 1 to

YYamatogumi, 3 gold rings.yen 940

Extra, like

SHakuosha, iris

\{Okaya, sun ............ 930

Best. No. 1, like

SHosansha, peony

Fukokukan, turtle ........yen 920

No. 1 hard nature, like $\left\{\begin{array}{l}\text { Hayashi, cup of gold } \\ \text { Yamato, } 3 \text { fans .......... } 900\end{array}\right.$

No. 1-1/2 Yoko- $\quad$ Nipponsha, gold peach boy

hama jo-ichi, like $\{$ Katakura, gold diamond ...yen 890

No. $1 \frac{1}{2}$, like

SNipponsha, silver

$\{$ Katakura, silver ...........yen 885

The above are understood to be white silks. Yellow silks have the same classification but are sold at a lower price.

\section{Kakeda}

Gold Cup, size about

Lady

11 to 12 prices in yen.

One Horse

12 to 13

900

$$
13 \text { to } 14 \mathrm{I} / 2
$$

870

Two Horses

Three Horses

$13 \mathrm{r} / 2$ to $15 \mathrm{I} / 2$

850

14 to 16

830

Chickens

16 to 17

810

17 to 18

790

770

A small quantity of the three first chops are imported to America. 


\section{Tamaito (Doppioni)}

\section{Sanshu}

Cherry Flower, size about $20 / 25$

Maple

$30 / 50$

Peacock

$30 / 50$

Five Doves

$30 / 55$

Chicken

$35 / 55$

Rose

$40 / 50$

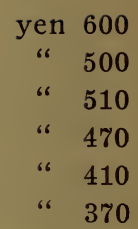

A good sized quantity of the Rose chop is imported to America.

\section{Oshu}

One bamboo, size about

$25 / 35$

Two bamboos

$35 / 45$

Djoshu.

Extra, size about

1

2

3

$180 / 200$
above 200
"“

yen 250

" 220

“ 190

“ 150

\section{CHINA}

Steam Filatures. Comparative Prices in Taels.

Double Extra, like $\quad\{$ Sin Cheong, factory

$\{$ Soy Lun, anchor .........880

Extra, like

YYuen Zen, centaur

$\{$ Yah Ha, W. T. K........ 860

Best No. 1 to

Extra, like

Best No. 1, like

Koon Tai, mulberry

$\{$ Dah Lun, stork .......... 840

K Kin Zen, geranium

Soy Fong, mountain .......8 820

No. 1, like

YYoung Tai, deer

Chue Zen, fountain ........800

No. $1-1 \frac{1}{2}$, like

Ting Yue, jacquard

\{Yuen Fong, moon star ...... 780

No. 2, like

$\{$ Zee Lun, parrot

$\{$ Chue Zen, sampan ........760

No. 3, like 
Szechuen, Mienchu and Shantung filatures, whether Shanghai or Japan style, are used in too small quantity on the New York market to be classified.

\section{Classification of Shanghai' Re-reels}

\section{Crack Chops}

Comparative Prices in Taels.

May Hun Yee

May Hun Yee.

May Hun Yee

May Hun Yee

Shing Hwa

Woo Son Dong

Zun Kee

Tai Kong

Pee Van May

Pee Van May

Tai Shing

Yin Kee

Chur Yue Mow

Mow Kee

Zung Kee

Yue Chong Zung

Hung May Chong

Yung May

Tuck Wah Chang

Sze Sze Shing

Tai Chang Foo Kee

Shou Soo Shing

Ching Kee

Sun E. Tah

Zee Shing

See May Zee

Foh May Yue
Gold Eagle \& Bell Ex.1.2. 660/50/40

Blue Dragon

Almond Flower \& Moon “

Red Almond Flower “

Gold Dragon

Gold Dollar

Stars and Stripes

Lion and Scale

Two Gold Swallows Ex.1.2

Old Black Horse

Solstice

Blue Monster

Gold Fish

Double Gold Eagle

A.B.C.

Ex.1.2

Dragon and Flag

Gold Peacock

Gold H Mark

Gold Zebra

Five Lions

Cloud and Lion

Gold Motor Car

Flying Eagle, Gold Silver\&Red 630/20/10

Three Gold Josses Ex.1.2

Red Mark

A.B.C.

$640 / 30 / 20$

Galley Red, Blue, Black 625/15/05

Gold Sycee Boy Ex.1.2 615/05/595

Gold Riding Horse $\quad 1.2 .3$ 
Middling Chops.

May Hun Yee May Hun Yee May Hun Yee May Hun Yee Shing Hwa

Woo Son Dong Zun Zee

Tai Kong

Pee Van May

Pee Van May

Tai Shing

Yin Yee

Chur Yue Mow

Mow Kee

Zung Kee

Yue Chong Zung Hung May Chong

Yung May

Tuck Wah Chang

Sze Sze Shing

Tai Chong Foo Kee Shou Soo Shing Ching Kee

Sun E. Tah

Zee Ching

Zee May Zee

Foh May Zue

May Hun Yee

May Hun Yee

Yin Kee

$Y$ in Kee

Foh $\mathrm{Mu}$ Yee
Silver Eagle \& Bell Ex.1.2

Feima or Flying Horse

Almond Flower \& Stone "

Green Almond Flower “

Gold Pagoda or

Gold Crown

Fountain

Red Indian

Sheep and Flag

Two Silver Swallows Ex.1.2

Old Yellow Horse

Two Globes

Silver Fish

Race Horse

Double Silver Eagle

Wild Man

Silver Peacock

Silver H. Mark

Silver Zebra

Leopard

Flying Stork

Silver Motor Car

Horse Gold, Silver \& Red 600/590/580

Three Silver Josses Ex.1.2

Blue Mark

Dragon Boat

A.B.C.

Silver Sycee Boy

1.2.3 595/585/575

Silver Riding Horse

Ex.1.2 585/75/65

Blue Eagle and Bell

Gold Mowtai Peony

Gold Kangaroo

Flying Dragon

1.2 .3

$605 / 595 / 585$

Ex.1.2 610/00/590

$1.2 .3 \quad 600 / 590 / 80$

Blue Horse
Ex.1.2

1.2 .3

66
$630 / 20 / 10$

6

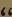

66

66

66

66

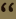

66

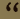

if

66
$590 / 80 / 70$ 
Common Chops

Shing Hwa

May Hun Yee

Sze Yu Ching

Yue Chong Zung

Yin Kee

Taichong Too Kee

Pee Van May

“

Yah Kee

Sze Sze Shing

"

66

Tak Kong

Lun Kee

Ho Foh Nien

Sin Chong

May Hun Yee

Yung May

Yoa Dai Zung

Sze Sze Shing

Tsun Kee

Zung Kee

May Hun Yee

Pee Van May

Sze Sze Shing

Chin Tah

Yah Kee

“

“

May Hun Yee

Tsun Kee

Tsze Yue Ching

Tai Kong

Yue Chang Zung

Foo Kee

Foh May Yue

Shing Hwa

King Kee
Columbia

Black Lion

Three Arrows

Red Peacock

Gold Dollar

Gold Eagle \& Skein

Old White Horse

Two Red Swallows

Wild Dragon

Small Buffalo

Gold Stork

Gold Phoenix

Oregon

Moon and Fairy

Gold Watch

Gold Buffalo

Black Mowtai Peony

Blue Zebra

Red Elephant

Mars S.S.S.

Black Hand

Medal

Water Lily Flower

Two Black Swallows Ex.1.2

Silver Stork

Double Mars S.S.S.

Gold Mars

Shield \& Flag

Arrow \& Bow

Blue Star

Yellow Lion

Clock

Crossed Flags

Woman \& Loom

Soleil

1.2 .3

Ex.1.2 575/565/555

1.2.3 $570 / 560 / 550$

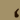

$1.2560 / 550$

Ex.1.2 560/550/540

“

"

$1.2 .3555 / 545 / 535$

$1.2555 / 545$

$1.2 .3555 / 545 / 535$

$1.2555 / 545$

Black Double Guns

Red Riding Horse

Gold Cash

Savage
$1.2 .3550 / 540 / 530$

$1.2540 / 530$ 


\section{Classification of Tsatlee Cross-reels}

Extra Best Chops

Comparative Prices in Taels.

May Hun Yee

Woo Son Dong "

Sun Pai Zan 66

Vee Kee

s6

Chur Yue May "6

Yin Kee 66

So Yuet Kee "6

Soh Sun Meh e6

Sun Chin Kee

Chee Kee

Sun E Tah

Tai Chang Foo Kee

Lee Hun Tah
$\mathrm{H}$ Blue Dragon

H Feima or Flying Horse “ $610 / 600 / 590$ Gold Butterfly Butterfly and Almond Flower

Fighting Cock

Cock and Centipede Old Man

Double Man

H Blue Monster

$\mathrm{H}$ Race Horse

$\mathrm{H}$ Gold Fish

H Silver Fish Cloud \& Stork Blue Lion Cat \& Gold Butterfly Ex.1.2 620/610/600 Cat and Bee Extra Chops.

Plough

Gold Hand Skein

Sun E Tah

$1.2 .3630 / 620 / 610$

Ex.1.2 640/630/620

“ $600 / 590 / 580$

A.B.C. $630 / 620 / 610$

$1.2 .3600 / 590 / 580$

Ex.1.2 630/620/610

$1.2 .3600 / 590 / 580$

Ex.1.2 630/20/10

" $600 / 590 / 80$

" $625 / 15 / 05$

" $595 / 85 / 75$

“ $620 / 610 / 590$

$1.2 .3590 / 580 / 570$

$1.2 .3590 / 580 / 570$

$1.2 .3600 / 590 / 580$

A.B.C.

Ex.1.2.3 600/590/580/570

Gold Flying Dragon " Good 1 Chops.

Sze Sze Shing H Buffalo Ex.A.B.C. 580/570/560/550 "

Pee Van May

H Pegasus Ex.1.2.3

H Black Horse "

Tai Chang Foo Kee Bicycle

Nien Kee

Yee Tsun

$\mathrm{H}$ Grasshopper

Ex.A.B.C.D. $580 / 570 / 560 / 550 / 540$ Gold Pheasant

\subsubsection{580/570/560/550}

Chun Kee 
Shou Yuet Kee

Shee $Y$ in Kee

Sing Cheong

Lee Hun Tah
Blue Lion

Flying Tiger

$$
\text { A.B.C.D. } 580 / 570 / 560 / 550
$$

Red Eagle Ex.1.2.3

Double Fish Ex.1.2

No. 1 Chops.

Tai Chang Foo Kee

Lee Kee

Gold Goat 1.2.3.4 560/550/540/530

Yellow Tiger

$$
\text { 1.2.3.4 }
$$

Sze Sze Shing H Small Buffalo

Pee Yin Tah

$\mathrm{Y}$ in Kee

Gold Tiger

Ex.1.2 560/550/540

Pee Van May

H Gold Dollar

H Gold Mars

Tai Chang Foo Kee Eagle and
6
$1.2 .3550 / 540 / 530$

Ex.1.2

66
Tah Kong

Sze Sze Shing

So Yuet Kee

Tsung Mue

Chun Tah

Yue Chang Zung

Oregon

H Mars SiS

Marks SYK

$\mathrm{H}$ White Horse

Ex.1.2.3.4 545/535/525/515/505

H Gold Mars Ex.1.2

Gold Unicorn

Ex.1.2 540/530/520

No. 2 Chops.

Kee Dah

Kung Kee

Tai Chang Foo Kee

Ying Kee

Sze Sze Shing

Soo Kee
Mercury Ex.1.2 535/525/515

H Mars

Genet

H Star \& Cloud

Steam Boat

Double Birds “

$1.2530 / 520$

"6

" $520 / 510$

" "

"6
6

66

$545 / 535 / 525$

"6

$\mathrm{H}$ means that these chops produce also Heineens of same classification. 


\section{Tussah Filatures}

Extra

like $\left\{\begin{array}{l}\text { Black Pagoda } \\ \text { Double Dragons }\end{array}\right.$

Taels.

Best No. 1

like $\left\{\begin{array}{l}\text { Black Magpie } \\ \text { Worm and Leaf }\end{array}\right.$

310

300

No. 1

like $\left\{\begin{array}{l}\text { Gold Toad } \\ \text { Single Deer }\end{array}\right.$

290

No. $1-1 \frac{1}{2}$

like $\left\{\begin{array}{l}\text { Black Fir Tree } \\ \text { Lighthouse }\end{array}\right.$

No. 2

like $\left\{\begin{array}{l}\text { Gold Watch } \\ \text { Five Stars }\end{array}\right.$

280

270

No. 3

like $\left\{\begin{array}{l}\text { Green Locomotive } \\ \text { Blue Cash }\end{array}\right.$

250

\section{CANTON FILATURES}

Mex. \$

Special Double Extra

like $\left\{\begin{array}{l}\text { Wing Cheong Seng } \\ \text { Tsung Wai Hang }\end{array}\right.$

840

Extra Extra A, Cracks like $\left\{\begin{array}{l}\text { King Seng } \\ \text { Mee Kee }\end{array}\right.$

800

Extra Extra A

like $\left\{\begin{array}{l}\text { Kwong Shun Cheong } \\ \text { Kwong Wo Hing }\end{array}\right.$

Extra Extra B, Cracks like $\left\{\begin{array}{l}\text { Kwong Seng } \\ Y u \text { King }\end{array}\right.$

Extra Extra B like $\left\{\begin{array}{l}\text { King Shing } \\ \text { U Hau Cheong }\end{array}\right.$

Extra A like $\left\{\begin{array}{l}\text { Soey Lun } \\ \text { Fook Kee }\end{array}\right.$

Extra. B like $\left\{\begin{array}{l}\text { Kum King } \\ \text { Hip Kee }\end{array}\right.$

New style or re-reeled filatures are worth about (Mex.) $\$ 100$ more per bale. 
RAW SilK FirmS OF THE WORLD 


\section{Raw Silk Firms \\ Raw and Waste Silk Exporters in the Far East.}

YoKOHAMA

Bavier \& Co.

Buisson, A.

Compagnie Generale d'Extreme Orient.

Comptoirs Soies

Cornes \& Co.

Dourille \& Co., P.

Eymard \& Co., C.

General Silk Importing Co., Inc.

Isaacs \& Co., S., Ltd.

Jardine, Matheson \& Co., Ltd.

Jewett \& Bent

Nabholz \& Co.

Pfister \& Co., R.

Pila \& Co.

Piq \& Cie., C.

Samuel Samuel \& Co., Ltd.

Siber, Hegner \& Co.

Strahler \& Co., F.

Sulzer, Rudolph \& Co.

Villa Bros. of Japan, Ltd.

Vivanti Bros.

Zellweger \& Co., E., S.A.

Gosho Kabushiki Kaisha.

Hara Yushutsuten

International Trading Corporation

Kuhara Trading Co., Ltd.

Mitsui Bussan Kwaisha

Mitsubishi \& Co.

Nichi-Bei Shoji Kabushiki Kaisha

Ono \& Co.

Shinyei \& Co.

Suzuki \& Co.

Takata \& Co.

Yokohama Ki-ito Kwaisha, Ltd. 


\section{ShaNGHAI}

A. Arnaud-Coste \& R. V. Dent

Arnhold Brothers \& Co., Ltd.

Azadian, Jacques

Boyer, Mazet \& Co.

R. Pfister \& Co.

General Silk Importing Company

Burkhardt, Amidani \& Co.

Burkhill \& Sons, A. R.

Carisio, C.

China Silk \& Agency Co., Ltd., The

Clerici, Bedoni \& Co.

Codsi Freres

Dyce \& Co.

Goyet, E.

Heffer \& Co., F. C.

Huber \& Co., E.

Jardine, Matheson \& Co., Ltd.

Little \& Co., William

Madier Freres

Marthoud Freres

Mitsui Bussan Kaisha, Ltd.

Nabholz \& Co.

Patel \& Co., A. C.

Paturel, C.

Probst, Hanbury \& Co., Ltd.

Puthod, A.

Rayner, Heusser \& Co.

Reiss \& Co.

Rheims \& Rini

Sassoon \& Co., Ltd., David

Sauvayre, J.

Shahmoon, E. E.

Somekh \& Co., B. A.

Sulzer, Rudolph \& Co.

Suzuki \& Co.

Tata Sons \& Co.

Villa Bros. of Shanghai, Ltd. 


\section{Canton}

Arnhold Bros. \& Co., Ltd.

Boyer, Mazet, \& Co.

Compagnie Generale d'Extreme Orient

Deacon \& Co., Ltd.

Herbert Dent \& Co.

La Generale Soies

General Silk Importing Co., Inc.

Gerin, Drevard \& Co.

T. E. Griffith, Ltd.

Hogg, Karanjia \& Co., Ltd.

Jardine, Matheson \& Co., Ltd.

Madier Freres.

Mitsui Bussan Kaisha, Ltd.

Reiss \& Co.

J. Sauvayre

Spalinger, Dowler \& Co.

U. Spalinger

Th. Varenne \& Co.

Villa Bros. of Canton, Ltd. 


\section{Raw and Waste Silk Importers}

\section{New YoRK}

American Raw Silk Co., 25 Madison Ave.

Arnhold Brothers, 21 State St.

Betchtel, Ed. E., 112 East 19th St.

Beolchi \& Co., V. M., 25 Madison Ave.

Berizzi Bros. Co., 15 East 26th St.

Doblin, Leo L., 404 Fourth Ave.

Eagle, J. H. \& C. K., 265 Fourth Ave.

Equity Silk Co., 95 Madison Ave.

Facchetti-Guiglia, A., 354 Fourth Ave.

Franck, Henri, 432 Fourth Ave.

Frost, Inc., Frank, 15 East 26th St.

General Silk Importing Co., 440 Fourth Ave.

Gerli \& Co., E., 119 East 27th St.

Giriat, D., 450 Fourth Ave.

Gosho Corporation, 334 Fourth Ave.

Guerin \& Fils, Vve., 106 East 19th St.

Gwalter \& Co., H. L., 95 Madison Ave.

Hadden \& Co., 25 Madison Ave.

Import Service Corporation, 95 Madison Ave.

Innes \& Co., Inc., 132 Front St.

Japan Cotton Trading Co., Inc., 25 Madison Ave.

Jardine, Matheson \& Co., Ltd., 25 Madison Ave.

Kahn \& Feldman, Inc., 38 East 29,th St.

Kuhara Trading Co., 471 Fourth Ave.

Kyosangumi \& Co., 32 Union Square

Littauer \& Co., Inc., Ludwig, 30 East 33rd St.

Mindlin \& Rosenman Co., 105 East 29th St.

Mitsubishi \& Co., 295 Fifth Ave.

Mitsui \& Co., Ltd., 25 Madison Ave.

Morimura, Arai \& Co., 44 East 23rd St.

Muller, Paul, 95 Madison Ave.

Murray, Russell, \& Co., 454 Broome St.

Nielsen, Victor, 235 Fifth Ave. 
Ohki, S., 225 Fifth Ave.

Raw Silk Trading Co., 31 East 27th St.

Ryle \& Co., Wm., 225 Fourth Ave.

Salembier \& Villate, 404 Fourth Ave.

Smillie \& Co., Chas. V., 27 Cedar St.

Strahler \& Co., F., 95 Madison Ave.

Straus \& Co., F. A., 451 Fourth Ave.

Sulzer, Rudolph \& Co., 334 Fourth Ave.

Suzuki \& Co., 297 Fifth Ave.

Takata \& Co., 432 Fourth Ave.

Universal-Industrial Corp., 354 Fourth Ave.

Villa \& Bros., A. P., 95 Madison Ave.

Vivanti Bros., 95 Madison Ave.

Wenger \& Co., S. A., 95 Madison Ave.

SILK ASSOCIATION OF AMERICA, 354 Fourth Ave.

U. S. TESTING CO., 340 Hudson St. 
Raw and Waste Silk Dealers

LYONS

UNION DES MARCHANDS DE SOIES, 29 rue Puits Gaillot.

CONDITION PUBLIQUE DES SOIES, 7 rue St. Polycarpe.

Alex. Saubiez \& Co., 14 rue Desiree

Arnaud Coste \& R. V. Dent, 11 rue du Garet

Armandy, Veuve G. \& Co., 2 quai de Retz

Aubert Broschenin \& Cie, 2 rue des Feuillants

Bechetoille, A., 16 rue Pizay

Bertrand, H., 26 rue Lafont.

Boutet Freres \& Co., 4 quai de Retz.

Boyer, Mazet \& Co., 1 quai de Retz.

Chabriere, Morel \& Co., 20 rue Lafont.

Chamonard, Frachon \& Co., 9 rue de l'Arbre Sec.

Champagnac \& Montrion, 21 ru des Caprucins.

Chantelot P. \& Co., 11 rue du Garet.

Chavanis, P., \& Cie., 8 quai de Retz.

Compagnie Generale d'Extreme Orient, 72 rue Vendome

Cozon Freres, 5 quai de Retz.

Crouzon, M. \& Co., 24 rue Pizay.

Debrabant, 16 rue Desiree.

Dent, Herbert, \& Co., 7 rue Terraile.

Deprez, F., 8 rue du Griffon.

Deydier, Barmont \& Cie., 19 rue Puits Gaillot.

Emery, L., 13 rue du Garet.

Etienne P., Rochette \& Co., 3 rue Pizay

Faure, L. E., 4 rue Desiree.

Geoffray, 43 Vielle Monnaie.

Gerin, Drevard \& Cie., 15 rue du Garet.

Gros \& Co., 3 rue du Garet.

Guerin \& Fils, Vve., 31 rue Puits Gaillot.

Hara \& Cie., 11 rue du Garet.

Julien, J., 27 rue Puits Gaillot. 
Lacroix, H., \& Leblanc, 24 rue Lafont.

La Generale Soies, 27 rue Puits Gaillot.

La Soie, 13 rue Dubois.

Lienard, A., 20 rue Ste. Catharine.

Longin \& Co., 33 rue Puits Gaillot

Marchand, Etienne \& Co., 2 rue Puits Gaillot

May, J., \& Co., 16 rue Lafont.

Mayor, Ch., \& Co., 7 quai de Retz.

Millet \& Miniere, 2 rue Lafont.

Mitsui \& Co., Ltd., 8 rue Lafont.

Mollard Freres, 5 petite rue des Teullants.

Moreau, C., 22 rue Lafont.

Morin, Murit \& Douarre, 11 rue de 1'Arbre Sec.

Morin-Pons, 11 rue de 1'Arbre Sec.

Muggiani, I. Bertholon, 14 rue Desiree.

Nabholz \& Co., 3 quai de Retz.

Neyrard, J., 1 rue Puits Gaillot.

Palluat, Testenoire \& Cie., 13 rue du Griffon.

Payen, L., \& Co., 9 rue Pizay.

Payet, Louis, 26 Place Tolozan.

Pezaz, M., 23 rue du Bat d'Argent.

Peillon \& Merieux, 1 rue du Theatre.

Perrin, H., Bruno \& Co., 4 rue Desiree.

Peyrac, R. P., 33 rue de la Republique.

Pila \& Co., 2 rue de la Republique.

Rose, Marius, \& Cie., 2 rue Puits Gaillot.

Societe Lyonaise sericole et soies d'Extreme Orient, 1 rue de la Republique.

Soies Asiatiques, 19 rue du Bat d'Argent.

de Soulange, J., 11 rue du Garet.

Sulzer, Rudolph \& Co., 14 rue du Garet.

Terrail Payen \& Cie., 1 rue de la Republique.

Tranchand, J., 3 rue Pizay.

Tresca, L., \& Cie., 17 rue du Bat d'Argent.

Trunel, Riviere \& Picolet, 16 rue Desiree

Varenne \& Proton, 19 rue de l'Arbre Sec. 


\title{
Raw and Waste Silk Dealers
}

\author{
MILAN
}

Sociata Anonima Cooperative per la

STAGIONATURA E L'ASSAGGIO DELLE SETE ED

AFFINI IN MILANO, 33 via Moscova.

Alberico, Carlo, 44 foro Bonaparte.

Andreae, A. \& Cia., 2 via Cernaia.

Appendeller, Giovanni, 22 via Solferino.

Banda fratelli, 18 via Lauro.

Bandera, Giuseppe, 10 via Ciovassino.

Banfi, Bernardo \& Lorenzo, 9 via Brera.

Barzaghi, Giovanni, 8 via Oriani.

Beaux, Auguste, 5 via Cusani.

Beaux, Giorgio, 42 foro Bonaparte.

Beretta, Annibale, 18-20 via Brera.

Bonazzi, G. \& Figlio, 5 via Palermo.

Boneschi, Arturo, 1 via Romagnosi.

Bortolotti, Romeo, 12 via Pontaccio.

Borzoni, Gaetano \& Verasi, 2 via Ciavassino.

Boselli fratelli fu Alfonso, 14 via Pontaccio.

Bosone, Carlo, 10 via Pontaccio.

Bossi, Hoppeller \& Farrario, 21 via Bigli.

Boutet, A. \& Co., 4 via Bossi.

Branca, Ernesto, 5 via Goito.

Buzzoni, Fraschini \& Cia., 7 via Orso.

Caminada, Pietro, 26 via Borgonuova.

Cappela, A., 10 via Pontaccio.

Capriolo, Carlo, 10 via Ciovassino.

Caraceni, Carlos, 4 via Cusani.

Casanova, Carlos, 6 via Orso.

Castagna, Dionigi, 14 via Pentaccio.

Cavadini, Albondio, 10 via Filodrammatici.

Cavadini, L., 1 via M. di Pieta.

Cavenaghi, G., 12 via Brera.

Cesaris, Camilio, 5 via S. Tomasco.

Chicco, Francesco, 6 via Ariosto. 
Colli, Giocamo \& Cia., 11 via Solferino.

Colombo, Edoardo, 2 via Giovassino.

Colombo, P. \& Co., 70 foro Bonaparte.

Comi, Achille, 14 via Brera.

Consoonno, Aless., 8 via Lauro.

Consonno, Fortuna, ditta, 8 via Brera.

Corsi, Giovanni, 13 via Cusani.

Corti, ing. G., 18 via Brera.

Cova, Leopoldo fu E., 7 via Meravigli.

Cundig, Sacchi \& Co., 1 via Stelvio.

Curti, Edoardo, 54 foro Bonaparte.

Del Bo, Croci \& Casati, 8 via Nerino.

Dell'Oro, A1., 16 via Cusani.

Dell'Orto, Att. \& Co., 18 via Brera.

De Ponti fratelli, 6 via Lauro.

Dilatura Seriche Cuzzi, 4 via M. di Biera.

Dozzio, Giov., e Figlio, 37 via Monte Napoleone.

Dubini, G. \& Cia, 11 via Borgonuovo.

Dubini fratelli \& Co., 2 piazza Belgioiose.

Dubini, Mario, 24 via Solferino.

Fabbriche Riunite di Seterie Da Fano \& Co., 4 Maggiolini.

Facchetti-Guilia, A., 4 via Brera.

Ferrario, Francesco di P., 11 via Ciovasso.

Fossati, Decino, 21 via Brera.

Gadda, E. \& Co., 16 via Brera.

Gallese, Giuseppe, 5 via Brera.

Garavaglia, Francesco, 4 via Lauro.

Gavazzi, Pietro, 8 via Giuseppe-Verdi.

Generale Soie, La., 19 via Solferino.

Gerosa \& Ghidini, 21 via Brera.

Giambarini, Antonio, 14 via Solferino.

Gilli, Giovanni, (ditta), 13 via Statuto.

Gilbert, A. \& Cie., 20 via Brera.

Giraud, Ugo, 18-20 via Brera.

Grandi, Rinaldo, 7 via Giulini.

Graffelder, Enrico, 10 via Brera.

Guerin, Veuve \& Fils., 4 via Giuseppe Verdi.

Guzzi, Cesare, 6 via Lauro.

Handmann, Arminio, 35 via Boccaccio.

Hauffmann, Carlo, 6 via Bottonuto. 
Hilaret, Carlo, 11 via Ciovasso.

Hirzel, Emile-W., 1 via Oriani.

Introini, E., 14 via G.-B. Bazzoni.

Job, Carlo, 10 via Pontaccio.

Lazzaroni, A., 2 via Ciovassino.

Locatelli, Luigi, 3 via Bossi.

Maga, Ang., 3 piazza Scala.

Magnocavallo, succ., 34 foro Bonaparte.

Mambroni, Angelo \& Co., 3 via Lauro.

Marchetti, Carlo, 46 foro Bonaparte.

Marimonti, Luigi, 2 via Orso.

Maumary, Eug., 5 via Maddalena.

Melgunoff, Sergio, 11 via Andegari.

Meregalli, Carlo, 8 via Oriani.

Meyer, Edoardo, 2 via Borgonuovo.

Meyer, Enrico \& Co., 4 via M. di Pieta.

Mira, F., 16 via Moscova.

Mira \& Roth, 16 via Brera.

Mischio \& Miozzi, 18 via Solferino.

Muller \& Teodore, 7 via Fatebenefratelli.

Nahmias, Salvatore, 46 foro Bonaparte.

Negri Eman \& Co., 12 via Torino.

Oriani, Giorgio, 14 via Cusani.

Orio, Riccardo, 14 via Cusani.

Parisio, G. \& Co., 2 via M. Macchi.

Parravicini, Antonio, 18 via Solferino.

Pattay, Maria, 5 via S. Tomaso.

Perlasca, Alfredo, 14 via M. di Pieta.

Peladini, G. \& Co., 11 via Carmine.

Piccaluga, A., 7 via Fiori Osculi.

Piccolini, Giuseppe, 11 via Brera.

Pisonis, G.-M., 9 via Brera.

Piva, Sigismondo, 19 via S. Andrea.

Pollaroli, Francesco, 5 via G. Verdi.

Ponti, Orseo, 25 via Pallavicino.

Ponzoni fratelli, 16 via Orso.

Pozzi, Giuseppe, 21 via Ponte Vetero.

Prima fratelli di Tremolada \& Co., 17 via M. di Pieta.

Radaelli, Leone, 8 via Amedei.

Redaelli, Felice, 18 via Solferino. 
Riggio, A., 22 Piazza Castello.

Riva, C., 18 via Lauro.

Rocca, Vittorio, 9 via Cappuccio.

Rocca, Romeo, 1 via Lauro.

Ronchetti, Antonio, 8 via Cernoia.

Ronchetti \& Co., 11 via Ciovasco.

Ronchetti, G. fu P.-A., 16 via Brera.

Rosina, Roberto, 9 via Monte di Pieta.

Rusconi, A., 14 via Monta di Pieta.

Rusconi, G. et Figlio, 7 via Orso.

Rusconi, Giuseppe, 11 via Cusani.

Savisci, Ugo, 16 via S. Marco.

Sbarbaro, Avrigo, 16 via Orso.

Scioli \& Stringa, 18 via Brerá.

Scotti, Arist., 3 via Bigli.

Semenza, Enrico, 28 piazza Castello.

Semenza, H., 19 via Solferino.

Semtov, J. Aelion, 11 piazza Castello.

Sericicole Italo Lyonnaise, 4 via Brera.

Sessa, E., 19 via Rovello.

Setificio fratelli Salvi, 4 viale Garibaldi.

Silvestri, Guido, 21 via Brera.

Sigg \& Keller, 19 via Solferino.

Sinigalia, Giovanni, 1 via P. Frisi.

Societa Filatura Cascami di Seta, 3 via Brisa.

Societa Italo Brasileira, 8 via G. Uberti.

Societa Serica Italiana, 22 piazza Castello.

Sommaruga, Cesare, 12 via Brera.

Spasciani, E. \& Co., 8 via Andegari.

Steimann, E., 16 via Orso.

Stucchi, Raul, 14 via Cusani.

Talamano \& Lecchi, 38 via Broletto.

Tanzi, Primino, 71 c. Garibaldi.

Tesini Malvezzi \& Co., 14 via Orso.

Torriani, C., 14 via Pontaccio.

Torricelli, Francesco, 14 via Cusani.

Tramonti, Edoardo, 18 via M. Pieta.

Treves Charollais \& Co., 8 via Brera.

Trudel, Ernesto, 24 via Solferino.

Ulisse Tavolaccini, 16 via Brignole. 
Valpondi Balilla, 3 via E. Sirtori.

Viscardi, Caro, 16 via M. di Pieta.

Vannoni, Giuseppe \& Co., 18 via Brera.

Vegezzi, Arnoldo, 52 via Spiga.

Vigano, Federico, 2 via Lauro.

Villa, A. \& Bros., P., 13 via Statuto.

Viscardi, Carlo, 16 via M. di Pieta.

Vistarini, M.-L., via Marone.

Vitali, Rodolfo, 7 via Rugg, Buscovich. 


\section{Raw Silk Dealers}

\section{ZÜRICH}

Abegg \& Cie, 30-1 Bahnhofstrasse.

Appenzeller, E., \& Cie, 6 Tiefenhofe.

Banco Sete, 7-1 Tholstrasse.

Basler \& Cie, A. G., 32-1 Bahnhofstrasse.

Beder \& Cie, 38-2 Bliecherweg.

Bianchi, Carl, 12-2 Gartenstr.

Bodmer, L. H. Gebruder, 20 Peterstr.

Bourgeois, Serge S. A., 1-1 Manneggplatz.

Buchholz, C., 61-1 Talst.

Buschor \& Cie, 20-1 Peterstr.

Corrodi \& Cie, 13-1 Stadthausquai.

Diener, C., 32-1 Brandschenkerstr.

Dreyfus, Albert, 2-2 Splugenstr.

Dursteler, F. \& Cie, 12-6 Gallurstrasse.

Eichenberger, Herm., 1-2 Traubenstr.

Enz, Oscar R., 14-1 Fraumunsterstr.

Fleckenstein, Rob. E., 7-1 Tiefenhofe.

Fritz, Pruppacher, 7 Waaggaste.

Furer, Kurt, 197-8 Dufourstrasse.

Geilinger, H. \& Co., 13-1 Barengasse.

Grossmann, A., 83-8 Seefelsdrstrasse.

Hausamann, Emile, 14 Thalstrasse.

Hegetschweiler, Hch., 58 Bleicherweg.

Huber, Alb. J., 14 Fraumunsterstrasse.

Kunz, Otto, 34-1 Limmatquai.

Landolt, Rhyner \& Cie, 11 Stadthausquai Metropol.

Landolt, Rob., 40-2 Stockerstrasse.

Landolt \& Cie, 12 Thalstrasse.

Matt, Gaston, 3-1 Ramistrasse.

Meister, M., 10 Borsenstrasse.

Muller, O., 28-2 Bleicherwegasse.

Nabholtz \& Co., 6-1 Annastr.

Nussberger, A., 10-1 Peterstrasse.

Pfister \& Cie., 23-1 Thalacker. 
Plattner, Jakob, 32-1 Thalacker.

Pruppacher, F., 7-1 Waaggasse.

Schneider, W., 8-1 Torgasse.

Schnewlin, E., 19 Barengasse.

Seeburger, E. \& Co., 19 Pelikenstrasse.

Sieber, Hegner \& Cie., 14 Thalstrasse.

Sigg, R., 6-7 Wilfriedstrasse.

Spinner, E. \& Cie., 52 Bahnhofstrasse.

Spillmann, H., 13-1 Barengasse.

Streuli, Emile H., 46-7 Minervastrasse.

Sulzer, Rudolph \& Co., 8 Fraumunsterstrasse.

Trude1, E., 11-2 Bleicherwegasse.

Vetter, A., 8-1 Leonhardstrasse.

Wermann, R., 32-6 Rotelstrasse.

Wettstein, Th., 49-1 Lowenstrasse.

Zimmermann, Alfred, 57a-8 Bahnhofstrasse.

Zollinger \& Cie., 34-2 Dreikonigstrasse. 

ADVERTISEMENTS 


\section{AMERICAN RAW SILK COMPANY}

(Incorporated)

\section{IMPORTERS}

25 MADISON AVENUE

NEW YORK

Geo. Walworth Middleton

Telephone Madison Square 6531-6532

Cable Address

Geomid 


\section{MINDLIN \& ROSENMAN}

柴紫
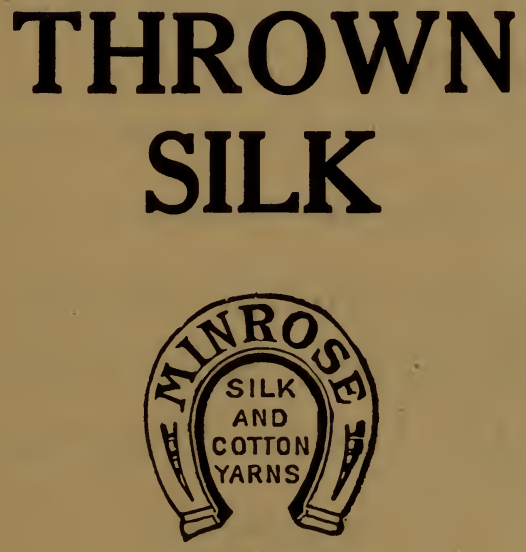

TRADE MARK

Silk, Artificial, Cotton

Hosiery Tram

Specialists

Mills : Dunmore, Pa., Scranton, Pa., Long Island City, N.Y.

105 EAST 29TH STREET

NEW YORK 


\section{United States Testing Company, Inc.}

340 HUDSON STREET

NEW YORK CITY

Paterson Philadelphia New Bedford Shanghai, China

\section{General Textile Testing on Cotton, Wool, Silk, Linen and All Textile Materials}

Conditioning Boil-off

Sizing

Elasticity

Tenacity

Cohesion

Cleanness

Etc.
Uniformity

Count

Strength

Twist

Wool Scouring

Microscopy

Etc.
Tests on

Dyestuffs

Chemicals

Soaps

Oils

Fuels

Etc.

Chemical analyses of materials and the investigations of technical chemical problems are undertaken.

Expert advice and assistance in the development of industrial processes will be furnished. 


\section{Società Anonima Cooperativa}

a capitale illimitato

\section{per la Stagionatura e l'Assaggio delle Sete ed Affini 33, VIA MOSCOVA, MILAN (Italy) ESTABLISHED 1888}

Branch Offices in Milan: 38, via Moscova and 11, via Ciovasso

The largest concern in this line Won the highest awards at the Expositions of Paris 1900 St. Louis 1904, Milan 1906, Turin 1911

Amount of silk conditioned and weighed in 1919: 4.487.294 kilograms-tested: $\mathrm{N}^{\circ} 87.394$-boiled off: $\mathrm{N}^{\circ}$ 1.734 -net weighting of cocoons and silk waste: 3.630 .020 kilograms.

Movement in the general warehouse expressly built for storage of silks, cocoons, silk waste and other textile materials: 19.570 .017 kilograms. Warrants issued to the amount of 106.030.112 Lires.

In addition to the usual Conditioning House tests, as conditioning, weighing, boiling off, sizing, measuring, tenacity, elasticity and twisting tests, our concern has annexed:

Chemical Laboratory for all sort of researches and studies on silk, cocoons, etc.: in 1919, 2,867 analyses were accomplished from orders of the trade, especially to estimate the weighting in raw and thrown silks.

Mechanical Factory for the turning out of instruments and appliances of precision in conditioning (Corti's Ovens, now adopted by all up-to-date Conditioning Houses), weighing, sizing, tenacity, elasticity and twisting tests.

Banking Branch for collecting capital to be directly adyanced on own warrants.

TERUZZI RAG. ANDREA, Manager 
Telephones $\left\{\begin{array}{l}8406 \\ 8407\end{array}\right.$ Madison Square
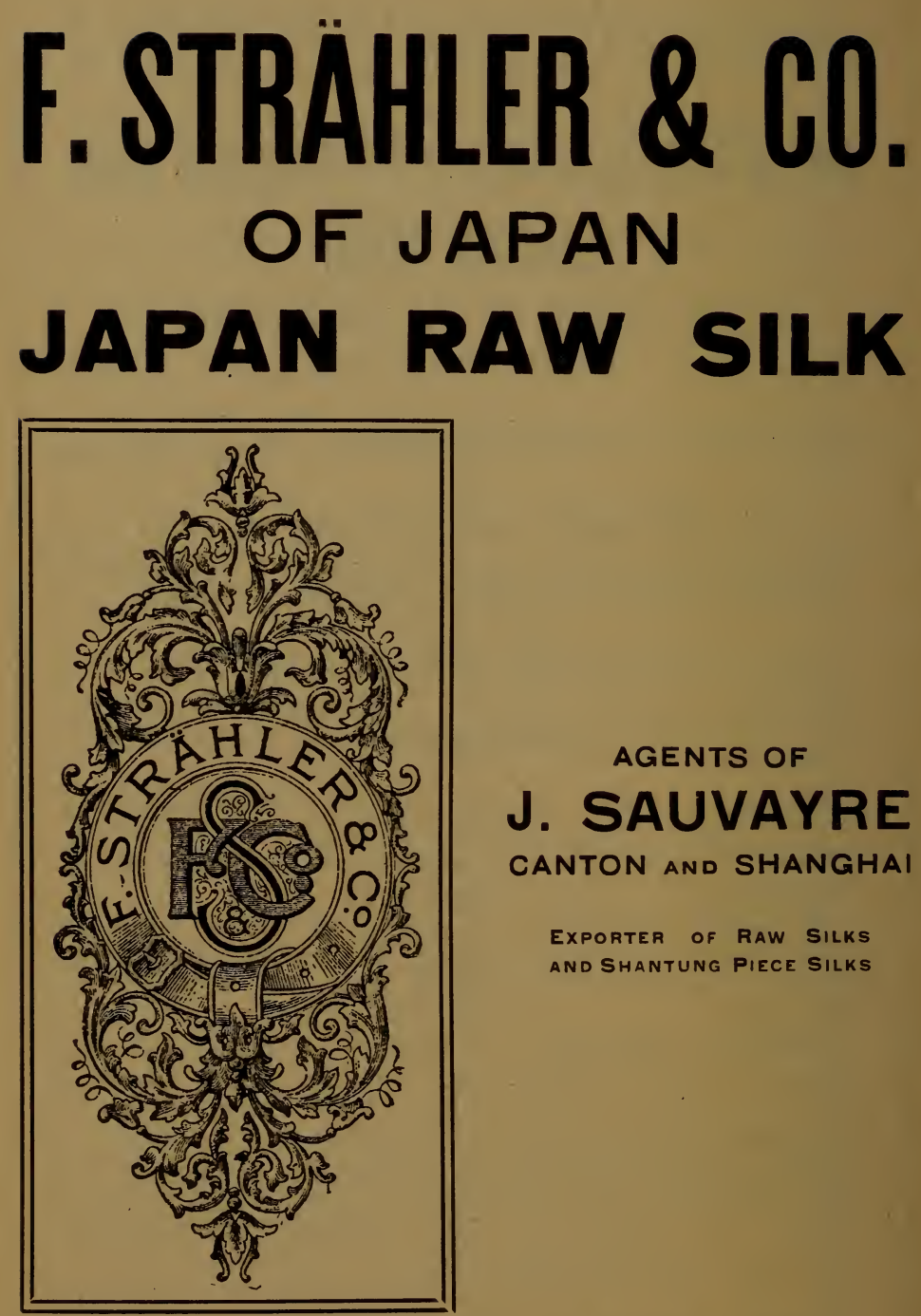

\section{AGENTS OF \\ J. SAUVAYRE \\ CANTON AND SHANGHAI}

EXPORTER OF RAW SILKS AND SHANTUNG PIECE SILKS

\section{MADISON AVENUE NEW YORK}




\section{F. A. STRAUS \& CO. 451-453 FOURTH AVENUE NEW YORK CITY}

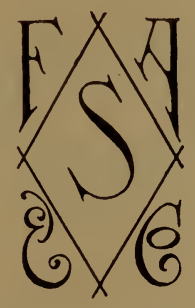

RAW, THROWN and ARTIFICIAL

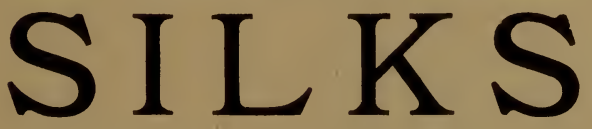

TSATLEE

CHINA STEAM FILATURES

TUSSAH

CANTONS

JAPANS

MILLS, TRENTON, N. J. 


\section{A. P. Villa $\mathcal{E} 2$ Bros., Inc.}

Raw and Thrown

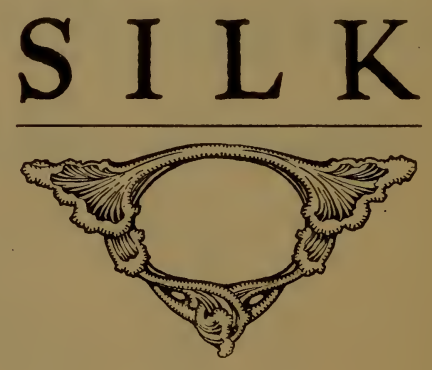

NEW YORK

MILAN, TURIN, LYONS, YOKOHAMA, SHANGHAI, CANTON

ษ

New York Office:

95 MADISON AVENUE

Telephone: Madison Square 3200

ঋ

\section{MILLS AT}

Passaic, N. J. Netcong, N. J. Mifflinburg, $\mathrm{Pa}_{\mathrm{a}}$ Turbotville, $\mathrm{Pa}$. Erwin, Tenn. 


\section{Universal-Industrial}

Corporation

354 FOURTH AVE. - NEW YORK

Manufacturers of

ORGANZINE TRAM

and other

TEXTILE YARNS

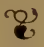

Mills:

MAYFIELD

TOW ANDA

WA'TSONTOWN

TRI-BOROUGH

NEMOLOTON

MONTOUR

SEMINOLE

COLONIAL

NAMTR AH
ONTIORA

DALMATIA

LIVERPOOL

EYNON

MILLVILLE

NEW MILFORD

DUNCANNON

COLONIAL ANNEX

DURYEA

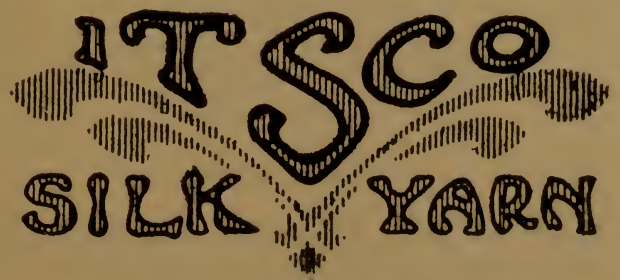

(Registered Trade Mark) 


\section{Vve GUERIN \& FILS}

(Founded 1650)

106 East 19th Street

New York

\section{IMPORTERS OF \\ ALL KINDS OF}

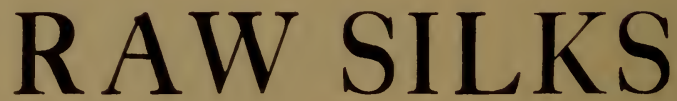

From France, Italy, Orient, Bengal, Shanghai, Canton, Japan

\section{HEADQUARTERS \\ LYONS (FRANCE)}

BRANCHES

Paris, St. Etienne, (France) Milan, (Italy) Beyrouth, (Asia Minor) 


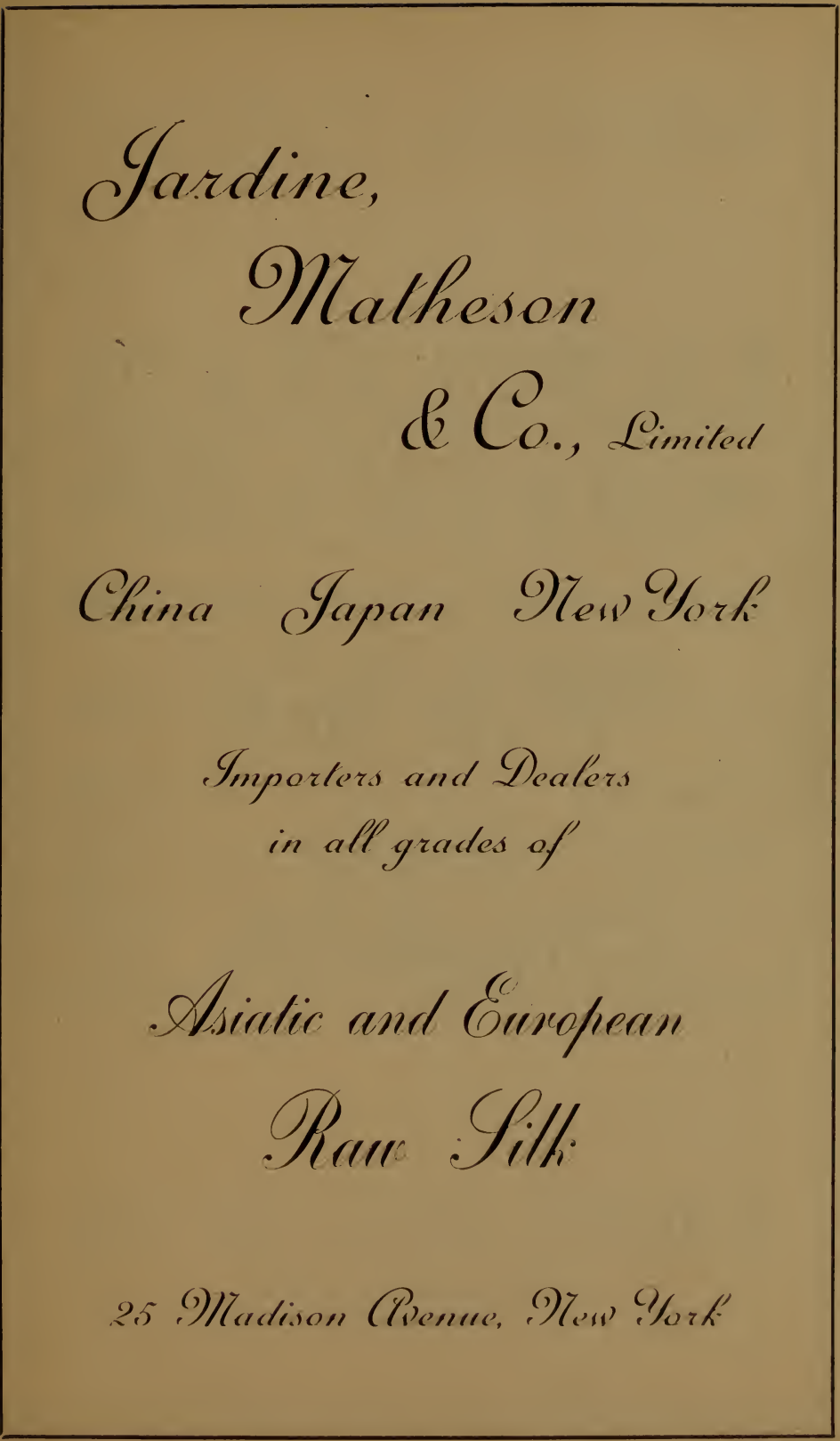


S. A. WENGER, Pres. \& Secy. JOHN E, BOLTON, lst Vice-Pres.
JOHN SHIGO, 2nd Vice-Pres.

A. J. MAGAGNA, Treas.

\section{S. A. WENGER \& CO. INC}

$I m p o r t e r s$ of

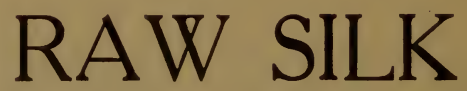

and Manufacturers of

\section{Thrown Silk}

95 MADISON AVENUE, NEW YORK

Telephone Madison Square

6466-6467-6468 


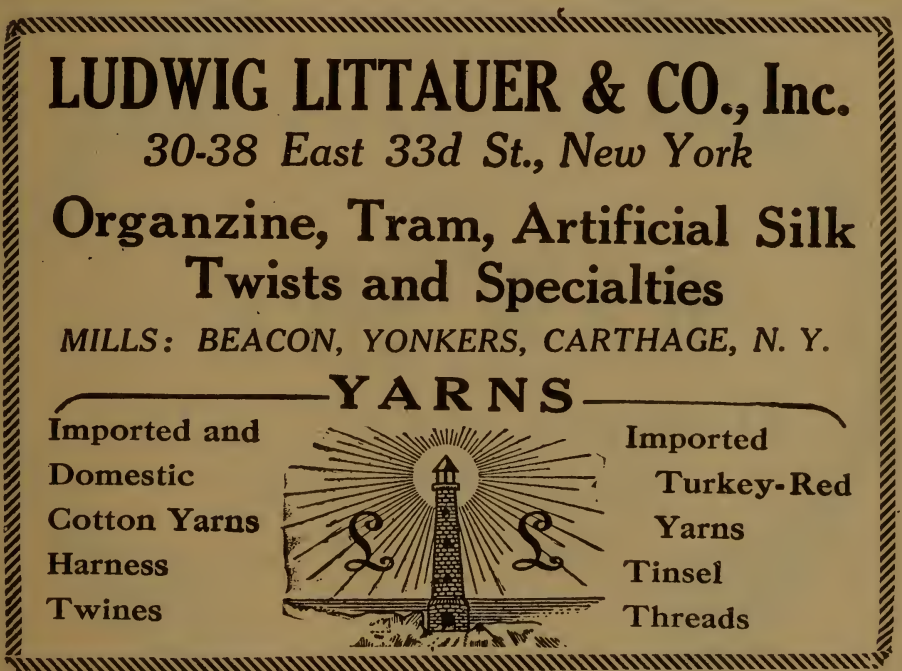




\section{Arnhold Brothers \& $C_{0}$.}

L I M I T E D

\section{CHINA}

Head Office: SHANGHAI

BRANCHES :

Hong Kong, Canton, Hankow, Chinkiang, Changsha,

Chungking, Tientsin, Newchwang,

Peking, etc.

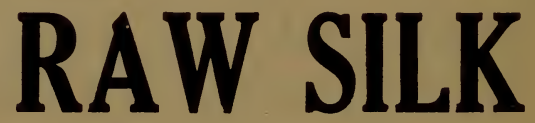

TUSSAHS, WASTE SILK

PONGEES AND

\section{HABUTAIS}

P. DOURILLE \& CO., Yokohama

Agents and Home Offices:

ARNHOLD BROTHERS

LONDON: 14 Fenchurch St., E. C.

NEW YORK: 21 State Street

LYONS: L. CHERFILS \& P. FAYOLLE, (5 Rue Pizay) 


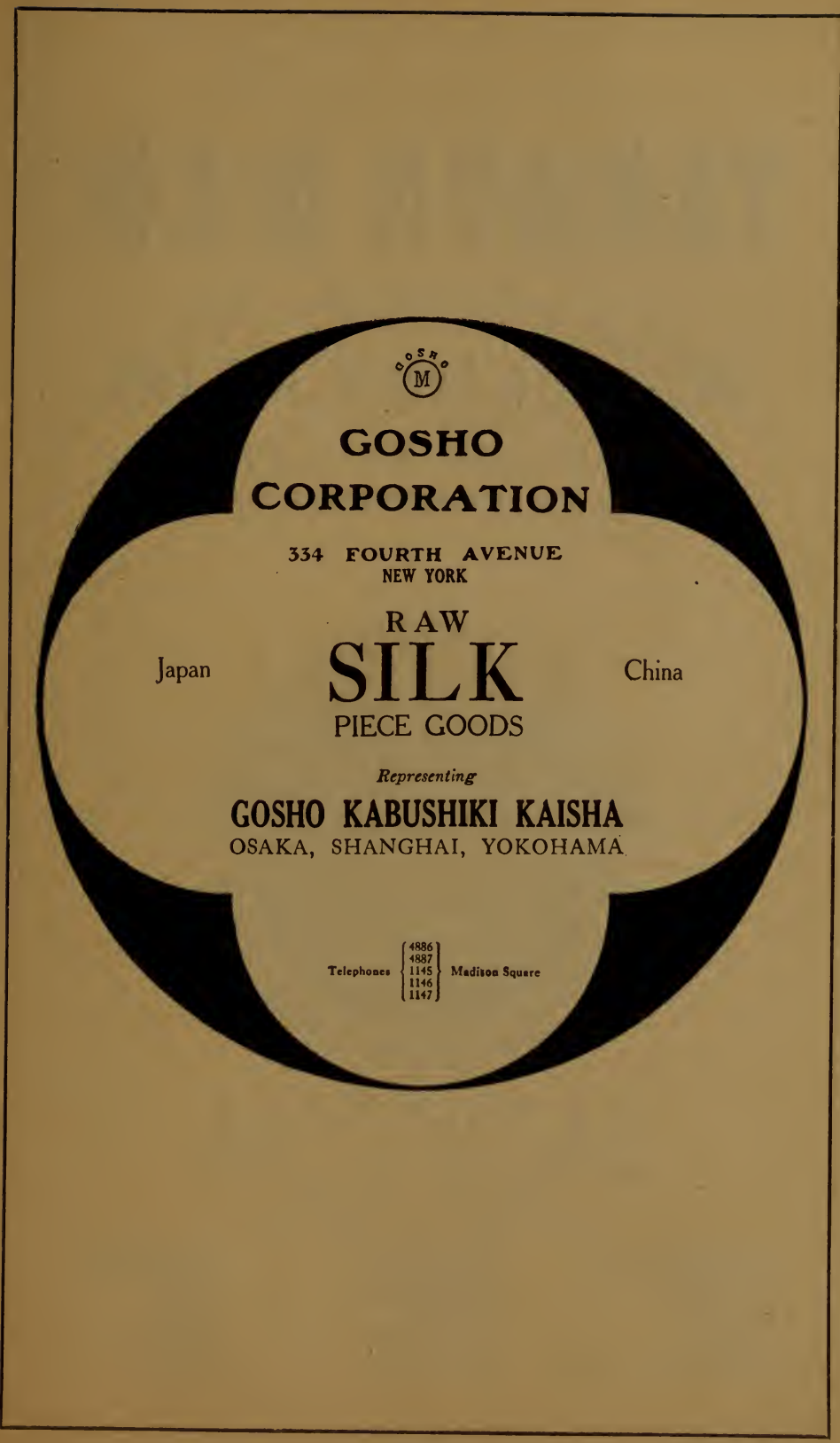




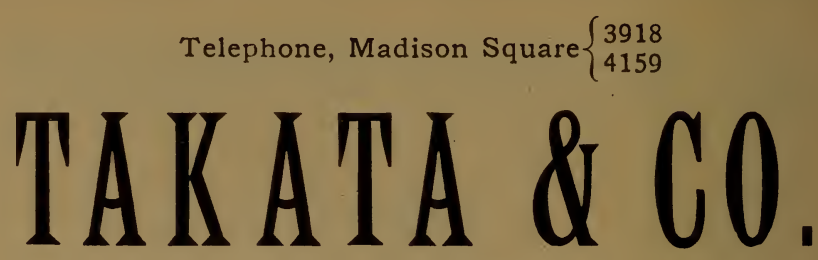

Established 1880

432 Fourth Avenue, New York

IMPORTERS, EXPORTERS MANUFACTURERS

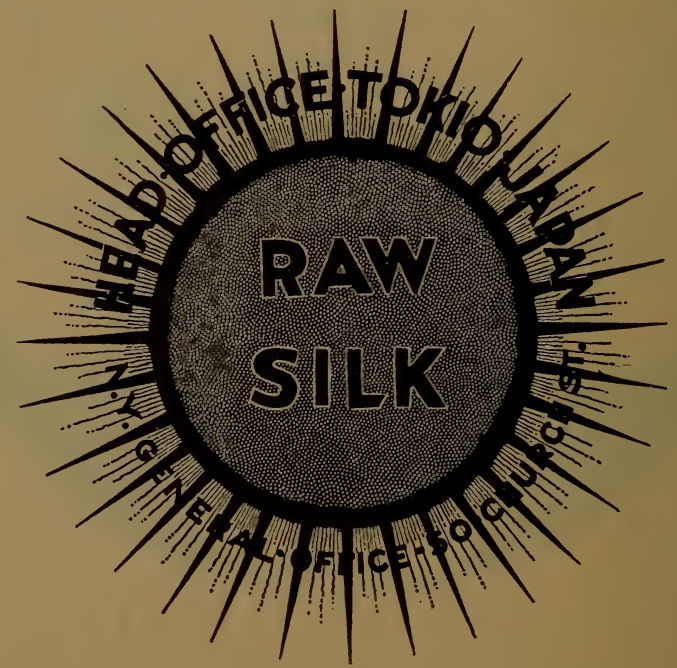

BRANCH OFFICES

YOKOHAMA SHANGHAI

$\begin{array}{lll}\text { LONDON } & \text { SEATTLE } & \\ \text { VLADIVOSTOCK } & \text { PEKIN } & \text { PETROGRAD } \\ \text { HANKOW } & \text { DALNY } & \text { SSINGTAN } \\ \text { TAIPEH } & \text { OSAKA } & \text { KOBE } \\ \text { NAGOYA } & \text { HAKODATE } & \text { MURORAN } \\ \text { KURE } & \text { MAIDZURU } & \text { MOII } \\ \text { YOKOSUKA } & \text { NAGASAKI } & \text { SASEBO }\end{array}$




\section{SUZUKI \& COMPANY}

297 Fifth Avenue

New York

Telephone Longacre 5854

$\mathrm{OS}$

RAW SILK

:

ARTIFICIAL

SILK 


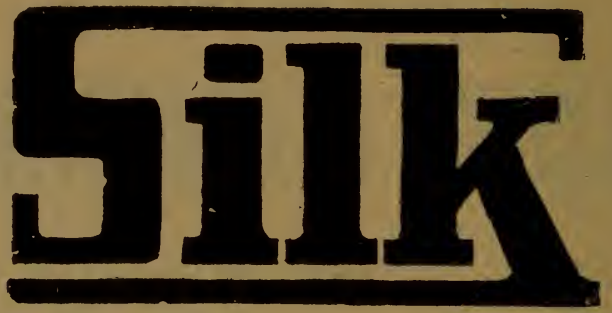

An illustrated monthly magazine devoted to the technical development and manufacturing interests of the silk industry.

$$
\text { Price }\left\{\begin{array}{l}
\$ 2.00 \text { per year in U. S. } \\
\$ 3.00 \text { foreign subscriptions }
\end{array}\right.
$$

THE SILK MARKET WEEKLY DIGEST Published every Saturday

A summary of the activities of the silk market and its various branches

$$
\text { Price }\left\{\begin{array}{l}
\$ 4.00 \text { per year in U. S. } \\
\$ 6.00 \text { foreign subscriptions }
\end{array}\right.
$$

SILK
DIGEST $\$ 5.00$ for one year in the United States

Published by the

SILK PUBLISHING COMPANY

$$
\begin{gathered}
1123 \text { BROADW AY } \\
\text { NEW YORK }
\end{gathered}
$$




\section{RA W SILK}
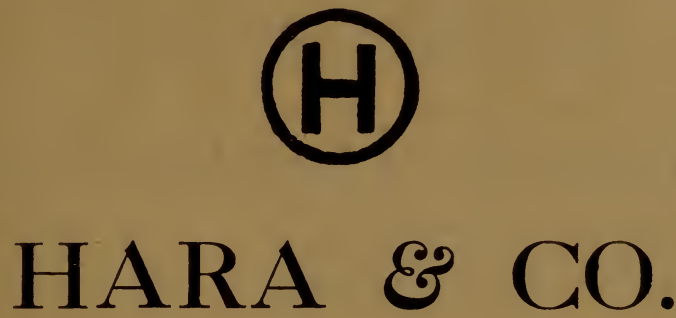

(Hara Gomei Kaisha)

443 Fourth Avenue, New York

Telephone, Madison Square

$8120,8121,8122,81238124$

Branch Offices and Agencies:

Lyons - London

MAIN OFFICE:

YOKOHAMA, JAPAN

Owners and Sole Distributors of Well Known

HARA FILATURES 
Compliments of

\section{Leo L. Doblin Co.}

FACTORS

AND COMMISSION

MERCHANTS

404 Fourth Avenue

New York 
John C. Welwood

Corporation

SILK RIBBONS

ฆ

ALSO

SOLE SELLING AGENT

FOR

Welwood Silk Mills Broad Silks

Hawley, Honesdale, White Mills, PENNSYLVANIA

260-266 Fourth Avenue

New York City 


\section{Dependability}

7 HE outstanding feature of Dunlop Organzine is its dependability. With QUALITY

1 as our single objective for more than half a century our organization continues to devote itself to the maintenance of Dunlop Standards. Hard work and close study have been devoted to the task of keeping our product at all times up to the demands of discriminating manufacturers, and it is gratifying to know, that our efforts are appreciated.

We guarantee Dunlop Organzine to surpass any other Japanese Organzine in both quality and quantity of production, and we will gladly undertake to demonstrate, at our own risk, the soundness of this claim.
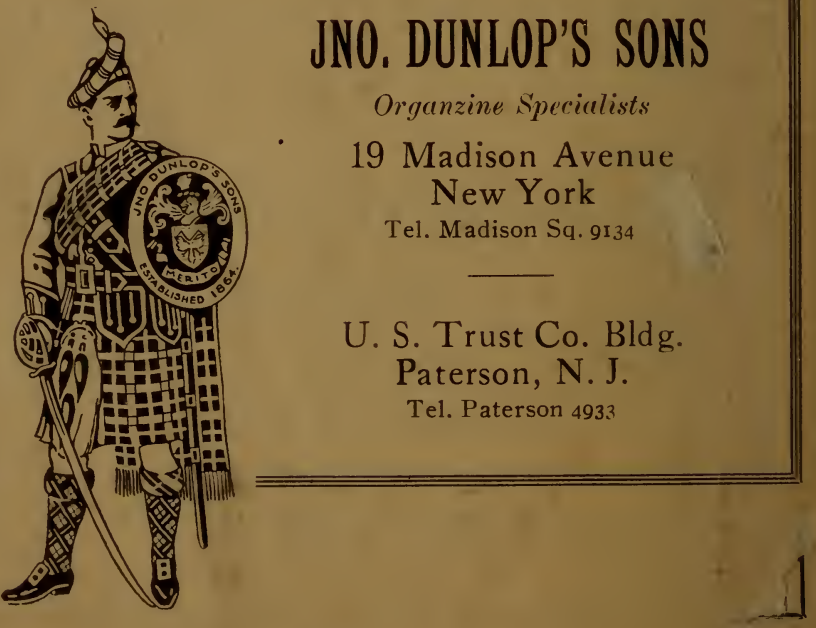


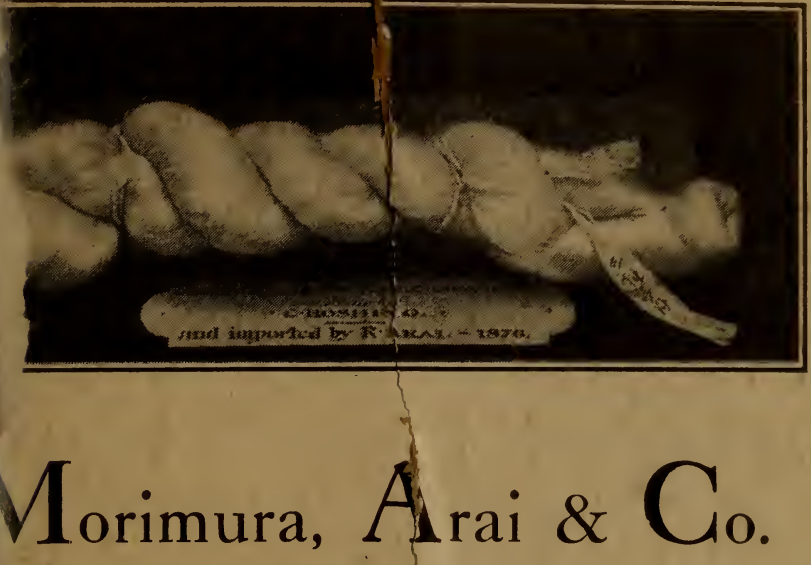

44 East 23rd Strer New York

$=$ Represent

Yokoha

Ki-ito Kwais Ltd.

IPAN SHANGHAI CANTON

RAW SILK 
SMITHSONIAN INSTITUTION LIBRARIES

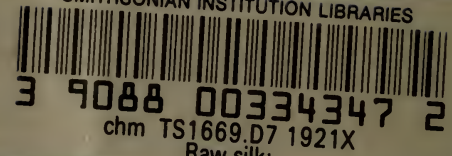

Raw silk; 